
$12 \mathrm{~V} 6$

$T 245$

1875

UNIVERSITY OF CALIFORNIA

C.ALIFORNIA COLLEGE OF MEDICINE IIRQDPV

MAY 2. \& 1971

IRVINE, CALIFORNIA 

Digitized by the Internet Archive in 2007 with funding from

\author{
Microsoft Corporation
}


. 



\section{SYPHILITIC LESIONS}

OF TH E

\section{OSSEOUS SYSTEM}

IN

INFANTS AND YOUNG CHILDREN.

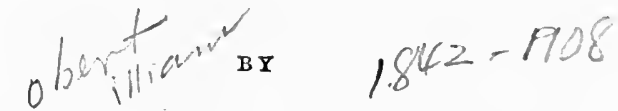

R. W. TAYLOR, M.D.,

SURGEON TO THE NEIY YORK DISPFNAARY, DEPARTMENT OF VENEREAL AND SKIN DISEASES. PHYSICIAN TO CHAIITY HOSPITAL, NEW YORK.

NEW YORK :

WILLIAM WOOD \& COMPANY, 27 GREAT JONES STREET.

1875.

7409 


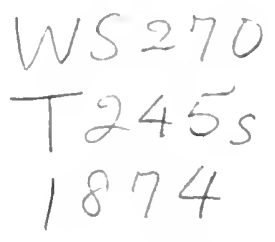

Entered according to Act of Congress, in the year 1874 by R. W. TAYLOR, M.D.,

In the Office of the Librarian of Congress at Washington.

JонN F. TROW \& Sov, PRINTERG AND BOOKBINDER8, 2u5-213 Ertst 12th si, NEW YORK. 


\section{WILLIAM H. DRAPER, M.A., M.D.,}

CLINICAL PROFEsSor OF DISEASES OF THE SKIN IN THE COLLEgE OF PHYSICIANS AND SURGEON, NEW YORK; PHYSICIAN TO THE ROOSEVELT hOSPITAL, ETC., ETC.,

IN ACKNOWLEDGMENT BOTH OF HIS STERLING PERSONAL QUALITIES AND OF HIS HIGH PROFESSIONAL ATTAINMENTS.

THIS VOLUME IS RESPECTFULLY DEDICTAED

BY

TH E A UTH O R. 


\section{PREF A CE.}

Wuen my attention was primarily drawn to lesions of a syphilitic nature occurring in the- osseous system of infants, so little was known upon the subject that I was soon compelled to turn my inquiries from the few works in which, indeed, it was but casually mentioned, to the disease itself, as presented in the sick, to a number exceeding a dozen, the details of which I have been careful to give at length. In a word, the volume of Nature was before me, and in that I studied. As a consequence of which I trust it will be found that, if my descriptions are sometimes ininute, it is because the appearances were attentively examined; and that not only are those lesions which constitute the principal topic described with complete accuracy, but certain others which had been previonsly confounded with them demonstrated to be essentially different.

In this way, it is true, has occurred that the treatise has been somewhat extended; for, especially, in order to slow in what respects scrofulous and rickety affections are distinct from those exclusirely specific, I was obliged to go into a close analysis of them, and to make them fully understood; a matter the more necessary, as, up to the time I undertook the inquiry, Science had given it but a rery insufficient share of her attention. But not this alone, since, as will be seen, I had to dwell also on that separation of the epiphysis which depends on 
syphilitic as con-tradistinguished from that which arises from simple causes; and thereby establish a distinction previously unknown to diagnosis, though one clearly essential to prevent serious mistakes in practice.

In fact, the field I entered upon was almost untrod, while in one dirision of it more especially so, or that wherein I was led to investigate those lesions in infants which originate in acquired syphilis, and show that this class of affections do not proceed from congenital causes only; for of these it is but truth to say that, as the last were but imperfectly understood, so were the former entirely undescribed.

On the whole, I trust the student will herein find a treatise at once original and complete, or, at least, one that, based on immediate researches in Nature, is, if on that account only, not unentitled to notice. Such as it is, however, though I thought it due to myself to speak of as the product of protracted study, I deem it also proper to apologize for, as; doubtless, but too likely to disclose eertain of those inaccuracies incidental to every undertaking of the sort.

I have but to add that the drawing to depict the morbid osseous changes is after a photograph taken for me by my friend, Dr. J. W. S. Arnold, whose known skill in this department of art I was very glad to avail myself of.

125 East 12th Street, N. Y., January, 1875. 


\section{CONTENTS.}

Page

I.-Introductory ............................ 9

II. -The Histories of Personal Cases................. 13

III.-Résumé of Cases of the Various Observers............ 42

IV.-General Considerations and Division of the Subject........ 5i)

V.-Description of the Osseous Lesions of the Upper Extremities.. 58

VI.-Enlargements upon the Clavicle, Sternum and Ribs....... 65

VII.-The Swellings at the Extremities of Tibia and Fibula...... 68

VIII. -The Swellings upon the Femur.................. 72

IX.-The Enlargement of the Carpal, Tarsal, Metacarpal and Metatarsal Bones, and of the Phalanges.............. 75

X.-The Swellings upon the Cranial Bones and upon the Bones of the Face.............................. 91

XI.-The Swellings on the various Irregular Bones.......... 94

XII.-The Development, Course, and Distribution of the Osseous Swellings............................ 95

XIII. -The Effect of the Osseous Enlargements upon the Integuments and upon the Joints........................ 99

XIV.-The Degenerative Changes which may occur in the Osseous Swellings. The Superficial Form............... 102

XV.-The Separation of the Epiphyses from the Diaphyses........ 104

XVI. -The Symptoms induced by the Osseous Swellings......... 111

XVII. - The Periostitis of the Hereditary Syphilis of Infants....... 114

XVIII. - The Effects of the Osseous Lesions upon the Ultimate Strncture and Shape of the Bones.................... 116

XIX. -The Period of Invasion of the Osseous Lesions . ......... 120

XX.-Can similar Osseous Lesions be developed in Acquired Infantile Syphilis ?........................ 121

XXI. - The Intensity of Syphilis in those Cases in which Osseous Lesions are observed. ........................ 124

XXII. - The Condition of the Syphilis of the Mothers in whose Infants Osseous Lesions are observed................... 125 
XXIII - Pathological Anatomy

XXIV.-The Question of the Relation between Rachitis and Syphilis.. 138

XXV. - The Differential Diagnosis..................... 141

XXVI. - The Treatment............................. 154

XXVII. - The Swellings which occur later in the Life of those Hereditarily Syphilitic, at the Junction of the Diaphyses with the Epiphyses............................ 160

XXVIII. - The Course of the Gummous Osseous Lesions of Older Children contrasted with the Lesions of Infancy.......... 164 XXIX_-Miscellaneous Clinical Notes...................... 169

XXX. - Certain Non-specific Affections of the Bones sometimes regarled as Syphilitic. ....................... 171

Appendix. ............................. 175

Index $\ldots \ldots \ldots \ldots \ldots \ldots \ldots \ldots \ldots \ldots \ldots \ldots \ldots \ldots \ldots \ldots \ldots, 177$ 


\section{SYPHILITIC LESIONS}

\section{OF THE OSSEOUS SYSTEM IN - INFANTS AND YOUNG CHILDREN.}

\section{I.-INTRODUCTORY.}

Tuere is, perhaps, no portion of the ficld of syphilography in the study of which less progress has been made, than in that of the lesions of the osseous system in infants and children. Prior to the last few years the statement made by early observers, that such lesions were very rare, held full sway, and the baneful influence of the impression thus produced can now be clearly appreciated in the facts that observers attributed to other diseases lesions of this system which were due undoubtedly to syphilis, and that they did not follow np the study of these cases, because under the weight of the prevailing almost unequirocal statement, it was thought that such syphilitic lesions rarely if ever occurred. In fact, I. think that in the whole range of medical literature, there is not a stronger illustration of the blind manner in which acquiescence is given to a dogmatic statement, than that which has been accorded to this. Emanating from early writers upon the venereal diseases of children, whose observations were purely clinical, and which were not matured and confirmed by pathological research, this view has been transmitted from one to another over a long period of years, and it finally came to be accepted as an undoubted clinical truth. Within the past twenty years, the work of Diday, ${ }^{1}$ which reiterated this statement, has, perhaps, exercised a most signal influence in tending to spread it. Following him, in didactic treatise, came Vidal, ${ }^{2}$ who in his work acquiesced in the opinion, and after them writers upon diseases of children range themselves in an unqualified manner. There

1 Traité de la syphilis des enfants nouveau nés et des enfants à la mamello. Paris, 1854.

${ }^{2}$ De la syphilis congénitale. Thèse pour l'agrégation. Paris, 1860. 
are certain reasons, however, beyond this of nere popular belief, which tended to strengthen this view, and these are that the syphilitic lesions of the osseous system in infants presented several strong points of resemblance to the bone-lesions of riekets, and that as they did not in erery instance present elear syphilitic features they were attributed to serofula. As these two diseases were brought out in a salient manner, the idea gained ground, that when osseons lesions oceurred in children, they were due to either one of them, and some writers put forward the views that syphilis could cause rickets, and that the two diseases were frequently found in the same patient. Thus it can now be readily seen how unprecise were the diagnostic points thus drawn, and what a great barrier existed in the way to true progress in clinical investigation. I have no doubt but that this confusion has tended to produce some of the discrepancies in opinion which now exist among some observers as to the peculiarities of the osseous lesions of rickets. Thus it happened that rickets and struma were in the majority of cases considered as the diseases causing many lesions of the bones in children, while their syphilitic origin, in many instances, escaped entirely from consideration. In spite, howerer, of this well-grounded belief and of the reigning confusion, cases of bone-lesion were from time to time reported as being due to syphilis, and the opinion lurked in the mind that such lesions might occur. If this had not been so, it is very probable that the standstill wonld have been greater than it really was. These reported cases, however, were not numerous, nor, in the majority of instances, were they carefully and elalorately reported, so that they did not afford the material necessary for clinical study and dednction. This was the state of affairs when, in 1870, an important article was published by Dr. G. Wegner, the assistant to Professor Virchow, in Berlin. In it he gave a minute microscopic deseription of the lesions of the bones in twelve syphilitic children, and he showed quite clearly that the pathological processes are sui generis. Besides this, he rentured the statement that such lesions were not rare, but were even quite constant. These observations, though not quite exlıaustive, have since been fully confirmed, and, in some partienlars, added to, by Profs. Waldeyer and Kölner, who also agree with Wegner as to the frequency of occurrence of the lesions. In two years, 
subsequently, they were again confirmed by Parrot, in Paris, who gives a point of some valne in their clinical history. The grand result of these observations has been to place the matter in a more precise light, to give science a standard to work upon, and to produce an inpetus for observation which will finally lead to the dissemination of aceurate clinical and pathological knowledge of these lesions. About a year prior to the publication of Wegner's article, a case came under my observation, 'which, at the time, greatly interested and puzzled me. It led me to search literature thoronghly, and I finally found a few eases, which conrinced me that my own was one of syphilitic origin. One of these cases, that of Ranvier, was accompanied by some interesting pathological details. Early in 1870 I read Wegner's article, and it fully confirmed my view, and it has since greatly assisted me in clearly interpreting rarions featnres of other cases, which have, fortunately for me, fallen under my notice in the various public charities with which I am connected, through the kinduess of friends and in private practice.

Thongh Wegner's article lends much assistance in the study of these lesions, the aid is wholly in the matter of pathology, as no clinical facts are given. Then again, on this division of the snbject, it is not exhanstive, as it treats mainly of a certain form of lesion found at the junction of the diaphyses with the epiphyses of long bones, and it does not consider, at equal length, the syphilitic lesions of the short and flat bones; therefore it is a contribution but to a portion of the subject. Parrot's articles combine clinical and pathological facts, but in the former field he confines himself mainly to the appearances induced by separation of the epiphyses from the diaphyses, describing the resulting condition, a loss of motion, as a psendoparalysis. Antecedent and advanced stages are not touched upon, nor does he enter upon the study of diagnosis. In fact, it must be confessed that his papers are narrow in scope and desultory in conclusions.

Wegner's article is certainly one of the most important recent additions to our knowledge of syphilis, and one which, by positively stating the fact that these lesions are not uncommon, will tend in future to call attention to their study. It must, however, be said in justice to Ranvier, that he sketched the 
same pathological processes some years before, and showed how syphilis might affect the bones. The great point in Vegner's performance is the fact, that he cited a greater number of cases, and that he based his observations upon a large field of research. These observations and the occurrence under ny care of twelve eases, and the opportunities of observing several others, have led me to study the clinical history of these lesions with great care and attention for the past four years. I have also been fortunate in meeting with cases, which, though not of syphilitic origin, liave suggested points of resemblance, and have materially assisted me in my studies of their diagnosis. I have, therefore, endearored with this material, which will be seen to be quite ample, to trace the development, course, and decline of these lesions, and the various concomitant circumstances which attend them, and to give, if possible, a complete picture. The lesions due to hereditary syphilis in infants are quite fully described, as -the cases are quite numerous, and the question as to whether similar lesions conld be dereloped in the acquired syphilis of infants and young children is, I think, quite fully settled in the affirmative, as two illustrative cases are given. This is a subject of considerable-importance, and until now not treated of, though the opinion was entertained on very insufficient ground that snch could not occur. The impression will be conveyed, I think, by our stady, that the lesions as observed in the infant are such as may be engrafted on the bones in a greater or less degree during the whole period of their development; and this is another point of very great pathological import. Then again, in the study of these varions cases, it will be found that two show quite clearly a complication of great interest, namely, separation of the epipliyses from the diaphyses. This is a condition attended with much important consideration, and one which has yet not been clearly brought out. In fact, the two cases hereafter detailed, are the only ones on record which show the course of the lesion and its ultimate results in a subject which survived the disease. In a surgical point of view, these cases are of considerable importance. I give the history of my cases as well as those of every reported case in as suecinet a manner as possible. Many, if not all, of the cases reported by others lack very essential particulars in their history, and they are chiefly valuable from the fact that they call attention to bone-swellings. I have en- 
deavored to bring ont every point mentioned by the various authors, and to show their importance by a comparative examination of them. The result will be found to be, if not an exhanstive treatise, certainly a suggestive one, and one in which the essential points of these lesions are set forth. It occurred to me that perhaps I oecupied too much space with the cases; but as they are the store-house from which the dednctions are made, and as they may serve in future a useful purpose as prototypes, I have given them all without unnecessary words. Another reason which led me to do this was, that these cases have never been before united in a collection, and as I have been careful to draw them from the original sources, I have thought that they might be of use for future reference. Though the commentary and cases hinge the one on the other, they of course may be read separately, the descriptions being given in a didactic manner in the commentary, while the clinical features may be grasped from a perusal of the cases. In this clinical department, as I have said, the contributions have beer scanty, and the deductions have heretofore been wholly wanting.

I have taken pains to review the field of pathology carefully, and I give original illustrations, which I think will fully explain in a simple namner the rarions changes. Though I give the views and observations of other observers, I have also given my own, which in one or two particulars have cleared obsenre points. The sections upon diagnosis and treatment are as complete as I could make them. I shall give my cases first, and after them place those of the various other observers.

\section{II.-THE HISTORIFS OF PERSONAL CASES.}

Case I.-James B. came under my observation at the College of Physicians and Surgeons in May, 1872. The patient was then a little more than three months old, and thongh not very fat, still was not thin, and was quite compactly built. Its mother informed me that it had always nursed well, and that its general health was quite good. In answer to inquiries, I learned that it had not had any night sweats of a local character, and that it had not suffered from fever at night, during which period it usually slept quite well. The mother's history was as follows: She was thirty-five years of age, and had been 
married twelve rears. During the first nine years of her married life she had given birth to three healthy children, who are now living. In the tenth year after her marriage she had "sores" npon the genitals, which were followed by a general condition of ill-health; and she also noticed a roseola of a persistent character, and mucous patches, and condylomata. In the two years succeeding this syphilitic infection she had two miscarriages at five months withont any known canse. Within a year after that her health improved markedly, and she then became pregnant with the present child. The father was a very uneommunicative man, and I failed to get his history.

The child had the snuffles very severely when about a month old, but no rash was observed. When it was six weeks old, the mother noticed that the bones of the forearms were enlarged just above the wrists. These swellings grew gradually larger, and when they had existed six weeks the child came to me. On very careful examination I found a slight papular syphilitic rash, with evidences of a declining roseola. These cutaneous manifestations were quite clear, and were regarded by me and by iny friend; Dr. H. B. Walker-who was present at the examination-as undoubtedly syphilitic. They had evidently escaped the notice of the mother, but had certainly existed several weeks. The cranium was normal in every particular, as also were the ribs. As the child was not very fat the swellings on the forearms were quite readily seen. The two bones of each side seemed joined together by a deposit of firm tissue, which was evenly distributed around their lower ends. At this enlargement the interosseons space was not discernible with the tip of the finger, though it was readily found above this point. The surface of the swellings was in their greatest extent smooth and rounded, beginning abruptly from the shafts of the bones, and then forming a decided elevation of fully half an inch, and merging into and being lost in the expanded epiphysis. The swellings on the ulnæ were very plainly marked just above the styloid processes, which were lost in them. The integument was slightly stretched, but was normal in appearance, and conld be slid easily orer the swellings. The parts did not present any perceptible elevation of teinperature. Upon manipulation no nneasiness seemed to result, and there were no evidences of the presence of spontaneous pain. 'The mother stated that the 
swellings had attained their present size in a month after she first noticed them, and that for a fortnight she had observed that they did not increase in size. I prescribed for the child the mixed or combination treatment, composed of bichloride of mercury, one grain ; irdide of potassium, four drachms ; syrup and water, each two ounces: of this mixture it was to take six drops three times a day. In June the entaneous lesions had disappeared, and, as the medicine was well borne on the stomach, I increased the dose to ten drops; there was no perceptible diminution in the size of the bonc-swellings. The dose as thus increased was continued during the month of July with very little irregularity, owing to temporary diarrhoca, and in Angust the swellings were unmistakably smaller in size. This diminution in size was most marked at the nlnæ, as it becane possible to define the contour of the styloid processes. Though the osseons lesions had been benefited by the treatment, the general condition of the child was not very good. It had become pale, and flabby, and thin. Yet it had never manifested any disturbance of the gastro-intestinal tract, nor had it showed any particular morbid symptom. I also noticed a tendency to lateral expansion of the skull similar to that of chronic hydrocephalus. This led me to examine the bones very carefully, and I could not find the least abnormality about them. I examined the ribs again also, but they were normal. Under these circumstances I rednced the dose of the mixture to six drops, and ordered that it should take besides one teaspoonful of the sweet wine of iron, and a similar quantity of cod-liver oil. In September a pustular syphilide and mucous patches were observed. In November I saw the child for the last time. The enlargements. of the bones had almost wholly disappeared, and their contonr's could be clearly defined. Upon the radins, at the diaphyso-epiphysal junction, there was a slight ridge of a height of about two lines, and a breadth of about a quarter of an inch. Upon the uhn very slight upliftings of the surface of the bone were felt just above the styloid processes, which seemed normal. At this, the last visit, I saw that the enlargement of the head had got rather more prominent, but there was no alteration of the fontanelle. The general condition of the child was very bad; its skin was wrinkled and scurfy, and the subcutaneous fat was nearly all absorbed, and the muscles were 
wasted,-in fact, it seemed profoundly cachectic. I am convinced that it died soon after, as its mother attended so regularly before.

CASE II.-John B., a male child three months old, was brought to the Woman's Medical College of the New York Infirmary, and was transferred to my clinic on the twenty-fifth of Norember, 1872. At that time I ascertained that its mother had been syphilitic nearly two years, but I could obtain no history of the father. Upon examination I found a roseola and papular roseola of undonbtedly syphilitic origin, upon the trunks and extremities. The body of the right testicle was enlarged to more than twice its natnral size, and there was an hydrocele of the tunica vagrinalis. The distal ends of the bones of the forearms were also the seat of morbid changes. Thus just at the junction of the diaphysis with the epiphysis of each bone an enlargement was felt, which began quite abruptly and attained a height of fully half an inch, and merging into was lost in the expanded epiphysis. The surface of the swelling was perfectly smooth, and when carefully examined, both radius and ulna seemed soldered together by a new deposit. The swellings corresponded in size on each arm. If they had not been carefully sought for, these enlargements would have escaped recognition, as the child was quite fat, and at each wrist it was particularly so. The treatment consisted in the administration of one grain of hydrargyrum cum creta and of one grain of iodide of potassium at intervals of half an hour between each dose three times daily. The testicle received proper treatment. The cutaneous lesions disappeared, and in six weeks there was a marked diminution in the size of the enlargements. I have since learned that the treatment was contimued for two months longer, and that then no swellings were perceptible upon the bones. There was not at any time any apparent impairment in the use of the limbs, and the joints were not invol red. The case also presents an interesting feature, as showing the development of a sarcocele in a hereditarily syphilitic child, a lesion, the existence of which was once denied. The fontanelles were normal, as were also the ribs and skullbones. The child had not had local nocturnal sweats, nor had it suffered from gastro-intestinal disturbance. 
Case III.-Mary J. cane under my observation on the twentieth of October, 1871. She was then about two months old. Her mother was found to be srphilitic, and had been infected about six months; that is, in the fifth month of pregnancy. Her lesions were of a severe character, and she seemed very much debilitated. She had been treated for syphilis for about three months, but not very actively. She stated that shortly after the child's birth it hall had a dark rash, which had continued to exist, and that its month had been very sore, and that it was rery restless at nighlt, seening to be in pain. Upon examination I found that the child was quite well developed, and tolerably fat. The eruption alluded to was a roseola, which had becone coppery in tint, and was eridently declining. There were two nucous patches in the month, and a condyloma latum upon the margin of the anns. Upon examining closely the varions bones of the body, I found that several of them were the seat of enlargement. At each wrist there was a very evident swelling, which began abruptly from the shaft of the bone, and then attaining a height of about three-quarters of an inch, having a smooth surface, merged into the expanded and enlarged epiphyses. The swellings were perfectly symmetrical in size, and an examination of them gave the impression that both bones were welded together with an encir ling tissue. At the lower end of the shafts of the tibia and fibula a similar condition was found. Ilere, howerer, the swelling was less abrupt from the shaft, and the enlargement of the epiphyses was much more considerable in comparison. Both bones seemed to be joined together inseparably ; in fact, at their two ends they had a somewhat quadrangular shape, and their surfaces were smooth. Each malleolus conld be clearly made out, at its lowermost part, as normal in shape; consequently the process had only involved itó upper part. No other bones seemed to be involved. The mother was mnable to give a history of these bony tumors. She had not recognized those of the wrists, probably owing to the fatty tissue, but she thought that the condition of the ankles was not natural. The movements of the arms and legs were apparently performed normally. I ordered for this child five drops of the mixed treatment three times a day; but I only saw it once after, and then, as but three weeks had elapsed, no apparent change had been produced. 
I afterwards learned that it had died early in December, of a pulmonary tronble.

Cuse IV.-I was asked by its uncle to see P. C., a male child aged fourteen months, on the 10th of July, 1873. I found it to be a quite delicate child, but not remarkably thin. Upon each side of the frontal bone was a very prominent swelling, and this condition was the cause of my visit. Besides these bone-swellings there were enlargements of the bones of the forearms. An inquiry into the history of the ease brought out the following facts: The child had been well at birth, but when a month old it had been covered from head to foot with a rash, had had snuffles very badly and for a long time, and had a very severe inflammation of one eye. When three months old the swellings on the forearms were noticed, but up to that time the child had nursed and slept well, and in spite of its lesions had grown proportionately. It had never had ferer nor swéats at night, but when its nose was stopped up with the coryza its respiration was sometimes a little impeded. At this time it was treated by a village physician, who evidently regarded the case as one of rickets. When the child was six months old, the node on the right frontal eminence had been noticed, and in about three months after, that on the left formed, or rather was noticed. The treatment followed, as nearly as I could ascertain, consisted in the administration of quinine, iron, and cod-liver oil. It was nursed by its mother until three months before the time at which I first saw it, and after that was fed on milk of good quality. In Jannary, 1S73, it had suffered sererely from sore month, and the lesion being persistent, it was touched several times with nitrate of silver stick. An examination of the case resulted in obtaining the following facts: The cranium was normal, except at the points mentioned. There were no evidences of thickening of the bones at any of the sutures, no soft spots or depressions upon any of them, and the fontanelle was not abnormally large. The node on the right side of the frontal bone was nearly three-quarters of an inch in all diameters, it being quite round. It was elevated above the plane of the skull nearly one half-inch, and had abrupt but even borders, and its surface was smooth. The node on the left side was about half an inch in diameter, and it corresponded exactly to 
its larger fellow. The integument orer both swellings was, though slightly stretched, normal, and not in any manner adherent. At the line of junction of shafts with the epiphyses of the radius and una was a well-marked ring of bone. The npper border of the ring began abruptly at the shaft of the bone, and attaining a height of half an inch, bevelled off again into the epiphysis, having occupied an area of about three-quarters of an inch of the continuity of the bones. When examined from the wrist-joint upwards, the swelling was not as abrupt as it was when felt of from above. This was due to the expansion of the epiphysis. The surface of this ring was smooth, and orer it the integument, which was normal, could be readily slid. As the child was not very fat, the swelling conld be seen very plainly. The lesion was symmetrical on both bones of both forearms. Upon the ulnæ, just above the styloid processes, the swellings were particularly well marked, and their lower borders fused into and enveloped the upper part of the styloid processes. The ribs were normal, and no other enlargement was found upon any of the bones. The wrist-joints were not at all impaired in their motion. Upon the inner side of the left labial commissure, the mucons membrane was very much thickened, of a white color, and cracked in various directions. There was a slight opacity of the left cornea to the right and above its middle part.

The mother's history was as follows: She had been married three years prior to the birth of the present child, dnring which time she had twice miscarried. She had become ill soon after marriage, had some eruption of the skin, and suffered severely with sore-throat, or as she called it, diphtheria. She also had had condylomata around the vulva. She had not been treated regularly. The father was said to suffer from rhenmatism.

I prescribed the same mixture, combining the bichloride with the iodide of potassium ; and ordered that the child should take ten drops three times daily, and to increase the dose in a month to fifteen drops.

As the child lived in the country, I did not see it again for a month, at which time I learned that the medicine had been given quite regularly, except an intermission of a few days, owing to diarrhoea. At this examination $I$ found that the nodes were somewhat less elevated-a fact which could be seen by the 
eye as well as appreciated by the tonch. As there was no marked change in the swellings on the forearms, I ordered that they should be rubbed every day with ung. hydrarg. The dose was then increased to fifteen drops. This line of treatment was followed mutil Norember, at which time I saw the child again. The nodes had entirely disappeared, and on the site of their former position a distinct depression of about one-third of a line was found involving their whole area. This fact was well shown on both frontal eminences. As the tip of the finger was passed along the surface of the frontal bone it wonld slide snddenly into these depressions. The former rings of bone on the radius and ulna were now almost imperceptible ridges. The general condition of the child was good.

CAse V.-The history of the next child is somewhat incomplete as to the course of the lesions under the influence of treatment, but still it presents other interesting points.

T. C., a male child, aged two months, eame under my observation in September, 187\%. I liad treated its mother for secondary syphilis about a year previonsly; its father was not examined by me, nor could I obtain any history of him. The child when first seen was covered with a very confluent roseola, had severe eczema of the genital and anal region from the irritation of a number of neglected condylomata, and it suffered from aplithæ of the month. The bones of the forearms were the seat of cliange at the junction of the shaft with the distal epiphysis. The swelling consisted of what appeared as a ring encircling both bones; it had fully three-quarters of an inch of area, and was raised a little more than half an inch. At the seat of lateral opposition of the two bones the swelling was so much developed that they appeared as if fused together. The surface of the swellings was nearly smooth-not at all ridgey. The integument abore was uplifted, and the tumors were clearly visible, as the child was quite thin. At the head of the radins and ulna on each arm a similar but smaller ring of bone was found encircling each; but they wonld have escaped attention if not felt for, as they did not produce any bulging of the integument. The swelling on the ulna was more perceptible on the back of the arm, at the base of the olecranon process. There was no impairment in the use of either limb. 
At the junction of the shafts of the tibia and fibula of each leg with the lower epiphyses was a ring of bone similar to that observed on the arm ; and there was a similar elevation of the integument, which was very perceptible just above the ankle. The remaining portion of each malleolus appeared as if unaffected. The integunent was slightly stretched, but normal. No other bones appeared affected. 'This child had been vaccinated when a month old, and its mother thonght that all its troulle resnlted from that. I orrered for it an appropriate treatment; but I nerer saw it again, as its mother left the city.

2.

$\mathrm{C}_{\Delta \mathrm{SS}}$ VI.-The mother of the next child presented a clear syphilitic history, she having been infected at about the fifth month of pregnancy, her husband having then become syphilitic. When first seen by me she presented well-marked syphilitic lesions. She came under my observation on the 1st of June, 1871, having been sent to me by my friend Dr. W. H. Draper. Her child's history is as follows :-

Matilda C. came under my observation June 1st, 1871, she being then six months old. At birth she presented no lesions of the skin, and was seemingly a well-developed child; but when a month old she was afflicted with a roseola, mucous patches, and smuffles-all of which disappeared, and were replaced by a general papular syphilide. When the child was six weeks old its mother noticed that its riglit middle finger was somewhat enlarged, but she could not obtain any evidences of pain. The enlargement slowly increased for two months, when the skin covering the first phalanx became slightly red, thickened, and tender, and very tense from pressure within. This inflammation of the integument and enlargement of the bone progressed very slowly, and at the end of ten weeks-which wonld be the fourth and half month of the existence of the trouble-fluctuation was discovered, and an incision was made by a surgeon on each side of the finger, thris liberating a quantity of pus. At this time the patient eame under my care, and the right hand presented the following appearances: The middle finger was greatly swollen, being fully an inch in all diameters, and having a circumference of two and three-quarters inches. The diameter of its fellow was one-third of an inch, and its cirenmference slightly less than an inch. The finger was markedly flexed, and 
could not even by pressure backwards be fully extended-a condition which was due to the tension produced by the swelling upon the flexor tendon. The fore and ring fingers were very much separated, and were rendered unwieldy by their abnormal position. This was very noticeable when the child clasped any small article between the thumb and forefinger. The ulcers which resulted from the incisions had a sloughy base similar to that observed in ulcerating gummata, were surrounded by a livid, undermined edge, and they secreted considerable quantities of a sanious pus. The inflammatory condition of the adjacent integument was quite well marked. There was no evidence, nor had there been, of spontaneous pain; but the finger was sensitive to handling, as evidenced by the distressed look of the child's face. According to the mother's statement, the child nursed and slept well, and its strength was not impaired. TThe mother was placed upon appropriate antisyphilitic treatment. For the child I ordered a grain of hydrargyrum cun creta three times daily, and treated the ulcers by slightly pencilling them with a solution of nitrate of silver, and the continuous application of an ointment composed of ung. hydrarg., two drachms; ung. simpl., six drachms. During the month of June rery little change took place in the finger, but the eutaneous and mucons lesions disappeared. At the end of July it was noticed that the ulcers discharged less, that their edges were less everted and undermined, and that there was a diminution in the circumference of the phalanx of one-quarter of an inch. This was probably due both to the lessened size of the bone, and also to the less thickened condition of the integument. [)

During the month of Angust there was also an improvement, the finger being an eighth of an inch less in circunference. During the early part of this month the child had taken the powders only ten days, in consequence of a gastro-intestinal disorder, and later in the month they were replaced by the mixed treatment. I had been testing the progress under a strictly mercurial treatment.

The case progressed farorably during the months of September, October, and November, for during this period the bone became markedly less swollen.) The ulcers, however, did not wholly heal, and required stimulation once a fortnight as exu- 
berant granulations appeared on their floor. It was then evident that the healing process at the base or floor of the ulcers was seated directly upon the bone, and there was a tendency to very slight contraction or bending of their edges towards the bone. Early in Junnary these ulcers were fully healed, and they left behind a thin cicatrix on each side of the finger, which by its central part was adherent to the bone. At this time the finger presented the following appearance: It was three-eighths of an inch longer than its fellow of the other hand, owing to elongation of the first phalanx, which was flattened laterally, so that its transrerse diameter was a little less than half an inch, while its antero-posterior diameter was about three-quarters of an inch. The mobility of the finger seemed perfect, and the child was able to grasp any article with the hand with normal power. In the management of the case I found it advisable-as the progress previously was not satisfactory to me, the treatment however being somewhat experimental-to change the simple mercury for a combination of iodide of potassium with inercury. The child took for six weeks five drops, and after that to the period of cure ten drops of a mixture composed of bichloride of mercury one grain, iodide of potassium four drachms, mixed with four omees of syrup. I should add that there were periods varying between a few days and a week, that the nother failed to give the remedy; but she was upon the whole faithful to her duty, considering the length of time occupied by the treatment. Besides the lesion of the phalanx above described, there was a similar trouble of one of the metatarsal bones of the left foot. In July the mother noticed that this foot was wider across the instep than its fellow of the opposite side; and I found by measurement that snch was the case, there being half an inch greater circumference at this point than on a similar point on the other foot. This swelling gradually increased, in spite of gentle pressure continuously applied, until the 14th of August, when the tumor was quite large. As far as a careful examination would reveal, I inferred that one of the cumeiform bones, perhaps the middle, was the seat of disease. There was a considerable hydrarthrosis in the articulation between the cuneiform and scaphoid bones. There being evidences of fluctuation over the middle cuneiform, I made an incision into the most prominent part of the swelling, and 
gave vent to about a large teaspoonful of thick healthy pus. The resulting ulcer was of similar appearance to those of the finger, and was a very long time in healing, it being treated in a similar manner. The effusion into the joint was slowly absorbed, the pain ceased, and in December the nlcer had filled up' and was covered by a cicatrix, which was slightly adherent to the bone beneath. Upon manipnlating the joint I found it was less mobile than natural, but I felt convinced that this condition would gradually cease by exercise of the parts. The abscess of the bone had not resulted in any very perceptible loss of tissue, and it was a matter of surprise to me that the reparative process had been so perfect. At my last observation of the child, January 5th, 1872, its syphilitic lesions had wholly disappeared, those of the osseons system having lasted respectively. elereu months in the finger, and six months in the foot. I I entment dis,

The mother of the two clildren, the history of whose cases now follows, came under my observation in November, 1870 , she being sent to me by my friend, Dr. W. H. Draper. She was then in the seventh month of her third pregnancy, and was also in the first year of syphilis. She had been infected by her husband when about three months pregnant, and when first seen by me, having been syphilitic about four months, she was suffering very severely with angina and laryngitis. She luad become markedly emaciated, and was very weak. Abont the vulva were large masses of very much hypertrophied condylomata lata, which had the bluish congested appearance of these lesions when developed during the gravid condition. Her body was covered with a very copious papular syphilide, and there were slightly pigmented spots over the whole surface of a roseola which had been her first rash and had faded. There was a rery well-marked cranial alopecia, and on each angle of the lips was a fissure which commenced in a mucous patch on the inner surface of these parts. Under the circumstances, I placed her upon an active mercurial course combined with tonies; besides this, the lesions of the mucons nembrane were treated locally. Early in January, 1871, she was delivered of a female child, which at birth was well developed, and did not present any evidence of syphilis. The mother had a severe relapse of her syphilis in March. 
I examined the father in December, and ascertained that he had had a chancre and secondary lesions within the year.

Case VII.-Minnie C., the infant daughter of this woman, was brought to me in March of the same year for treatment. I ascertained that, when a month old, the child had had roseola, mucous patches, and coryza, and at this time she had become cross and peevish. The urgent symptoms, when seen by me, were the coryza, mucous patches, and emaciation of the child. I ordered it, then, appropriate internal and local treatment, and did not see it again until about the middle of June of the same year. At this time I observed serious lesions of the bones and joints, and that the mucous patches in the mouth still persisted. The child's left arm was semiflexed, and it showed a disposition to protect it from handling and from any slight blow. Its mother said that it had held it in this position for nearly two weeks, and that it was evident that it was painful. Upon examination, I found that the elbow-joint was swollen, and that it was rery hot to the touch. There was a swelling in the upper part of the olecranon process, which was mueven, particularly on its superior surface. This swelling, which I could distinctly define as belonging to the bone, was fully as large as a chestnut. There was considerable effrnion into the elbow-joint, which was most perceptible to palpation on its posterior aspect. Though I used some force, I was wholly unable to fully extend the arm. On the other arm I found a swelling, about the size of a pea-nut, just above and almost upon the internal condyle of the humerus. The swelling was not very prominent, and to the tonch appeared smooth and rounded. There was no impairment of the use of the joint, no perceptible effusion, and no unnatural position of the limb. On the same arm I found a slight enlargement of the radius, just above its styloid process. This swelling seemed to be dereloped around the circumference of the bone. There was no interference by it of the working of the wrist-joint, or of pronation or supination. Upon the right leg, involving the portion of the tibia and fibula which correspond to the point of union of the lower epiphyses with the shafts, was a large swelling just above and merging into each malleolus, which appeared somerhat quadrangular. Though carefully examined 
by me, I could not, by tracing the longitudinal ontlines of the bones, and following down with the tip of the finger in-the space which is normally definable between them at their lower end, make out their outlines at all. The impression conveyed to my mind was, that the swelling had extended around and between the bones, and had here bonnd them together. The bones of the left leg were not inrolred. Iordered a local application of a roller bandage, saturated with an eraporating lotion, to the left arm, leaving the other swellings to be influenced by internal treatment. For the latter purpose I prescribed a mixture of bichloride of mercury one grain, iodide of potassium four drachms, syrup and water of each two ounces; of this the child was to take ten drops three times daily. July 15th, child was brought back. Its general health was improred, and its mother thought that it was better, as it was not as fretful as it had been. The elbow-joint was not as perceptibly swollen as when seen last. The bone presented the same enlargement at the olecranon, but there was less effusion into the joint, and mobility was slightly increased. During this interval of three weeks, the bandage had been applied by the child's mother every day, and she had ceased applying the lotion according to my directions, when heat was not pereeptible in the joint. The dose of the mixture was now increased to fifteen drops three times a day.

In two weeks there was perceptible diminntion in the size of the various swellings, particularly in the left elbow-joint, which was more mobile, and in the right tibia and fibula. The dose of the mixtnre was again increased to twenty drops three times a day. Thongh the weather was quite warm, the child had not discontinued its medicine, as it had not suffered from any gastro-intestinal tronble.

Late in the month of August, the lesions of the bones having then existed nearly three months, and when the child had been under active treatment fully two montlis, rery marked improvement was noticed in these parts. The dose was continued at twenty drops for a month longer. In September the left elbowjoint was, to all appearance, normal, and the swellings on the various bones had entirely disappeared. They had not left any material change in the shafts of the bone, either by increase or loss of tissue, and careful exainination failed to rereal any 
abnormal condition whatever of the portions previonsly the seat of disease. The whole treatment had occupied three months, and the lesions of the bones lad existed nearly four months. During this time the child had suffered from mueons patches in mouth. The integument over the various bone-swellings was normal. The general liealth of the child was much improved.

Case VIII.-Lorette C., the sister of the child whose history is just given, was brought to me on the 7th of June, 1871; I then learned that she had been perfectly healthy until a month before, sinee which time she had suffered from what her parents supposed to be rheumatism. When first seen by me she presented a papular syphilide upon cheeks and forehead, a declining roscola on the body, mueous patches in the mouth, and condylomata lata around the anus. The child suffered most severely at night, when she slept very little. The painful points were the lower end of the left radius, the upper part of left ulna, and the metacarpal bone of the right index finger. At this time the parents suspeeted that syphilis was the cause of the child's suffering, as the father had been similarly afflicted, and this eaused them to bring it to my office. As I knew that this child had not been syphilitic very long, and that it must have acquired its disease, I earefully examined for the initial lesion, and I found that there was an ulcer, sluggish in character and slightly indurated, on the inner aspect of the lower lip, which was accompanied by an enlargement of the submaxillary gland of the same side. I learned that its father had noticed it a month before, and had tonched it occasionally with a solntion of nitrate of silrer, which he used for the mucous patches of the other ehild, whose history precedes this. The mucons patehes of the baby sister were mndonbtedly the source of the contagion of the present child.

Upon examination I found that the metacarpal bone just mentioned was greatly enlarged, and presented a perfectly oval shape. At its middle it was about an inch and a quarter in diameter, from which point it gradnally shaded off on each end, and at its articulation on each end there was scarcely any enlargement perceptible. This bone, thus enlarged, completely filled the triangnlar space which exists normally between it 
ard the metacarpal bone of the thumb. Upon the palmar surface, the swelling was also quite perceptible, while upon the dorsum of the hand the swelling stood saliently out. To the most casual observation it was perfectly evident that the swelling was accurately limited to the region of the second metacarpal bone, for just beyond this region, on the portion of the back of the hand where the third metacarpal bone was situated, a distinct depression was seen in consequence of the abrupt shading off of the tumor. On the palmar surface it was evident that the swelling was distinctly localized in the second bone, and if the child was told to flex the thumb towards the base of the little finger, or if this was done for her, it was seen that in consequence of the swelling she conld not quite place the tip of her thmmb on that site, but that a space of half an inch interrened between the two, whereas, on the left hand this morement was very readily accomplished. To the touch it was quite evident that the enlargement was confined exclnsively to the bone, as this structure could be defined in all its relations to the surrounding parts. The swelling was perfectly even on its surface and the integument, which, though slightly stretched, was normal, and could be slid very readily over any part of the swelling. Upon manipulation pain was prodneed in this swelling, but the child said she was very much troubled with pain at night, but not during the day.

At the lower end of the left radius, just above the styloid process, was a swelling which encircled the bone, but which I could define clearly as not involving the nlua. This swelling was rounded and smooth on its surface, and was comparable to a round ring having a width of about three-quarters of an inch and being about half an inch high. The swelling on the ulna was upon the sides and posterior aspect of the olecranon process; it was abont the size of that on the radius, but it was irregular on its surface. Both of these tumors were painful on manipulation, and they rendered the child alert as to where she placed her arms, and to aroid having them struck.

I ordered this child to take fifteen drops of a similar mixture to that ordered for her sister, and at the end of a week her pains had ceased and the parts could be manipulated more freely, as they were less sensitive. On the 8th of July, having taken the medicine regularly for a month, the size of the af- 
fected metacarpal bone had diminished to nearly three-quarters of an inch; there was a corresponding diminution in the size of the other. The dose of the mixture was then increased to twenty drops three times a day, and I may here say that during the whole period it was faithfully administered. In the early part of September these bone-lesions had entirely disappeared. I was not able to determine any difference in the size or shape of either of the second metacarpal bones, and the radius and ulna, which had been affected, were not perceptibly abnormal. At the time this case and that of the sister whose history immediately precedes it, were under my observation, I was struck with the peculiarity of the almost simultaneous coincidence of the development of osseous lesions in sisters, the one a victim of heireditary, the other of acquired, syphilis.

Case IX.-James McE. came under my observation in September, 1870. His father had been under my care for abont fifteen months at the New York Dispensary, he having suffered sererely from syphilis during that time. The history of the syphilis in the mother was quite clear, she having been infected about a year previonsly. The child, which was the first, was born early in July, appearing well at birth, but breaking out; with a general rash when about two months old. On this point I could not get positive information, but the mother thought that the child did not have a rash until then. It had at that time also snuffles, and was treated by my friend Dr. Grunhut, one of the physicians for children's diseases at the New York Dispensary. When first seen by me in September, the child seemed quite well developed, having considerable fatty tissue upon the body. It nursed from its mother's breast wholly, she having an abundance of milk. There was no history of any gastro-intestinal disorders, nor of any morbid symptom except the snuffles, with which the child had suffered severely. It had grown in weight during its life, and certainly looked well nonrished. The anterior fontanelle was not abnormally large, and the others were closed. There were no soft spots or thinned places on any of the eranial bones. My questions also elicited the facts which follow. When about two months old, the mother observed that the bones of both forearms became swollen just abore the wrists. Very shortly afterwards the bones 
of the legs swelled near the ankles, and a swelling was found under the left knee. The swellings increased in size quite rapidly for a month, at which time Dr. Grunlunt mentioned the ease to me, and transferred it to me for observation and treatment. The child was three months old when first seen by me. I found the distal ends of the radius and ulna much enlarged, the swelling upon the bones reaching fully a halfinch, and being about three-quarters of an inch long, and involving all the sides of the bones. They appeared as if fused together. The swellings on the ankles were as follows: the right fibula was enlarged at its diaphsso-epiphysal junction, in the form of a quite prominent swelling, which began abruptly at the shaft, and ended, after attaining a lieight of over a half-inch, by fusing into the epipliyses. The ends of the malleoli were not enlarged. On the inner side the swelling seemed to coapt closely with the tibia, which, however, was not at all swollen. On the left tibia a precisely similar, but proportionately larger swelling was fomnd, while the fibula was normal. Upon the npper part of the right tibia a quite large swelling was seated. It began about at the apex of the tuberosity, and could be traced around the bone from the fibula to its posterior portion, where it was not perceptible to the tonch. Its surface was quite uneven, and its lower edge began abruptly, and it ended by its upper part at the joint. It was mnch more clearly defined if viewed when the leg was considerably flexed than if it was extended. The ribs were normal, as also was every other bone. I prescribed for it six drops thrice daily of the mixture already spoken of, making no local application. The child came regularly to me for a month, at which time I increased its dose to ten drops. At this time, Oct. 15, there was a decided diminution in the size of the swellings. I then lost sight of the child until early in January, 1873, when I songht it at its home. I found that the progress had been very unfarorable in the ten weeks which had elapsed. Over the swelling of the left radius I found an ulcer of a diameter of half an inch and a depth of a quarter of an inch, with very red undermined edges, a grayish sloughy base, and secreting a copious amount of unhealthy pus. If the edges of the nlcer were mored with the tip of the finger, it conld be seen that they would slide over the bone to a slight ex- 
tent, and that the base was evidently seated upon the bone. The skin for fully three-quarters of an inch around was thickened and of a dusky red color. I inferred from these facts that the ulceration had been induced by degenerative changes in the bone-swelling. I shonld add that this uleer was seated on the back of the wrist, and that it encroached slightitly towards the styloid process of the bone. On the right wrist, over the radius, the integmment was rery much elevated, and from its redness it appeared as if the seat of an abscess, and at its centre fluctuation was distinctly felt. On the outer side of right ankle was an ulcer of the same general appearance as that ou the left arm, but it was somewhat larger in size. On inner side of the right ankle a very minute uleerated opening in the integument was seen, from which a thin, gumnny fluid could be made to escape. As far as I could learn, the swellings had increased in size about a month or six weeks previously, and that they had formed the ulcers seen at this time. The treatment had not been followed for two months. This was owing to the intemperate habits of the mother. I opened the abscesses on the radius and upon the tibia, and a quantity of thin pus escaped. The general condition of the child was good. I touched all of the ulcers with a very strong solution of carbolic acid, and filled them with charpie saturated with the same. Under this treatment the ulcers became much improved in a week, as their sloughy appearance had passed away. I then ordered that they should be thoroughly covered with iodoform once a day, and then well protected with lint. The medicine was resumed in ten-drop doses. Early in February the ulcers were very superficial in character and of healthy appearance. The bone-enlargements were somewhat smaller. The dose of the mixture was increased to fifteen drops. The incisions made in January enlarged and formed ulcers, which, owing to treatment, did not assume the sloughy condition of the first two. During February I found it necessary to touch the nlcers lightly with stick nitrate of silver, as they became covered with granulations when they approached the level of the integument. In March they were all thoroughly healed, leaving slightly depressed red cicatrices, which at their centre were adherent to the deep parts. At this time there was a decided diminution in the size of the enlargement at the head of the 
left tibia, and the other swellings were slightly less in size. The medicine was given with tolerable regularity, areraging perhaps two doses daily. It was well borne by the stomach. At the end of April the swellings had all disappeared, and when the diaphyso-epiphysal junctions were examined, the only trace of them was a slight ridge of bone about one-quarter of an inch in breadth. This was well marked on the upper part of the tibia. During the month of March the child had several condylomata lata on the margin of the anus.

C.sse X.-Einma N., aged seven weeks, was brought to me by her mother, July 8,1869 , who stated that at birth the child had no appearance of any skin disease upon its body, but that when it was two weeks old it became hoarse, and was so much troubled with the snuffles that its breathing was rendered difficult. She had also noticed that about the same time an eruption began to appear on its body, and that very soon after that, perhaps a week, she had observed that some of its bones began to swell. At this time she called her husband's attention to these troubles of the child, and he being under my care for syphilis at the NewYork Dispensary, mentioned them to me, and I expressed a desire to see the child.

Upon examination I found that a very sanions and fetid discharge issued from the nostrils, and that it had excoriated tho upper lip. Upon the arms, trunk, and legs there was a very copious, sinall, flat, papular syphilide, the eruption being greatest on the trunk and forearms. On the latter site it showed a decided tendency to form circles and segments of circles, a feature which I had never until then observed in the papular eruptions of hereditary syphilis. There were well-marked condylomata lata around arms and vulva, but the mouth was free from lesions. The child was not very much darker than a white child, and its mother, a mulatto, was quite white. It was well nourished, and its muscles, which were quite well dereloped, vere covered with considerable adipose tissue. Upon the shafts if the bones I found some very peculiar lesions. The sternal end if the right clavicle was very much enlarged, beginning at the loint which corresponds with the junction of the diaphysis with the epiphysis. The swelling began here quite abruptly, a ud attaining a height of rather more than half an inch; it ended 
quite abruptly at the joint which examination showed to be unaffected. The swelling was perceptible to eye and touch, jutting out slighitly besond the chest-walls and npwards towards the neck. It was very clearly defined when the mother held the child on her lap horizontally, and then let the head fall back without any support. This stretched the sterno-cleido mastoid muscle backwards, and the integument quite firmly over the tumor. The latter strncture was normal. At the junction of the second and fourth ribs of the right side with the eartilages, were two quite similar enlargements, though somewhat smaller, being rather less than half an inch in height. The surfaces of these swellings were smooth and did not adhere to the integnment. Two precisely similar swellings were fonnd on the left side, involving the second and third ribs. At the lower end of the left humerus was a large irregular swelling which expanded the bone laterally to a transverse diameter of full two inches, and which bulged out posteriorly in a markedly pereeptible manner. Just over each condyle the swelling spread out, forming quite a distortion of the bone, and involving it along the condyloid ridge for a space of three-quarters of an incli. The swelling was also developed on each side of the olecranon process, and complete extension of the arm could not be prodnced, and it remained continually in a semi-flexed position. There was evidently a small quantity of serum in the joint, as two puffy swellings were found just above the oleeranon. The integnment, which was not at all adherent, was slightly reddened, and was perceptibly elevated in temperature. The joint was evidently painful, as the child shrank from its manipulation. At the distal end of the right radius and nlna, a perfectly smooth enlargement of the bones was noticed, which extended up their shaft fully two inches. The ends of the bones seemed as if welded together. The same condition was observed in the other arm also. At the lower end of the left tibia and fibula was a similar smooth enlargement, but in this instanee the swelling was very much greater and the deformity was very apparent, resembling somewhat a dislocation of the two bones forwards on the tarsal bones. Upon eareful palpation, I discovered a soft fluctuating spot in the centre of this swelling on each side, which corresponded to a point an ineh and a half abore the ends of each malleolus. The soft fluctuating sensation 
was found quite generally over the surface of the tumor, thongh less so than at the centre. It seemed to follow a line all around the two bones corresponding to a point just an inch and a half above the malleoli, which was the most prominent part of the swelling. Upon further manipulation I diseovered that these lower segments of the two bones were detached from the shaft. They could be moved quite considerably in each lateral direction, but I conld not assure myself that an antero-posterior motion was produced, owing to the movements of the joint. The lateral motions were attended with soft but distinct crepitation. I used traction on the parts, but I did not satisfy myself that any separation was produced between the upper and lower segments of the bones; the joint-structures seemed to yield, and thus I was unable to localize the point of separation. The upper part of this swelling did not begin abruptly, but it arose gradually from the shaft fully two inches and a half above the malleoli, and became prominently swollen at two inches, as just now stated. In the upper portion the periostenun was evidently thickened. There was considerable tenderness of the parts, as the child cried if they were manipulated. The integitment, though stretched, was not inrolved, nor was it the seat of perceptible preternatural heat.

Upon the right leg a very similar but much larger swelling was found, but in its centre the fluctuation was more distinct, the artificial morements in the varions directions were more freely accomplished, and the crepitation was equally as distinct. On the inner ankle it was evident that the integument was involved, for it presented for a space of the size of a silver halfdollar a brawny sensation, was there quite hot to the tonch, and was not freely morable over the bony tumor beneath. As this thickened and inflamed part gradnally shaded off into normal integument all around it, it was plain that suppuration had commenced in the deep connective tissue. The mother informed me that the swellings had come on during the previous month, but that she had noticed that those of the leg had increased in a very marked manner during the preceding fortnight. Her attention had also been attracted towards a seeming inability of the child to more its feet and legs, and that it did not show a dicposition to draw them up. When seen by me the legs lay stretched out as if paralyzed, and the two feet turned in 
towards one another, and if they were everted they immediately fell inwards as soon as they were released from the grasp. This position of the feet is noticed in the normal condition to a certain extent, but in this instance it was observed in an extreme degree. If the soles of the feet were tickled, or if the integnment of them was pinched with a pair of forceps, a very slight jerking motion was produced, which, however, was localized in the thighs, and was not communicated to the muscles passing from the leg to the feet. As far as I could ascertain by very careful examination and observation, the inability to move the limbs and their apparent obtuseness to peripheral irritation, were equal on both. With the exceptions of the bones spoken of, all the others were to all appearances normal. The cranium was normal in every particular. When first seen at this time, I was rather puzzled with the appearance of the osseons lesions, as I knew nothing then about these swellings at the epipliyses as being of syphilitic origin. I ran over in my mind the osseons lesions of rickets, but could not satisfy myself that the case was one of that disease. On consulting anthorities I could only find the reports of the cases of Roger and Fournier, which were in a slight degree similar, and upon conversing with friends who had large experience I could gain no information. However, knowing the undoubted syphilitic history of the child and of its parents, I concluded that all of the lesions resulted from syphilis, and placed it upon an appropriate treatment. In the conrse of subsequent reading I found Valleix's case, recorded in Bouchut's treatise on diseases of children, which presented almost similar features, and then I felt certain of iny ground. The somewhat unusual character of the case led me to follow it with nuch attention and care. The mother was directed to give the child a powder containing one grain of hydrargyrum cum creta three times a day. The nose was to be treated locally. In à week the child was again brought to me, and I found that the cutaneous lesions were somewhat less distinct, and that the coryza was benefited. The osseous lesions on the legs were not at all improved, the swellings were even greater, I thought. That of the left leg was larger in size, it having grown more perceptibly, but the integument was not involred, whereas the integument over the other tumor on the right leg at the spot indicated was evidently undermined with 
pus. I therefore made an incision into the thimmest part of the skin, and a quantity of thick pus escaped, which, after the parts were moved slightly, was followed by a tenacious secretion, viscid in character, yellow or brownish in color, and of the consistence of mucilage of gum arabic diluted with an equal quantity of water. This fluid was examined with the microscope, and found to consist of granular matter and a few myeloplaxes. After the evacuation of the contents of the abseess I again examined the parts earefully. The separation of the epiphyses from the shafts of the two bones could be very distinctly made ont, and movements conld be produced in both lateral and autero-posterior directions. The crepitation was very distinct, but of a soft character.

In order to preserve the parts, as far as possible, from further inflammation and destruction, I rendered the joint immovable by strapping it well with strips of adhesive plaster, leaving an opening corresponding with the orifice of the abscess, into which I placed a tampon of lint, saturated with balsam of Peru. I then bandaged in like manner the other leg, with a view of preventing disorganization, and perhaps of resolution and absorption by pressure and rest. The elbow-joint was covered with lint saturated in a cooling lotion. At this time I ordered that the child should take three grains of iodide of potassium three times daily, an hour after each powder. This treatment was followed without any alteration for a fortuight, at the end of which time the lesions of the skin had almost disappeared, and the coryza was less troublesome. The bandages on the legs having become loosened, I applied others. The discharge from the right ankle had been quite profuse for some days after the operation, but had then become less, and was serous in character. The sinus was dressed as before, and directions were given to change the lint twice daily. There was a quite noticeable feature observed in this sinus; it had not grown much larger, and showed no tendency whaterer to ulcerate; around its orifice it had become slightly thickened, resembling somewhat the sinuses following suppuration of eervical glands. At this time, the child, being ten weeks old, and having been under treatment three weeks, was placed upon increased doses, the iodide in four-grain doses, and the hydrargyrum eum creta two grains three times daily. Nothing unusnal was noticed 
for four weeks longer, at which time, it being the seventh week of treatment, a very'marked diminution was fonnd in the size of the swellings on the clavicle, on the ribs, and on the hunerus, and the effusion into the joint had been absorbed. This latter effect had been accomplished simply by rest and the application of a cooling lotion. There was also a marked diminution in the size of the swelling of the left ankle, and the epiphysis seemed firmly adherent and continnous with the shaft, and it could be distinctly felt that the consolidation was complete, as uo munatural movements conld be produced. The treatment was followed up with tolerable regularity until November, when the following condition was found: The bones of the forearms, arm, and the ribs were apparently of their natural size, but just at the junction of each shaft with the epiphysis and of the ribs with their cartilages a slight unevenness of the surfaces was felt. They had been in this condition fully two weeks. The left ankle was also nearly normal, there only being a slight ridge of bone felt, running transversely around the bones. This ridge, which was about a line in area, and of the same height, was somewhat larger in this sitnation than those were on the other bones. There was no evidence of periosteal swelling upon the shaft, as had been noticed in July. Upon the right ankle, on the spot corresponding to the sinus, which had closed in the latter part of September, was a small, somewhat star-shaped, irregular filorous cicatrix, of a rosy-red color, and adherent, but not very firmly, to the bone beneath. During the past month spontaneous movements had been noticed to take place in the legs, and I found that there was scarcely any abnormal turning in of the toes, and that, if the feet were tickled or pinched, they were quite spasmodically pulled up, and with considerable force. During the summer the child had lived in the country, and had grown stouter. At this time the only progressing lesion of syphilis was a mucous patch in the mouth. Early in 1870 I saw this child again, and then I found that the ridges of bone already described had become almost effaced, wholly so on the arms, forearms, and ribs, and that they were extremely slight on the legs. There was only a slight undulation of the surface, just at the junction of the epiphyses with the diaphyses.

The history of the father was, that he became syphilitic about 
two munths before his marriage, having a chancre and rhenmatoid pains. IIe also had lesions of the mucons membranes and a papular syphilide, having a decided tendency to epidermal proliferation.

The mother was married three months before she noticed any rash on her body, and then she suffered severely from condylomata, and alopecia was observed on the scalp and in the eyebrows. The child was born a year after marriage, consequently she became pregnant and syphilitic about the same time. She expressed her opinion that the child had been born two weeks prematurely. She had not been actively treated, having taken medicine only during the sixth and seventh months of pregruancy.

CASE XI.-The mother of the child whose history follows presented well-marked syphilitic symptoms. IIer name is Kate MeM., and she was a person who, though not robust, enjoyed good health, and was moderately stout. She was married on the 25th of Angust, 1872, being then in her seventeenth year. Two months afterwards she had ulcers upon the genitals, and in Norember she applied for treatment at the Woman's Medical College of the New York Infirmary. At this time she presented a general roseolous syphilide, mucous patches, and she complained of rheumatoid pains. Her condition was the subject of a clinical lecture by me upon two occasions. She was placed upon a proper mercurial treatment, which she was irged to follow carefully and faithfully. Her attendance, however, was very irregular, and she probably did not undergo the influence of mercury for more than a month; consequently her syphilis, it is fair to assume, was not properly modified, and she might almost be considered as a patient who had not been treated.

In April, 1873, she became pregnant, and early in January, 1874, she gave birth to a male child. Prior to and during her preguancy she had enjojed fair health, and had not presented any severe lesion of syphilis.

On the 17th of February she brought her baby to the college, and stated that it was then six weeks old; that when it was two weeks old she had noticed a swelling of the right ankle, which increased, became red, and that an opening appeared in it which discharged some pus. Upon examination, I found the following 
appearances: The affected ankle, just over the ends of the malleoli, measured four and a half inches, which was an increase of three-quarters of an inch orer that of its fellow of the left side. On the immer aspect, an inch above the end of the malleolus, there was a small opening, from which a small quantity of thin pus flowed. The integument, in the shape of a band encircling and including the ankle from the end of the malleoli to a distance of two inches above, was slightly hyperæmic, this condition not being great anywhere, but being comparatively greatest just around the opening. The enlargement was quite perceptible, and it wasalso noticed that the leg was abnormally bent, thongh in a slight degree inwards, so that the bones of the leg were bow-shaped, the convexity looking ontwards. This appearance may be noticed to a slight degree in nearly erery young child, consequently it must be carefully examined in every (:ase before being prononnced to be abnormal. In this instance, the comparison between it and the other unaffected leg was well marked. This feature was also clearly made ont by my clinical assistant as well as several students. It was also observable that the child had very little if any power of using the limb, and its motionless condition contrasted markedly with the active altennate flexion and extension of its fellow. When examined, it was found that the epiphyses of the tibia and fibula were slightly enlarged, that the integnment over them was not at all adherent even at the orifice of the sinus, and that there was no perceptible preternatural heat. Manipulation gave the child pain, as it cried piteonsly, though it had very little power to pull away the leg. The flexed appearance struck me as being peculiar, and a suspicion occurred to me that a false point of motion existed between the epiphyses and the shafts. Holding the epiphysal extremity firmly with one hand, and grasping the leg in a like manner with the other, I was able with very little force to more the two separated segments, the one npon the other, in a lateral direction. We carefully listened for crepitation, but it was not heard, nor was a grating sensation commmicated to my hands; indeed, it seemed to me as if two soft substances were rubbed very slightly-the one over the other. "It is well to remark that the movement by lateral displacement of these segments was very much limited indeed, and I should think that I moved the onter edge of the epiphysis perhaps one-quarter or one- 
sixth of an inch beyond the corresponding edge of the shaft. At the same time, it was clearly perceptible to me that very considerable bending conld be prodnced here, and that such a motion was rery readily induced; but owing to the extreme suffering of the child I did not push the examination further. My reflection, after examining this case, was to the effect that in it the lateral forced displacement was quite limited, much less so than that which I obserred some years previously in the preceding case; and that flexion was the principal motion obtainable, and that perhaps cases may be observed in which the former motion may not be obtained, while the latter can be clearly performed. My explanation was that the intervening cartilage between the epiphyses and the diaphyses had not been to a rery great extent destroyed, and that as a result the motion was limited. When the epiphysal region was carefully drawn ontwards, the leg being held in a normal position, it was readily seen that the normal axes of the bones were restored. Upon examination of the other portions of the osseons system, every bone was thonght to be normal except the distal end of the left radius and ulna, the epiphyses of which, just as they merged from the diaphyses, were found to be very slightly enlarged, the difference in circumference between the corresponding parts-left and right--being abont one-third of an inch. Besides these osseous lesions, the whole integnmentary surface was the seat of a roseolous and papular syphilide. The internal treatment consisted in five-drop doses of the mixture already spoken of. The leg was placed in its nornal condition, and its malleolar extremity was carefully but firmly bandaged with strips of adhesive plaster, an opening being left over the sinus. The child remained under treatment for a month, in which time much improvement was produced in the osseous affection, so that there was very little, if any, tendency to abnormal flexion; and there was an evident soldering together of the detached segments. The cutaneous syphilides were improred. The child was not bronght again to the college, as its mother regarded it as cured. I have just learned that it was suddenly attacked with an affection of the brain, of which it very soon died, and which was called by the family attendant acute hydrocephalus. It is very probable that if the mother had continued her visits to the clinic regularly, and had faithfully 
followed our treatment, which would have been gradually - increased in strength, that her child would not have succumbed to the pachy-meningitis, of which undoubtedly it died, and which, to my mind, was of syphilitic origin. I was informed by the mother that the family physician did not regard the osseons lesions as being induced by syphilis. An interesting point in this case is the comparative immunity from inflammation which the integument presented, even though the seat of a copious syplilitic eruption. Without any treatment except pressure the sinus closed, and a very minute cicatrix was left. It is a noticeable fact, and one of diagnostic import, that such grave changes should take place in a limb, and that so little, if any, constitutional reaction should be induced. This point will be brought out again further on.

Case XII.-Throngh the kindness of Dr. H. T. Hanks, I had the opportunity in May, 1871, of observing a very interesting case of enlargement of several of the phalanges of the fingers. The patient was a child ten weeks old, born of a mother, who, upon examination, I found to have been infected with syphilis within a year. This child had enlargements of the first phalanges of the index and ring fingers of the right hand, and of the same phalanx index finger of the left hand. The lesions of these bones had been noticed when the child was a little more than a month old. The swellings consisted in a general enlargement to about three times the normal diameter of the phalanges; and they caused considerable tension of the integument, and in one finger much hyperæmia was observed. The swelled ring-finger displaced the fingers on each side very much, while the two enlarged indices were turned inwards, but did not push very much out of its line of direction the middle finger on either side. The affected fingers were very much flexed, and at their base being thick and bulbous, they gradually tapered off towards the ungual extremity in such a manner as to lead to the impression that the second phalanges were also enlarged. Careful manipulation and deep pressure showed very conclusively that these bones were unaffected. The swellings were alike observable on the palmar and dorsal surfaces; and though they rendered the fingers unwieldy, they conld be flexed and extended very considerably by a second person. It 
seemed evident to my mind at the time, that, unless treatment was early instituted, ulceration of the integument was inevitable in one finger. The lesion was due to stasis from pressure within, and not to gummy deposit. This case was sent to the Collegre of Physicians and Surgeons, and, at Dr. Draper's request (he being una roidably absent), I made it the subject of a elinical lecture. I saw the child but once.

\section{III.-RESUMÉ OF CASES OF THE VARIOUS OBSERVERS.}

M. Roger ${ }^{1}$ observed a case of acquired infantile syphilis, in a child two years old, who besides having syphilitic lesions of the skin and mucons membranes, presented enlargements of the inferior extremity and internal borders of both humeri, enlargement of the anterior surface of the head of the tibia, and nodes on the frontal bone. This is one of the very few recorded cases of the derelopment of osseons lesion in the early stage of acquired syphilis of a young child. It may be classed with my case No. 8. It is to be regretted that the date of contagion is not given, as from it we could have ascertained the date of apparition of the bone tronble. The case also is wanting in the detail of treatment, course and result.

Dr. T. Curtis Smith ${ }^{2}$ reports the case of a child, born of syphilitic parents, upon whom when three weeks old various syphilitic lesions appeared. When first seen by Dr. Smith it was six weeks old, and he found that the first phalanx of the index, middle, and ring fingers of one hand were much enlarged. The swelling of the bones was greatest at the joints, which, howerer, were not involved, and from there it tapered off rapidly towards the next joint, which was also normal. The integument was livid. The joints were not freely movable. The fingers were evidently the seat of mild spontaneous pain, but gentle manipulation conld be practised. Under a mercurial treatment the enlarged bones were reduced to their normal size in three and a half months. Both parents were syphilitic, the husband having contracted the disease two years before and having been improperly treated, the mother being contaminated shortly after and not being treated until after the birth of the ehild.

2 'Union Médicale, page 249. Paris, 1865.

- A Case of Congenital Dactylitis Syphilitica. American Journal of Byphilography and Dermatobogy, Jan., 1872, page 83. 
Fournicr's ${ }^{1}$ cases are as follows:

An infant, three months old, having papular syphilides, mucous patches, and coryza, had a swelling of the lower end of the right humerns, which was greatest at its intemal border.

Case second : a child, three months old, having a pustular and papular syphilide and coryza, had an enlargement of the upper portions of the radius and ulna. The nlua was double its size at its upper fourth, and the head of the radius was as large as a nut.

Bertin, ${ }^{2}$ in his treatise, says that he has seen cases of periostitis and exostoses in syphilitic children, and then reports the following:

Pierre S., thirty-six days old, was-bronght to the Maternity Hospital, on the first of January, 1809, having blennorrhagic ophthalmia and pustules and tubercles of the whole body, and a tumor of the size of a pigeon's egg over the left great trochanter, and a periostitis of considerable extent upon the upper and posterior portion of the ulna. The movements of the arm were impaired, and there was redness of the skin orer the tumor, and pain existed. The bone lesions and cutaneons rashes disappeared under a mercurial course alone, in five months.

Archambanlt, ${ }^{3}$ of Paris, reported a case of an infant, whose mother had tertiary syphilis, and who had mucous patches and an enlargement of the last phalanges of the fingers. Being at first regarded as false spina ventoza, it was nnsuccessfully treated with anti-strumons remedies; but when mercury was given the mucous patches soon disappeared, and the bones were reduced to their normal size.

Bärensprung's ' case was that of a child, born of a syphilitic mother, who, having had tubercles which underwent ulceration on varions parts of the body, especially on the head, died of exhaustion when four months old. At the autopsy the left parietal bone was found to be the seat of considerable necrosis, the morbid processes having involved the periostem and the

LUnion Médicale, page 540. Paris, 1865.

- Traité de la Maladie Vénérienne chez les enfants nouveau nés, les femmes enceintes et les nourrices. Paris, 1810. Page 361.

'L'Union M'dicale, No. 140, 1869, and American Journal of Syphilograohy and Dermatology, Jan., 1871, page 14.

- Dis hereditäre Syphilis, pages 126-7, 8. Berlin, 1864. 
onter lamella of bone. The case is very badly reported, but well illustrated by chromo-lithography.

The same observer speaks of a case in which changes in the bones were observed at the junction of the shaft with the epiphysis at the lower end of the right and at the upper end of the left femora.

In a third ${ }^{1}$ case mentioned, a swelling was found upon the sternal end of the clavicle in a child three weeks old.

Putegnat ${ }^{2}$ reports a case of a child, the subject of hereditary syphilis from a half month old, who had a swelling of the upper part of the right thigh, which was followed by an abscess and dislocation of the femur. The bone-lesion was considered by the observer as an instance of the development of rickets in a syphilitic subject. This anthor also says he has seen a cranial exostosis on a syphilitic infant.

Bulkley's ${ }^{3}$ cases are two in number, and through his kindness I have had ample opportunities for observation of them, and I quote them nearly in full :

CAsE I.-A rather delicate girl; was first seen when two years and nine months old. Though the early history of syphilis is not clearly made ont, the existence of traces of an early interstitial keratitis and the peculiar bone-lesions point to that disease as being undoubtedly their true origin. When fifteen months old, a swelling began on the top of the left ankle, which softened and opened in two months. A similar swelling appeared, two months later, on the outer side of right fout, and it softened and opened in two months. Abont the same time -that is, when the child was fifteen months old-the first phalanges of the thumb and index finger of the left hand swelled, and shortly after softened and opened. When the child was a year and nine months old, the right metacarpal bone of the index fingrer swelled and opened. The pain was so severe in the affected parts that the child's rest was disturbed. When first seen by Bulkley, the child was two years and nine months old ; consequently some of the bone-lesions had existed

${ }^{2}$ Ibid., page 192.

${ }^{2}$ Histoire et thérapeutique de la syphilis des nonveau nés et des enfants a la mamelle. Paris, 1854.

- Rare Cases of Congenital Syphilis. New Fork Medical Journal, May, 1874. 
eighteen months--the others a year. The affected phalanx of the left forefinger measured two and five-eighth inches-its fellow of the right hand measuring one and a half inches. The circumference of the first phalanx of the left thumb measured two and three-eighth inches-its analogne measuring about one and five-eightl inches. The swellings were greatest at the affected phalanges, and tapered off to the ends of the fingers. The joints were unaffected. There was an ulcer over each phalanx which extended down to the bone, and a discharge came from each. Upon the right hand there was an ulcer over the middle of the second metacarpal bone, which was swollen in its whole length. The whole of the left foot was moderately swollen, but it was evident that the fourth and fifth metatarsal bones were enlarged. Orer these bones was an excavated ulcer, and around it an infiltration and redness of the integument. Upon the outer malleolus there was an excavated ulcer, and upon the middle of the leg a, scar of a former ulceration. The following mixture was ordered: R hyd. bichlor. gr. ss., pot. iod. 3 i, ferri ammon. cit. 3 ss, syr. pruni $z$ iv; dose, one teaspoonful three times a day. Simple cerate was ordered for the nlcers. Under this treatment much improvement was observed in a month, as the ulcers on the feet were healed. There was also no discharge from the finger or thumb. The swellings remained the same. In a fortnight after, although a marked improvement of the general health had taken place, it was noticed that the swellings on the thumb and forefinger were slightly increased in size. From the 28th of April, 1873, the treatment was very irregularly followed, and during the greater part of the time neglected; but in January, 1874, a slight diminution in the size of the affected bones was found. There was a marked distortion observed in the thumb; it was, though thickened, shorter than normal, and bent inwards towards the forefinger, which was slightly flexed. The metacarpal bones were enlarged. All of the bone-swellings seemed indolent.

The second case was that of a child of a mother in the second year of her syphilis. Shortly after birth it dereloped wellmarked syphilitic lesions, and at the same time a swelling was noticed in the first phalanx of the thumb; the bone was enlarged to fully twice its natural size. The case was seen by Bulkley when a month old, and was placed unon treatment. 
The swelling gradually subsided, and in seven months was no longer noticeable, but it was observed that the affected phalanx was about one-twelfth of an inch shorter than its fellow, consequently the thumb was shortened. As there was nothing abnormal in its shape, it is probable that the shortening is due to an arrest in development during the existence of the lesion.

Mr. John Morgan: mentions the case of a child three years old, whose history of hereditary syphilis was clear, who had a very large swelling of the metacarpal bone of the thumb, which was perfectly globular in shape, and presented the appearance as if the thumb had been thrust through a ball of tightly stretched skin. Suppuration occurred, leaving a thickened condition of the parts. The case is rendered almost valueless by the fact that the date of invasion and history of the course of the lesion are not given. The case is similar to my eighth case. The same observer ${ }^{2}$ presented casts of several specimens of what he regarded as dactylitis syphilitica to the Dublin Obstetrical Society, but the descriptions given are so vagne and meagre that the cases are worthless for scientific purposes. In the discussion upon them the author's diagnosis was ealled into question.

Ranvier's case was related before the Society of Biology in June, 1864.

D. Z., a seamstress, eighteen years of age, of lymphatic temperament and delicate constitution, was admitted to Lourcine Hospital, service of M. Simonet, Jannary 19, 1864. She is pregnant six months. Has mucous patches on rulva and anus, adenopathies, roseola and angina. She was not treated other than by loeal applications. On the 16th of March she was delivered of a child in her eighth month of pregnancy. The child was thin, but did not present any signs of syphilis. The mother nursed it, and neither received treatment. On the 10th of April an nlcer was found upon the left olecranon, which was two-fifths of an inch in diameter, having a sloughy gray base, and edges thick, sharply cut and undermined. The Sisters of Charity stated that a week after its birth they noticed a tumor, which was regarded as a furuncle, and which opened and

1 Practical Lessons in the Contagions Diseases, page 235. London, 1872.

2 Dublin Medical Journal, April, 1873, page 351 et seq.

${ }^{3}$ Gazette Médicale de Paris, rol. xix., third series, page 596. 1864. 
formed this ulcer, which was considered by MM. Verneuil aud Simonet as a degenerated goumma. There was a slight papular syphilide of the body. It became emaciated and died on the 13th of April.

Autopsy.-Liver tolerably yellow, angmented in volume, two small pale tumors on under surfice, one on the npper. The substance of the liver was hardened, and minute points were seen, which consisted of connective tissue and young cells. This same condition was observed aronnd the various vessels and ducts. Other organs not markedly altered.

Condition of the Bones. - All the epiphyses are separated from the diaphyses, or so slightly adherent that the mildest traction separates them. On a longitudinal section corresponding to the long axis of the bone, the following points are observed: The proliferation of eartilage is perfectly normal in the portion called by M. Broca couche chondroide. The cartilage-cells are spread out as usual in the osseous areolas or spaces. But ossification is tardy, and it is only one-fifth of an inch beyond the limit of apparent ossifieation that we find osseous cells, whilst normally they are found at the most one millimetre from this line. The author alludes to the fact that if treatment is adopted the child is either cured or ameliorated, while if not treated, syphilis runs its comrse. He thinks that this observation supports the view that pregnancy retards the evolution of syphilis in the mother, and that after that process it breaks out again.

Bargioni's ${ }^{1}$ case occurred in the service of Professor E. Pellizzari, in the hospital of Santa Maria Nuova, in Florence. At the time it was under observation it attracted considerable attention and discussion, from the fact that it was said to be an instance in which syphilis was communicated together with small-pox in the process of gestation. The reasons for the suspicions of the latter disease were, that it was raging in the part of the country in which its mother lived, and that four papules on its buttocks resembled those of variola. Its mother had variola some years before. The truth seems to be clear to me, from a perusal of the case, that it was simply one of hereditary

- Ascesso articolare e gomme delle ossa e dei polmoni in neonato affetto da syphilide con eruzioni vajalosa congenita Lo Sperimentale, page 65, tom. xiv. July, 1864 . 
syphilis, and that some of its pustules resembled those of variola,-a feature sometimes obserred eren in acquired syphilis. The mother was not discovered to be syphilitic, but she stated that the child's father had syphilis before their marriage. The lesions on the integunent of the child were ummistakably syphilitic. They consisted of pustnles and bullæ, well marked on palms, and soles, and onychia; the unucous membranes were also affected, there being a mucous patch in the mouth, and the child suffered severely from snuffles. Its facies was of the peculiar senile expression of syphilitic children. The child gradually became weak, refused food, became emaciated, and died when twenty-two days old.

The autopsy was made thirty-two hours after death. In the head a yellowish mass was found between the dura mater and frontal bone. Under the microscope, it was found to consist of degenerated fat, pus-cells, and of connective tissne. In the lower portion of each lung little masses of induration were present.

Osseous System.-In the right elbow-joint was a quantity of thick yellow pus; the cartilages were eroded and articular surfaces partly denuded. In the long bones, at the juuction of the epiphysis and diaphysis, a mass of yellow, grumons matter is seen, and the parts are very easily separated. This material was infiltrated into the substance of the shaft of the bone, and it contained small portions of necrosed bone. The mieroscope showed this matter to consist of pus-cells and fatty detritus, whilst in other parts nucleated fusiform cells were found in the granuiar matrix.

VALEIX's CAse. '-A female foundling, born September 5th, 1834 , was found to have, on the 14 th of the same month, a few small pustules, containing a drop of white pus, and surrounded by tolerably red areola. On the 15 th, when the child was ten days old, it was observed that it could not move its right arm-that it cried if it was moved, and presented an anxious appearanee of countenance. On the 26 th, the child being three weeks old, a tumor in which fluctuation was distinctly felt, which oceupied and entirely surrounded the right radius, was

1 Bulletin de la Société d'Anatomie, tome ix., page 169. Paris, 1834. 
diseovered. Examination was painful, and the child kept the hands and finger's semi-flexed. The next day a similar painful and fluctuating tumor appeared upon the upper third of the left humerus, which apparently insolved the joint, and in elerating the deltoid cansed a considerable projection of the shoulder. Pain was present and an inability to more the limbs. The child cried if they were mored. When twentythree days old, it died of diarrhoa ani exhanstion.

Autopsy.-The tumor at the shonlder, which had displaced ressels, nerres, the deltoid, and other miscles, contained about an ounce of thin, inodorons pus, which was contained in a eavity formed on each end by the detached surfaces of the epiphysis, and of the diapliysis of the humerns, while the lateral walls were composed of the periostemm, which was transparent and adherent to the surroming comective tissue. The ends of the epiphysis and diaphysis presented a red and roughened appearance, and were bathed with the pus of the carity. At the end of the shaft spongy bone-tissue was seen. The periostenm was normal in its relations elsewhere on the shaft, and just abore the deltoid it was in contact with a slightly elevated portion of bone of irregular, spongy appearance.

A.t the wrist there was also a tumor, which contained pus. The epiphysal portion of the radius was separated from the shaft and also from the interosseous ligament, and its periosteum was detached. At the point on the shaft where the periosteum became detached a new formation of bone was found, which encircled the radius like a sheath, and was adherent to the periostemn, and reached to the head of the bone. At this portion the periosteum was thickened and shining, but readily detached from the bone with slight force. When the membrane was remored the new bony tissue was found to consist of longitudinal fibres, and was, when pressed, hard, heary and friable; and its interstices contained a yellow flnid. It rested upon healthy bone. The inferior portion of the nlna was normal, as was the wrist-joint.

The right tibia was also involved, its two epiphyses being separated, an abscess being present at each end of the bone. There was also a similar sheatl of bone, as in the radins, extending between both ends, where it terminated by a considerable increased thickening. In the left leg a precisely similar 
condition was discovered at the upper end. At the lower end there was no abscess, the periosteum was firmly adherent and normal. The epiphysis was not separated, but it was readily disunited by slight traction, and the two surfaces were rough, dry, and of a deep-red color. The pus escaping from the abcesses of the leg was thick and of the color of wine-dregs. Similar lesions were found in the right knee, in the sacrum and ossa ischii. Depaul's induration of the lungs was also found.

Parrot's Cases. ${ }^{1}$ - Case first had been obserred by $\mathbf{M}$. Gueniot, who had published its history. A child, of very delicate build, had a gangrenons ulceration of the right groin and an ulceration of the umbilicus. It seemed to be paralyzed in all of its limbs, and if they were elevated they fell hearily down. The forearms were pronated. Below each knee it was noticed that there was a separation of the shafts of both tilia and tibula from the superior epiphysis, and that a lateral motion conld be made. The cutaneous sensibility was lessened. It died when twenty-five days old. At the autopsy all the bones of the body, excepting the upper end of both radii and ulnæ, were the seat of inflammation. The lesion consisted of a well-pronounced injection and ecchymosis of the bone-tissue, near the epiphysis, and between the two tissues was a layer of thick greenish pus. The bone lesion was confined to the portion nearest the epiphysis, and was not deeply involved. Periosteum was thickened, red, and adherent, but readily separated. When the pus was removed crepitation could be produced. The joints were not involved. Pus was found under the capsule of the liver and under the pleura. At the time of obserration, Gueniot did not attribute the lesions to syphilis, but later Parrot suggested that disease as their canse. It is to be regretted that the history of the parents was not obtained, but the case is accepted by Parrot as one of syphilis.

The second case was that of a child, twelve days old. The history of its parents was not obtained. It was quite weak. It was noticed that its forearms were markedly pronated, and that when any of the limbs were elevated they would, if al-

- Sur une Pseudo-paralysie causée par une alteration du Système osseux chez les noureau nés atteints de Syphilis héréditaire, par M. J. Parrot. Archives de Physiolıgie Normale et Pathologique. Quatrième Année. No. 3, 4 et 5. Paris, 1872. 
lowed, fall heavily down. There was very little movement in the limbs, but some slight motion of the fingers. It died when a month old. At the autopsy an induration of lungs was found, as well as an increase of the connective tissue of the liver. The whole osseons system was said to be involved, the lesion being at the junction of the epiphyses and diaphyses. The first phalanx of the right middle finger, as well as the inferior extremity of the fourth metacarpal bone, were found to be involved, as were also the pelvic bones, the scapula, the axis, and the ribs at their junction with the eartilage of the sternum. This case is also aecepted by Parrot as syphilitic.

CASE III.-A ehild, about two months old when first seen, had a syphilitic eruption on its body. The right arm seemed normal, but the left hung by the side of the body. Upon pinching the skin very limited motion was produced. The legs were very thin, and, if pinched, their segments moved after the manner of a wooden toy-man. There was searcely any spontaneous motion. There was an abnormal eardiac bruit heard. The ehild died when a little more than a month old. Pulmonary hepatization and vegetations on the valves of the lieart were found. Nearly erery bone was altered. The cranial bones were mueh altered. The eoronoid process of the right inferior maxillary was thickened, and at its symplysis there was a thickening and softening. The ribs were involved. The point of ossification of the head of the right humerus was yellow, and at its internal and inferior extremity was an exostosis, the tissue of which was more compact at its periphery than near the primitive bone. The shoulder-joint contained a greenish-yellow liquid, which resembled pus, and its eapsular ligament was loosened, and permitted excessive motion. The upper part of the ulna was thickened by a superimposed bony layer, thick superiorly and beeoming thin and emerging into the shaft inferiorly, and again becoming progressively thick towards the inferior epiphysis, being developed upon the external part of the bone. A similar condition was found upon the right iliac. The two epiphyses of the little trochanters were morable, and the spongy tissue was altered. The upper epiphysis of the right tibia was mobile upon the diaphysis. At the lower epiphysis the les:on was less 
pronounced. The lesion was found to vary in intensity in the rarions bones; it was well marked upon the metacarpal and metatarsal bones and the phalanges. The ealcaneum, astragalus and the vertebrix appeared normal. The left scapnla was involved at the neck.

CAsE IV.-Child, syphilitic mother, having ulcers on thighs and buccal muguet; died when a month old. When periosteum was detached from long bones, new bouy tissue was found near epiphyses. Changes were noticed at the ossifying portions of diaphyses. Ribs were affected.

CASE V.-A child, having ulceration of both, corneæ and ulcers about the head and in the mouth; lived to be a month old. At the autopsy the shaft of the femur was found to be altered at both ends. The superior extremity of the humerus was markedly involved, and so was the superior extremity of the tibia. The upper end of the ulna was involved, but the lower end was normal. The radius was slightly altered, as were also the sternum astragalus and calcanemm. The clavieles were affected at their internal ends, and so were the ribs near the cartilages.

CASE VI.-A child, having extensive cutaneous lesions ; died, when about ten weeks old, from diarrhœa and exhaustion. The right femur was found to be altered. At the npper epiphysis was an increase of the chondroid layers. At the lower end of the bone the epiphysis was separated from the shaft by a gelatinous substance, upon the removal of which a space was left between the two segments of the bone. The tibia was involved at its upper portion more markedly internally than externally, and at its lower internal portion an exostosis existed.

CAsE VII.-A still-born ehild. The spongy tissue of the long bones was red at the middle of the shafts and violaceons near the epiphyses. There was an alteration of the distal ossifying layer of the left femur, and the epiphysis was readily broken from the diaphysis. The same eondition was found at the upper end of this bone, and also in the tibia and humerns, radius, metacarpal bones and ribs.

CAse VIII.-A still-born child. Tibia and fibula, humerus and ulna, were involved. 
Wegner's cases,' twelve in number, were those of children either still-born or who died a few days after birth; one only lired a month. Their chief interest is in the pathological conditions obserred in them, though they also furnish statistics for clinical deductions.

1. Srphilitic child, with extensive risceral and cutaneous lesions. The diaphyses of the long bones, inclnding ribs, were the seat of periostitis, and at their junction with the epiphyses there was softening of the tissue and separation of the parts.

2. Still-born child at seven months, having visceral lesions; on the line of ossification brittle chalky swellings.

3. Child having serere risceral lesions; gummy periostitis on frontal bone; softening and separation; at the junction of diaphyses with epiphyses, crepitation observed ; ribs much affected.

4. Child, which lived three hours, having pemphigus and visceral lesions; periostitis of long bones, irregular chalky zones at the line of ossification.

5. Child, which lived four weeks; lesions of ocnlar tissnes; small fluctuating abscess on right parietal bone; irregnlar line of ossification infiltrated with chalky masses; developing fatty degeneration of marrow of bones.

6. Child of mother having severe secondary lesions : periostitis of long bones; at epiphyses irregularity of ossifying process, same on ribs; risceral lesions.

7. Child of mother in second year of syphilis; eutaneous and visceral lesions; at all of the epiphyses of long bones and on ribs diffuse irregularity of spongy layers.

8. Child of mother two years syphilitic ; lived six days; on epiphyses of long bones and ribs extensive alterations.

9. Child which died soon after birth; cutaneous and visceral lesions; at the epiphyses of long bones and on the end of ribs diffused chalky infiltration.

10. Child of mother early in syphilis; visceral lesions; partial separation of epiphyses of some long bones, and changes in same situation in others.

11. Child of mother a year syphilitic; risceral lesions ; bone

1 Ueber hereditäre Knockensyphilis bei jungen Kindern. Archiv für pathologische Anatomie und Physiologie und für klinische Medicin. Band 50, Heft 3, pages 305 et. seq. Berlin, 1870. 
lesions in first degree on long bones and ribs; fatty degeneration of marrow.

12. Child, which died shortly after birth; visceral lesions; on long bones which are in first and second degree; partial fatty degeneration of medulla.

Waldeyer and Köbner's ${ }^{1}$ cases are also twelve in number. In each case the child succumbed from the severity of its syphilitic lesions, consequently the deductions which can be drawn from their study are chiefly in relation to their pathology. Certain points of clinical interest can also be deduced.

1. Child, born of a woman affected for two years with syphilis; had cutaneous and visceral lesions, and syphilitic changes at the epiphyses of both tibiæ and at the end of ribs.

2. Child, having extensive visceral lesions; had syphilitic affection of ribs, tibiæ, and bones of feet. Mother was regarded as syphilitic.

3. Child of a mother in the early stage of syphilis, having three pustules on the sole of one foot and one on the other; was born probably one week prematurely, and died when nearly a month old. During life an extraordinary flexibility of both hands was noticed. At the autopsy extensive visceral lesions were found, and that the epiphyses of both humeri and of the two bones of the forearm were separated from their diaphyses. Between the two separated portions a reddish matter was observed. ses.

4. Case in which epiphyses were separated from the diaphy-

5. Case showing changes in the second stage.

6. Case of child five weeks old, mother having a papular syphilide; visceral lesions, alterations at the epiphyses of tibiæ; other bones not examined.

7. Case in which changes of second degree were found at the epiphyses of the long bones. degree.

8. Case in which the epiphyses were affected in the second

9. Bone changes at the epiphyses.

10. Case of a boy who died when three months old, who had papular and pustular syphilides. At the autopsy macroscopic

${ }^{2}$ Boiträge zur Kenntniss der hereditären Knockensyphilis. Virchow's Archiv, Band 55, Heft 3 und 4, pages 367 et seq. Berlin, 1872. 
changes were noted at the borders of the epiphyses, which were verified by microscopic examination.

11. Child of syphilitic parents ; contagion probably five or six years previous to birth of child. Diffuse syphilitic changes were noted at the epiphyses.

12. Child, whose mother did not present any lesions of syphilis, but whose father had been syphilitic three years. Changes at the ends of ribs, also at the epiphyses of the radius, ulna, and humerus.

\section{IV.-GENERAL CONSIDERATIONS AND DIVISION OF TIIE SUBJEC'.}

We are warranted now in assunning that these series of cases and the details thus given include the bulk, if not all, of our present knowledge of the clinical features of bone-syphilis in infants and children. It becomes necessary, then, to study carefully the points and facts offered by this array of eases, and to deduce from them, if possible, true conclusions as to the clinical history, diagnosis, prognosis, and treatment of these lesions. In the résumé of cases I omitted the pathological details given by the rarions observers, but I shall fully include them in a subsequent portion of the work.

It will have been seen already that certain striking and frequently-occurring changes are observed to be seated at the junction of the epiphyses with the diaphyses of long bones, and that in addition, thongh somewhat less frequent, noticeable changes are found upon the flat, irregular, and small bones. We shall then study these changes in the order in which they are most frequent, as that method will tend towards a more correct presentation of the whole subject, and as it is, in fact, rendered necessary by the varying features presented by the lesions in these different classes of bones. In this connection it is essential to recall to mind, in a general way, the condition of the bones at the early periods of life, and also to indicate in a concise manner the pathological changes which they may undergo, reserving a minute description of their pathology to a subsequent portion of the paper. It will be remembered that in the young subject the bones are constantly undergoing active developmental changes, and that the majority of them, in the early years of life, are in an unfinished state, and are then, in 
the case of the long bones, formed of a shaft or diaphysis, composed of bone tissuc, constantly angmenting by increase, and of certain smaller portions, situated at each end, and continuous by an intermediate layer of cartilage, which are called epiphyses. Later on these parts fuse into one, then constituting a perfect bone. In the irregular bones the process is similar, except that a body or main portion exists instead of a shaft, but the relation between it and the epiphysis is precisely the same. In the long bones the increase in diameter is effected mainly by a laminar deposit from the periostcum, their medullary canal being formed in exact proportion to the growth of the shafts; while the increase in length is due to a derelopment of the ends of the diaphyses towards the epiphyses. The latter segments at this time are separated from the former by a layer of cartilage, of which tissue they themselves are composed. Then as the requirements of the skeleton demand, varying in point of time in the different bones, ossification begins in the epiphysis, extending toward the diaphyses, and there being met with a similar process which has been taking place in that portion of the bone during its whole existence. Thus it will be seen that at this sitnation very active changes are constantly going on. In the flat bones we find two modes of increase : first, the derelopment of the bone proper from its primary membranous condition, and second, by the deposit of layers of bone from the investing periostemm. In the small bones, also, we find the processes of derelopment are quite active, and that at varying times ossification begins in their substance, which is primarily wholly cartilaginons, and that they gradually alter in structure while they increase in size. Considering, then, the activity and extent of these morphological changes, it is not surprising that under the influence of syphilis, which so powerfully complicates and modities normal processes, the nutrition and increase of bones should be materially influeneed. Thus pathological studies are simplified by our knowledge of physiology and normal anatomy. So that, applying the nnited knowledge in this case, we can readily understand that in a giren syphilitic child, upon whose bones at the diaphyso-epiphysal junction we find noticeable enlargements, there is there a perversion or interference with the normal course of the development of the bone; and also, that when we find a small bone enlarged, or eren the sub- 
ject of more active and degenerative changes, or that a flat bone is studded with perceptible elevations, we can, in the light of our knowledge, suppose that certain pathological changes, perhaps induced by syphilis, have been engrafted npon the physiological. Then, again, when we pursue the subject further, and endeavor to ascertain by microscopic and macroscopic examination what these changes really are, our snspicions are fully confirmed by the appearances which are observed. In speaking of the swellings I shall, throughont the descriptive part of the work, merely allude to them as being due to increased cell proliferation in varying proportions, as this method will be simple in not presenting pathological details in advance, and in aroiding troublesome repetitions.

Commencing, then, according to the plan already laid out, with the study of the lesions upon the long bones, it must be remembered in advance that similar or somewhat dissimilar changes in the other kinds of bones may or may not be co-existent with them. There are cases in which the long bones alone are involved; others again in which they and the other varieties of bones are affected together; and others still in which the lesions are developed on the small or on the irregalar bones while the long ones escape.

A careful perusal of those of my cases in which these long bones are altered, shows clearly that they may be divided into two stages, or even classes: a first, in which the morbid processes, as evidenced by swellings, undergo resolntion without perceptible impairment of the structure of the bones, of the parts around and above them, or of the function of the member of which they form a part; and a second, in which resolution does not take place, but in which degenerative changes are observed. These degenerative changes may be limited simply to a destruction of the superficial portions of the swellings in greater or less extent, or they may be so severe as to involve the whole diameter of the swelling in destruction or liquefaction, in which event the epiphyses become separated from the diaphyses. A casual knowledge of this subject might lead to the impression that these cases are essentially different in kind, but, as I shall show further on, such an opinion is erroneous, as they are really representations of well-defined stages of development of one and the same morbid process. The swell- 
ings on the other bones may also be divided into similar varieties. Pathological facts, as brought out by the observatious of Wegner, Waldeyer, Köbner, and Parrot, show that this clinical division is the true one. The seat of the enlargements or swellings on the long bones is, for anatomical reasons, always at the junction of a diaphysis with its epiphysis, and, as my cases show, they are, as thus far met with in clinical practice, developed rather more frequently at the distal end of the bone than at the proximal end, though the reverse may be and has, as we shall see, been quite frequently found. When examined, the swellings are found to present quite well-marked characteristics. We shall study them in their order as just laid out, taking into consideration the degenerative conditions, after we have fully studied the first or resolntive variety.

V.-DESCRIPTION OF THE OSSEOUS LESIONS UPON THE UPPER KXTREMITIES.

In our study of the lesions of the long bones we naturally begin with those which are observed npon the npper extremities. In the main the swellings at the junction of the diaphyses of the long bones with their epiplyyses present many points of resemblance; therefore, thongh the description which immediately follows applies to the enlargements at the distal ends of the radius and ulna, the general features indicated are such as will apply with slight modifications to similar swellings elsewhere located, though of course we shall study them all separately. If now we trace, with the tips of the fingers, the continuities of the bones downward along their shafts, we encounter just at or before the commencement of the epiphyses a quite abrupt elevation, which is found to encircle the bone or perhaps bones. Usually this swelling can be felt on all of the surfaces except that which is in coaptation with its companion bone. The surface of this swelling is generally smooth, but it may be slightly undulating, not, however, ridgy. It is gently rounded off at its peripheral portion, where it may end by simply enlarging that part of the bone which corresponds to the ossifying layer between the shaft and the epiphysis, or it may extend further down and merge gradually into an expanded epiphysis. In the latter case the surface of the tumor is rounded at its proximal and flattened towards its 
distal end. In the first case, in which only a limited portion of the shaft and of the epiphysis is involved, the swelling, which is usnally from three-quarters to perhaps an inch and a qnarter, can be traced as a ring encircling the whole bone, and then the epiphysis beyond it is felt to be normal. In the other case a general enlargement is observed, though the fact may be noted that, though the epiphysis is enlarged, the bulk of the swelling is at its upper and middle parts, and the epiphysis does not seem out of proportion when it is examined just at and from the wrist-joint, with the function of which it produces usually no impairment. The conclusion, then, is obvious that in the cases thus far observed, the enlargement of the bone has been confined to the end of the shaft, and perhaps the proximal half or two-thirds of the cpiphysis, and does not militate at all against the supposition that in some cases the whole epiphysis may undergo great enlargement. The existence of this condition can be determined by future observation.

Such, then, is a comprehensive description of the shape and features of the individual swellings of the bones themselves, and of course applies to those of this situation. When the swellings on the two bones are examined together it will be found that there appears to be a direct fusion of the two epiphyses. This can be readily appreciated on a very thin child, but can also be determined, even if the arm is fat, by tracing with the tip of the finger, along the back part of the limb, the course of the interosseons space, which can be clearly made out until we reach the epiphysal region, where the finger meets with a seemingly continnous tissue, so that the usually well-defined furrow between the two epiphyses can no longer be distinguished. This condition is undoubtedly due to the great cell proliferation, which appears to have gone on here to such an extent that the bones feel as if soldered together. There is not, however, or rather the symptom has not as yet been observed, any impairment in pronation or supination of the limbs. Such are the points elicited by manipulative examination of the swellings. If now the limb is examined by the eye, the swellings of the bones may or may not be visible. Thus, in a child who has considerable development of adipose tissnes, the enlargements of the bones of the forearms may wholly escape 
the obserration of its attendant, and, in fact, the child may come to the surgeon for treatment of other symptoms or lesions, and the swellings may even pass unnotieed by him mless search is made for them. Thus in my second ease the child was bronght for other ssphilitic lesions, and when examined carefully the swellings were found, and were clearly demonstrated to the class. In my third case the child's mother thought that perhaps its bones were swollen, but she was not certain. In fact, I suspect strongly that, particularly among the lower classes, such swellings might eren be recognized and then not be regarded as abnormal, and also that they often wholly escape notice. In those clildien whose fatty tissue is abundant there is no evident stretching of the integnment by the pressure within. When, however, we examine a more or less thin child, upon whose forearms these swellings are seated, we can distinctly observe quite large rounded elevations of the integument, which can be clearly made out either by a lateral or vertical riew of the limb, and they are of such a character as to attract the attention. This fact was well observed in my first case. The swelling is seated just abore, or may appear even as if reaching very near to, the wrist-joint, and it involves the whole breadth of the limb. It begins by a gradual nplifting of the integument, attains a height of perhaps three-quarters of an inch-in some cases more, in others less-then having a longitudinal area of an inch, more or less, subsides by gradually rounding off at or above the joint. The integument in cases which nndergo resolution is of comse stretched to a greater or less degree. It can be moved orer the bony tumor with ease, and aecording to my observation lhas never been altered in color. The appearance is somewhat like that of a dislocation, and is identical with the donble joint of rickets.

The description which has been given is applicable to those cases in which both bones of the forearm are enlarged in the region of the carpal epiphyses. This brings us to a consideration of the point as to whether the swellings always involve both bones, and if so, whether the swellings are always symmetrically developed on both forearms. In the post-mortem cases, examined by Wegner and Waldeyer and Köbner, it was found by these observers that the lesion was always symmetrical in both bones and on both arms, but the results of clinical obser- 
vation, as drawn from twelve of my cases, slow that in practice this fact is not borne ont.' Thus, in these twelre eases, both bones were symmetrically involved in both forearms in seven ; in two the right radins only was affected, in one the radins and ulna of one side only were swollen, and in two the bones of the forearm and in fact all of the long bones of the body escaped. The symmetrical derelopment of the swelling on both bones of both forearms is the rule, and the unsymmetrical development is the exception, according to our present statistics, but further observation may modify this statement. The description of the swellings, as given when two bones are affected, fully applies to those involving only one bone, except, of conrse, that the latter are limited to one or other side of the limb instead of involving its whole breadth. The appearances to the eye are varied in the same manner.

Such, then, being the clinical features of the swellings on the distal ends of the radius and ulna, we come next to a consideration of those which are found on the upper ends of these bones. In this situation, owing to the conformation of the limb, the tumors are not as well marked in appearance as are those occurring below. In fact, when the limb is examined in an extended condition on its internal aspect, the swelling is not perceptible. If, however, the swelling should attain large proportions - a feature which has not as yet been obserred in clinical practice-it is obvions that it would be perceived even here.

1 This discrepancy is not as great as might be inferred from the text, and can be quite clearly explained. In many instances, upon post-mortem examination in which the lesions have been observed to be symmetrical, the development was found to be very unequal, and in some instances the process had gone on to such a slight extent on one side, that no enlargement had been induced, and had not the tissue been examined with the microscope there would have been no suspicion of its being the seat of pathological change. It can be plainly seen that in every instance the swelling must have attained some considerable development, otherwise it would not be appreciable to our tonch. Thus we must take this fact into consideration in determining the symmetrical and unsymmetrical character of these swellings, and we must bear in mind that more bones may be involved than we think, as we are powerless to determine in cases where the lesion has only gone on to a slight degree. In my eleventh case the enlargement at the junction of the epiphysis with the diaphysis of the right radius was very slight indeed, so much so that it was with difficulty made out, but still it was detected, and the feature was observed by several physicians and students besides myself. An instance like that derelops a suspicion that in syphilitic children these lesions may be much more common and extensive than we even now think them to be. 
But when examined closely on the posterior aspect of the limb, a swelling may be observed upon the olecranon if it has attained an appreciable size. The examination here is best made by semi-flexing the arm, as this movement stretches the integument over the bone and renders the ontlines of the olecranon more perceptible than in an extended condition of the limb. The main feature observed is an enlargement ontwardly and laterally of the olecranon process. When now we come to examine these bones by the touch, the swellings become very palpable. Those on the radius consist in a general round enlargement of the upper end of the bone, which, however, is difficult to trace in its upper part if the child is fat and its muscles are well developed, but can be readily traced to the joint and felt to move under the tip of the finger, if pronation is employed in cases of very thin children. It scems very probable that if the swellings on the radius became very large the movements of the limb would be impaired. Examination by the touch of the swellings on the ulna present nothing peenliar when practised npon the internal aspect of the limb, but when the bone is felt posteriorly the olecranon process is found to be enlarged, and to bulge out considerably beyond the plane of the bone as traced upwards along its posterior ridge with the tip of the finger. Besides this enlargement ontwardly a lateral expansion is felt distinctly, and when the process is examined near its apex or end it is here found to have a very uneven, if not knotty surface. According to present observation the upper parts of the shafts of the radius and ulna at their junction with their epiphyses are not as frequently the seat of these syphilitic swellings as the lower parts are. Thus in ten of my eases in which the lower epiphyses were affected, the upper ones were only found to be swollen in three. Then, again, in only one of these eases were both bones of both arms symmetrically involved, whereas in two cases the olecranon process only was involved. In this connection Fournier's observation is important, as in one of his cases both radius and nlna of one arm only were involved, while in the case related by Ranvier, the ulna of one arm only had been affected and the swelling was felt at the base of the olecranon process. In Bertin's case also, the ulna was the only bone of the upper extremity involved. The conclusion, then, is warranted, based on 
these combined cases, that in clinical practice the upper epiphyses of the bones of the forearms are not as frequently the seat of syphilitic lesions as the lower ones are, and that the swellings may be symmetrically developed on both bones of both arms, or that both bones of one arm alone may be involved, or even one bone of one arm, or again one bone of buth arms may be thus affected. The swellings of the upper epiphyses may or nay not coexist with similar swellings on the lower ones.

Turning our attention now to the condition of the humerns in syphilitic children, we find in clinical practice that it is even less frequently involved than the upper ends of the radins and ulna are. Thus, in only two of my cases was it noted as being enlarged, and the same condition existed in Roger's, in Fournier's, and in Parrot's third case. As thus far observed, the swellings at the lower end of the bone have not attained sufficient size to present such noticeable elerations of the superimposed parts as are observed in the wrist, and they would have, in all probability, escaped observation but for the fact that they were perceptible to the touch. A point of some importance has been here observed, which is, that the swellings are more often developed at the internal eondyle than elsewhere. This fact was well brought out by my case, and is substantiated by those of the three observers already mentioned. In Fournier's case, as well as in my tenth case, an enlargement was noted of the whole breadth of the diaphyso-epiphysal junction, but by the former it was stated to be greatest at the internal border. This point possesses interest both clinically and pathologically, as it proves that while the morbid process may involve the whole ossifying end of a shaft of a bone, it may attain greater proportions in one particnlar part than in another, and also that it may involve a more or less limited extent of surface of the diaphyso-epiphysal junction. In my ease, No. VI., the enlargement was seated just above and upon the internal condyle, occupying a space of perhaps three-quarters of an inch of the internal ridge, and was abont the size of a peanut. To casual observation this tumor would probably not have been noticed, but when attention was called to it, and the arm was with care slightly flexed and extended, it could be seen as an elevation of the bone playing under the integument. I can readily see that in a very fat child it would have eseaped observation entirely. 
As regards the distribution of these swellings of the lower end of the humerus, it would seem that they may be either symmetrically or unsymmetrically developed on the two arms. Thus, in Roger's case, both internal condyles were affected, while in my two cases, in Fournier's and in Parrot's case, only one shaft was enlarged. In this connection it is well to bear in mind that at its distal end the hunerus has four centres of ossification, and that we may find swellings localized at any one, or at all of them, either at the external condyle, at the condyle proper, at the trochlea, or at the internal condyle. Four of these eases, however, point strongly to the fact, which is important as regards etiology and diagnosis, that at the internal condyle these peculiar syphilitic swellings are rery liable to oceur. In my tenth ease, the swelling involved the whole ossifying region, being quite extensive and presenting an uneven surface to the tonch. If the swelling was limited to the trochlea, particularly if it was small, it might escape observation entirely. According to Wegner's observations, this portion of the humerus is not as frequently affected as the upper, and the syphilitic lesions were absent here more frequently than in any other of the long bones, except the upper ends of the radius and ulna, which site he found to be less often the seat of swellings than any other. Parrot found in his fifth case that the upper end of the ulna was involved, and that the lower one was mnaffected. Future observations on a greater scale, clinically and patholngically, may perhaps explain this discrepancy. In studying now the changes in the upper end of the humerus, weare forcibly struck with the fact that we have not a case in clinieal practice in which these syphilitic swellings were noted here. But in the records of the post-mortem cases of Parrot, Valleix, Wegner, and Waldeyer and Köbner, we find instances in which this portion of the bone has been affected, and, as said before, Wegner thinks the upper end is more often involved than the lower. In all of these cases, however, it so happened that the lesions were of a serere form, and went on to their last and destruetive stages, so that we have not the history of a tumor in this site in which resolution afterwards took place. To suppose that snch tumors might occur, we certainly have abundant evidence in the records of the autopsies, and in the fact that here there is a natural predisposition of the parts to the development of them; 
namely, an ossifying shaft and an epiphysis of consideral,le size. Supposing then an instance of the occurrence of these tumors here, it is well to bear in mind that there are at the head of the humerus two centres of ossification, and that the swelling might be general and evenly developed, or general and more prominent, at a given spot; or it might be localized, and then wonld be sitnated at either the greater or lesser tuberosity. This point is deduced by analogy from the ease of swelling of the internal condyle of this bone, and will also be exemplified hereafter in the case of the femur. As regards the recognition of such tumors by the eye, much would depend upon the quantity of the muscular and adipose development of the child ; for in a chubby infant they might escape ebservation, while in a very thin one they might be very apparent. In Valleix's case, and in Parrot's third case, the deformity was very perceptible. It is very probable that if the tumor attained a considerable size, it wonld interfere with the function of the shonlder-joint, in which event attention would surely be called to its existence. Like such lesions developed elsewhere, of course; they may or may not be symmetrically developed. The details of snch cases will be looked for and read with interest.

VI.-THE ENLARGEMENTS UPON TIIE CLAVICLES, STERNUM AND RIBS.

Passing now from the shoulder we naturally come to the clavicle, on which bone we find that these tumors sometimes form. In my tenth case, which is the only recorded one of a living child presenting the lesion, the sternal end of the right clavicle was enlarged. The swelling began abont an inch from the end of the bone, and becoming somewhat rounded, having a smooth surface, ended at the sternal joint. In this case the tumor was very evident to observation, and I should think that if these swellings attained even a moderate size, they would here be quite readily seen, even in fat children. They can be more clearly defined by allowing the child's head to hang down without support, while the body is held horizontally, as by this manœurre the integument is stretched and the sternocleido-mastoid muscle pnlled downwards out of the way. This position will be found useful in deciding whether a given tnmor is seated in the insertion of this muscle or on the sternal end of the bone, or even in regions not connected with these 
strnctures. My case, thongh mique in clinical practice, has its analogne in IBärensprumg's case, which died, in which the tumor was likewise sitnated at the sternal end. At the antopsy of Parrot's fifth case, both clavicles were found to be swollen at their sternal end. The fact that in the three cases this end of the bone was the only one involved, might leave the impression that this was perhaps the result of chance; but when we consider that at birth all of the elavicle except its sternal epiphysis is formed of true osseons tissue, it occurs to the mind that it is at this end that we should naturally look for these swellings, and not at the acromial end, where no epiphysis exists. Consequently, this form of tumor will not be met with there, though of conrse we may tind periosteal tumors. The cases, as thus far observed, show that, like other long bones, the clavicles may or nay not be symmetrically involved in the syphilitic process, for in one case both bones were affected, and in two cases only one bone was. In the child, then, a swelling at the sternal end of the clavicle would naturally excite a suspicion of its being of syphilitic origin. We shall see further on, that these swellings are interesting in the matter of differential diagnosis. As a result of acquired syphilis I have several times seen this part of the bone to be enlarged in patients in whom, from their youth, bony union of the two segments had not yet occurred. From the clavicles we arrive naturally at the sternum, upon which bone the syphilitic tumors under consideration have not been found in clinical practice. From the fact that in the early years of life this bone consists largely of cartilage undergoing ossification, it would be very reasonable to suppose that it wonld be the seat of the syphilitic change, particularly when we consider how frequently it is involved in the acquired syphilis of adults, but still clinical cases are wanting. Yet the records of autopsies show that it has been affected by syphilis, consequently cases may hereafter occur. Being situated under an integument which is never as thickly lined with adipose tissue as some other parts are, this bone is usually readily seen, and of course any tumors upon it would be proportionately prominent.

Thus far in our study of these swellings we have found them developed at the junction of a shaft with an epiphysis, a point where the process of ossification is going on actively. We now 
come to the study of them when developed at the sterual ends of the ribs. Ilere the ossifying end of the bone is not continuous with an epiphysis which later on undergoes ossification itself, but rather with a shaft of cartilage, which as a rule always retains its primitive structure. The difference, then, is simply in the ossification going on at the expense of, in one instance, temporary and, in the other, of permanent eartilage; the physiological processes being the sanle in each case. The swellings at the ends of the ribs have only occurred in one out of the fonlteen eases seen by me, and in that instance only two ribs were affected on each side, naniely, the second and fourth of the right, and the second and third of the left side. Parrot mentions the fact that he found at the autopsy enlargements of the ribs in his fourth and serenth cases, and Wegner and Waldeyer and Köbner mention these swellings as being found in the greater number of their cases. The lesion was observed by them here in all stages of its development. We are warranted, then, I think, in assuming that in clinical practice syphilitic swellings at the ends of the ribs are not frequent, at least not as frequent as similar swellings on other long bones; that they may involve all of the ribs, or that only a limited number of ribs may be involved, and that, judging from the distribution of these swellings elsewhere, they may be either symmetrically or unsymmetrically distributed. To the touch these tumors give the impression of a simple bulbous expansion of the shaft, their surfaces being smooth. Of course they may be more or less promineint in proportion as they are small or large, and as the child is fat or thin. They possess great interest clinically, as they are so liable to be attributed to rickets. In arriving at the diagnosis, it is well to bear in mind the fact of the limited number of syphilitie swellings, and also their possible mnsymmetrical occurrence. Yet we shall find that in rickets, though the symmetrical derelopment of the bulbous ends of ribs is the rule, it also has its exceptions. As the ribs possess in early life two regular epiphyses, one for the head, the other for the tubercle, it is very probable that these swellings may be dereloped upon them, but as they would be inaecessible to exploration they would be void of clinical interest, exeept, perhaps, in the event of their unusually large development, in which ease they might perhaps produce pressure on a spinal nerve. 
VII.-THE SWEllixgs AT THE EXTiEMTHES OF TIBIA ANi) FIBCLA.

Pursuing now the same course in our stndy of the bone-lesions of the leg as followed in that of the arm, we commence with the ankle. As developed upon the lower end of the tibia and fibula, the swellings have the same general characters as those found on the corresponding part of the radius and ulna. In tracing the continuity of the bones downward with the finger, a perceptible swelling is discorered abont two inches above the extremity of either malleolus. The swelling usually begins quite aluruptly, and attaining a height of half or threequarters of an inch, it either merges into the expanded epiphyses, or is distinctly linited to a space cf about an inch or an inch and a loalf in length, in which case it is recognizable as a ring surrounding the bones at their diaphyso-epiphysal junction. In those of my cases in which the epiphyses were generally expanded, the swelling was found not to involve the extreme portion of either malleolns, and it was evident that the morbid process stopped short of this point. In the ringed form the swelling was distinctly traceable all around the bones, and it seemed to the tonch as if perfectly continuons, their line of apposition being apparently lost. This line, though sometimes quite difficult to determine, can generally be distinctly made out, by tracing dowuwards between the two bones with the tip of the fingers, and in the examination of a healthy subject it is readily found. When, however, these bones undergo this local enlargement there seems to be a general fusing or soldering together of them. The surface of the swellings was quite smooth, and in no instance lave I found it nodulated. The integument, which in this part of the leg is less provided with adipose tissue than any other part except the region of the -knee, is usually stretched, but not in such a manner as to induce structural change. It can usually be slid orer the swelling beneath. The resulting deformity of such bone-enlargements is generally quite well marked, rather more so than at the wrist. Of course, it will vary with the greater or less development of the swelling, and with the amount of adipose tissue deposited here. It is well to remember that the child's leg, owing to the delay in muscular development, does not expand from ankle to calf, as it does later on; that the adipose tissue is more evenly distributed, particularly so at the ankles; and that the limb in 
its continuity preserves a somewhat uniforin shape; consequently, that these swellings, if not large, might not be regarded by the child's attcndants as abnormal, and might even escape their observation, and conld of conrse under the circunstances escape that of the surgeon, muless lie examined with reference to them. There is another point which is of especial interest to the surgeon in determining whether or not swellings exist upon these bones in infants, and that is that there is very often a seeming disproportion between the size of the shafts of the tibia and fibula and their epiphyses, the former appearing quite thin, while the latter feel as if musually large. This condition, which is normal and quite frequently foumd both in these bones and in the radius and ulna, might, if not borne in mind, lead to the wrong impression, that an enlargenent of the bones existed." In those cases in which the swelling is well marked the deformity is readily seen and is of peculiar appearance. It is most marked on the anterior aspect of the ankle just above the tarsal bones, and it looks as if the bones of the leg had heen dislocated forwards. The swelling is also in such cases well seen on the onter and inner sides of the ankle. In two of my cases the parts above the ankle presented a somewhat quadrangular shape, which was well marked. In exceptional cases the swelling may be more developed at one part than at another, and in some it may be rery slight; the rule being that it should be generally distributed. The local development of the swelling was observed in one of my cases, in Bulkley's case, and in Parrot's sixth case.

The statistics of the swellings at this portion of the tibia and fibula show that they occur here quite frequently; indeed Weg-

${ }^{1}$ Melchior Robert (Nouveau Traité des Maladies Véníriennes, Paris, 1861, page 692) states that he has seen cases in which, as he expresses it, the syphilitic virus was too feeble to cause special manifestations, and in which a species of atrophy of the diaphyses and thickening of the epiphyses was noticed, $\rightarrow$ a condition which he attributed to syphilis. From our knowledge of the influence of this disense upon the growth and development of bone, it is reasonable to suppose that it has no direct or specific action in causing this condition, particularly as it is said to arise de noro, and not to result, according to the author, as a sequela of typical syphilitic lesions. It would seem that these cases were similar to those above alluded to, in which the imperfect development was perhaps even more marked. If we concede to syphilis any influence in producing this condition, it must be in the power which it, like any other debilitating disease, has in impairing the growth and nutrition of tissues generally. 
ner ranks their frequency in this situation next in order to the lower end of the femur, which site he thinks the most frequently affected of any portion of the long bones, and Waldeyer and Köbner found them here also quite often. In the fourteen cases seen by me, swellings at the lower cnd of the tibia and fibula occurred five times; in Parrot's eight cases three tines, and they were found in Valleix's ease, Inaking a total of nine cases. As regards the mode of their distribution, they were found on both legs in three of my cases and in Valleix's case; in Parrot's cases the bones of the right leg were inrolved in case three, and those of the left in casc six, the tibia of one leg and fibula of the other in case eight; in my ninth case the left tibia and right fibula were the bones involved, the left fibula being only slightly affected, and in Bulkley's case only one bone, the fibula, was involved. The conclusions are, then, that the swellings may be symmetrically distributed on both bones of both legs, that they may occur on both bones of one leg, on either one or other of the bones of each leg, or that a swelling may occur on ono bone of one leg. They have always been found to exist coincidently with similar swellings on other bones; thus, in iny four cases, there were in two instances similarly situated swellings on the radius and ulna; in the two other's, besides this coincidence, there were swellings on other bones; in Bulkley's first case the swelling on the fibula was coincident with syphilitic lesions of the phalanges, metacarpal and metatarsal bones; and in Parrot's, Wegner's, Waldeyer's and Köbner's cases, various and numerons other bones were found to be coincidently the seat of similar changes. There is no reason why this site might not be the only one involved in a given case of syphilis, but as yet we have not the records of a case showing the fact. In my elerenth case the distal end of the tibia and fibula were enlarged, the lesion having gone on to a degenerative stage, and the only other appreciable bone lesion was a very slight swelling of the distal end of one of the radii. The tibia and fibula are very often affected at their lower ends by rachitic swellings, but the distribution is generally symmetrical, and other long bones, such as the radius and nlua, ribs and femora or the cranium, may or may not be coincidently involved, they being as a rule thus affected. This point will be touched upon when we come to treat of the diagnosis of these swellings. 
The distribution of the soft parts at the knee is such as to render the examination of the bones which compose the joint quite easy, particularly in the case of the tibia and fibula. The contonr of these bones, eren in the infant, is generally very readily discernible to the naked eye, and their exploration by the touch is proportionately easy; consequently any swellings which may occur here are generally very likely to be noticed, and of course they can be exanined readily. The peculiar swellings, snch as we have found on the lower ends of these bones, are also found here. In the fonrteen eases which I have seen, a swelling upon the tibia was found in but one. In that case the right tibia was involved and the swelling was distinctly visible on the anterior and lateral or internal portions of the bone, where the elevation of the integument was very well marked. The swelling, commencing externally jnst at the head of the fibula, was sitnated just above, and inrolved the tuberosity of the tibia, rmuning around the bone and being distinctly traceable until it reached the posterior surface, where it conld not be made ont. The eleration of the tmmor was fully three-quarters of an inch, and its area at its base was certainly an inch and a half. Superiorly it merged into the head of the bone, just near the joint. Its surface was somewhat nodnlated anteriorly, but it was quite smooth laterally. In Roger's ease a similar enlargement was found anteriorly. A similar swelling was also fonnd in Valleix's case, and Parrot, at the autopsy of five of his cases, found the head of the tibia to be the seat of morbid change. Of these cases there was one in which both tibix were enlarged, another in which the tibia and fibula of one leg were swollen, and three in which only one tibia was involved. Parrot states that in his sixth case the swelling was more perceptible internally than anteriorly. Waldeyer and Köbner fonnd this portion of these bones affected, and Wegner did also. The latter thinks that the swellings upon this site occinr the fifth in the point of frequeney of any of the long bones, while Parrot places their freqnency in the third rank, and those of the fibula in the sixth. It will be seen that in elinical practice only two cases have ocemred in which these swellings were found, and in each the tibia iras the bone involved; one of these cases is my ninth, the other is Roger's case, while they have been observed at least seven times at the autopsy. It is 
well to bear in mind, in explanation of this seeming discrepancy, that the cases of Parrot and Wegner were those of the severest form of syphilis, in which many bones were affected and in which the other lesions were so severc as to cause death. In the clinical cases the syphilis was comparatively mild in form, and did not destroy life. We can scarcely admit these cases unieserredly for purposes of comparison; but if we should do so, we shonld find that they warrant the following conclusions:

That the upper part of the tibia is more frequently swollen than the same part of the fibula; that the swelling may be symmetrical on the tibir of the two legs, or may occur on only one bone. We hare no recorded instance in clinical practice of a swelling upon the fibula alone, nor upon it and the tibia, nor, again, of swellings on both boues of both legs ; such cases, however, may occur. In this situation we find that though the swelling may involve the whole ossifying upper end of the shaft, it may be greater or rather more perceptible at one portion of it than at another. This, of comrse, is either due to the fact that the morbid process is greater at a given spot, or that it is distinctly localized there. We have already pointed out the same feature at the lower end of the humcrus, where its existence was explained by the fact of the multiplicity of ossifying centres; but this explanation fails in this case, as there is but one ossifying region, which, however, is very extensive.

\section{THE SWELLTNGS UPON TIIE FEMUR.}

Coming now to the lower part of the femur, we find that owing to its being deeply seated amidst muscles, fasciæ, etc., and also to its being covered with a greater or less amount of adipose tissue, that its examination is not very readily accom. plished. In childreu, however, there is not the same resistance or tirnness of the soft parts as may be obserred later in life, consequently in them the conditions are not as much unfavorable to physical exploration. The conditions of course vary very much with the amount of muscular and adipose development of the child. It is a situation, however, in which, when the swellings are developed as low down as the diaphysoepiphysal junction, they would be very likely, if sinall, to pass nnrecognized, more especially by the eye, and perhaps by the tonch. In but one of my cases was this part of the femur 
found to be swollen. In this there was no perceptible elevation of the integument, thongh the child was thin, nor could any swelling be discerned if the limb was viewed while it was being alternately flexed or extended. When deep pressure was made upon the bone, a swelling conld be felt just above each tuberosity, which could be traced to the anterior surface of the bone, and there quite distinctly made out, but conld not be felt posteriorly. The swelling arose quite abruptly from the bone, and was fully five-eighths of an inch highl, and occupied a longitudinal area of abont an inch and a half. Its surface was quite smooth and it rounded off, losing its lower edge in the bone. The integunent was of course nnaltered. According to Wegner, the lower end of the femur is more frequently found to be the seat of the peculiar syplilitic changes which we are considering than any other bone in the body of any variety. Whether this fact is to be explained by the condition of development of the femur, its lower epiphysis being the only one in the body in which ossification begins before birth, consequently the one in which the processes are most active, I am unable to say. In clinical practice, according to our present knowledge, it scems that it is very seldom involved; future observations, however, may establish a greater frequency of occurrence. Bärensprung mentions having found the femur enlarged at this site, and Parrot found it in three of his cases. Judging from our present facts, we should say the swelling is not as a rule developed symmetrically on both limbs, but of course such eases may occur. Although our present experience shows us that these swellings are uniformly distributed along the diaphyso-epiphysal junction, we may infer from analogy that they may be developed in one portion in greater size than in another, and, in fact, that the morbid process may be localized to one spot, as we have already found it upon the humerus and tibia. This part of the leg shonld be carefully examined in cases of hereditary syphilis, particularly if other bone lesions are fonnd.

The deeply seated position of the upper end of the femur renders examinations of any swellings upon it rather more difficult than at its lower end, and here snch swellings might readily pass unnoticed. I have never had the opportmnity of examining any syphilitic swellings on this portion of the femur, as 
they did not oceur in any of the fourteen cases seen by me. They hare, howerer, been found quite frequently after death, as Wegner places them in the third rank as regards frequency, and they were also found by Waldeyer and Köbner. Besides these observers, Parrot mentions them as occurring in several of his cases, and I3ärensprung gives fragmentary details of a case in which he observed a swelling of the upper part of one femur which coexisted with a similar swelling on the lower part of the opposite femur. Our knowledge of these swellings, then, is not gromnded upon clinical observation, but is derived by induction from our study of the anatomical structure of the bone, and also from analogical facts observed in these tumors when developed npon other bones of the body. We know that the upper end of the femur has three distinct centres of ossification, one for the head, another for the great trochauter, and a third for the lesser trochanter, consequently we can reasonably assume that these swellings might be developed at any one or at all of these sites. In case a swelling was dereloped at the neck of the bone, it is probable that the capsular ligament wonld prevent its recognition, and that it might render its examination impossible. If, however, a swelling was formed at either of the trochanters its existence conld be determined, even if it was only of moderate size, for in Bertin's case, a swelling of the size of a pigeon's egg was found upon the left great trochanter, and in Parrot's third case both of the lesser trochanters were found to be affected. In Putegnat's case, it is probable that the change took place at the neck, and as the swelling underwent degeneration, a dislocation of the bone was produced. This fact shows us the importance of the early recognition of this syphilitic lesion of bone, and the necessity of a prompt aud efficient treatment. There is a point of great interest relating to this portion of the femur, which may be of value as regarding syphilitic tumors developed here. It is this: early in extra-uterine life that portion' of the femur which includes the neck, as far down as the base of the two trochanters, is composed of cartilage, and continnous with the shaft below, which is already ossified; consequently, at this spot the processes of development are very active, and are very likely to be modified by syphilis. So that there is good reason for supposing that we may find a swelling involving the 
whole breadth of the shaft at this position, which would, of course, be proportionately larger. We are warranted, then, in assuming that we may find syphilitic swellings at the junction of the shaft with the upper portion of the bone; that, like those developed upon the lower end of the humerus, they may be either generally distributed over the whole ossifying surface, or may be localized at a given spot, in which case they wonld be either the result of a local exaggeration of the morbid process, or of that process being confined to that particular spot. As the surface of the femur is somewhat uneven, it is probable that the surface of the swellings would not be perfectly smooth. Reasoning again by analogy, we shonld be prepared to find either a symmetrical or an unsymmetrical distribution of these swellings on the bones of the two legs; at any rate, it is fair to presume that one localized spot might be the seat of swelling on one femnr, and another spot on the other, or again a general swelling. Swellings on other bones will in all probability be formed, and sinilar changes may be observed at the other end of the femur, as was observed in Parrot's case.

IX. -THE ENLARgEMENTS OF TIIE CARPAL, TARSAL, METACARPAL AND METATARSAr, BONES, AND OF THE PHALANGES.

Having now studied the clinical features of the swellings upon the long bones, we come, in anatomical continuity, to the study of the lesions of the bones composing the hands and the feet. Thus far, in our survey, we hare been ocenpied with syphilitic swellings developed at the junction of the diaphysis of a long bone with either of its epiphyses; now we come to the consideration of the swellings produced by syphilis in the short, irregnlar, and flat bones. In these latter the mode of enlargement is not the same as npon the long bones; for of the short and irregular bones the whole structure is more or less enlarged, while upon the flat bones peculiar; prominent, and circumseribed swellings are varionsly distributed upon their surface. The similarity in the general appearance of the swellings of the short and irregular bones which compose the hands and feet, as well as their intimate anato- 
mical relations, renders their study together peculiarly appropriate.

The clinical history and pathology of the syphilitic lesions of these bones in the adult subject ${ }^{\prime}$ have already been quite fully considered by me abont three year's ago, and last year ${ }^{2}$ I called attention to some of the features observed in the lesions of these bones of the young child when afflicted with sypliilis; but as this latter acconnt was limited to a cursory description of the swellings of the phalanges and metacarpal bones, it is necessary, in keeping with other parts of the treatise, to go over the whole subject systematically. Then, as there are certain wellmarked differences in the clinical features, and in the pathological processes between the swellings in infants and in adults, a separate description of them becomes the more recessary.

The clinical facts ${ }^{-3}$ which have thus far been elicited show that any of the bones of the hands or feet are liable to syphilitie lesions, and statistics show that certain of them seem to be more prone than others. Commencing with the phalanges, we find that they are very frequently involved. In Archambault's case all of the distal phalanges were found to be swollen; in my two cases, in Bulkley's two cases, and in Smith's case, the proximal phalanges were swollen, and I have very recently seen two other cases in which these same phalanges were enlarged. When the swelling invades the third or distal phalanges, the deformity is very striking, and the fingers have a bulbous or clubbed shape, similar, in a measure, to the deformity obserred in syphilitic onychia. We have no recorded instance of the second or middle phalanx being the seat of

${ }^{1}$ On Dactylitis Syphilitica, Am. Journal of Syphilography and Dermatology, Jan., 1871.

2 Clinical Observations on the Syphilitic Lesions of the Bones of the Hands of Young Children. Brown-Séquard's Archives of Scientific and Practical Medicine, No. 4, 1873.

a Though attention is callea in this work to swellings being more liable to occur upon certain bones and upon certain sites rather than npon others, it is not intended at all to convey the impression that there is any specific selection of site or of a particular bone, as such a view would be unphilosophical and untenable, as there is really no bone of the borly which possesses an immunity to the syphilitic action; on the contrary, it is only intended to draw general conclusions from what appears to be the most frequently occurring conditions or coincidences in clinical practice, as from experience we know that such are tolcrably good guides for the deduction of general facts. 
syphilitic lesion in very young children; but, judging from the appearances observed in a case of simple enlargement of the second phalanx in a very young child, I should say that such a swelling would present very well-marked features. As this case has considerable interest as regards diagnosis, I have thonght it advisable to append it in a foot-note. ${ }^{2}$ i finger thus enlarged would of course be quite chmisy in its movenents. As all of the phalanges seem to be prone to syphilitic iuflammation, it is very probable that cases of enlargernent of the second phalanx will be observed hereafter. I have seen three cases of syphilis in which this phalanx was swollen. One of them was the patient whose history, in all its details, has

'Sophie S., a thin child and of slight build, aged five weeks, was sent to me, in August, 18 11 , by Dr. J. Aub, then of New York, now of Cincinnati, with a view of determining whether or not it was the subject of hereditary syphilis, and whether its lesion was dactylitis syphilitica. The child did not present any syphilitic lesion or symptom, and a very careful examination of its parents convinced me that they were not syphilitic. The index finger of the left hand was very much enlarged, the swelling being greatest at the middle phalanx, and from that region it gradually tapered off on each end. Examination showed that this phalanx was enlarged uniformly, having a perfectly smooth surface. The integument immediately over the swelling was very much stretched and of a pinkish hue, elsewhere it was nornal. Under the integument which covered the enlarged phalanx a number of large vessels were readily seen. As I was examining the finger, in the midst of an almost dazzling sunlight, I was struck with the translucent appearance of it at this part, and when I shaded its borders and held it up between my eye and the sunlight, the translucency of the swollen phalanx was well marked; so much so that any small object, like the end of a lead-pencil, was dimly visible on its opposite side. The smaller vessels were also rendered apparent in this examination. The finger at the middle of this phalanx measured two inches and one-eighth, while its fellow of the right hand measured fifteen-sixteenths of an inch at this part. The swollen phalanx was very nearly as thick at each end as it was at its central part. The mother informed me that the swelling had been observed at birth, and that it was then fully as large as it was when I saw it, and she thought that it did not give the child any uneasiness or pain. As the parents were healthy, there was no reason for attributing the swelling to any inherited blood disease, particularly as it was an unique lesion, and occurring, as it did, in utero, traumatism was to be wholly eliminated as a cause. My diagnosis, then, was that it was a simple hyperplasia of the cartilage composing the phalanx, and that the proliferation had begun in all probability about the time when ossification had commenced in the bone, probably about the tenth or twelfth week of intra-nterine life. I am of the opinion, from the history of the case, that the swelling consisted of unossified cartilage, and the translucence of the tissue is somewhat in favor of such a view. 
already been published by me ${ }^{2}$ the second was the case of a man having tertiary sypliilis and enlargement of the first and second phalanges of the right index finger. In both of these cases the dactrlitis resulted from acquired syphilis. The third case was one of hereditary syphilis, and occurred in the person of a boy, aged eight years, who, when five years old, among other osseous lesions, had an enlargement of the second phalanx of the left middle finger. I shall describe this case at some length in an appended note, at a later portion of this work, for by bringing out its points in a clear manner, and by contrasting its features with similar ones observed in the young child, it will convey a true idea as to the differences in the clinical history of the osseous lesions of the bones of the hands as developed early in hereditary syphilis, from those developed in later years.

By far the most frequently do we find that the first or proximal phalanges are the seat of syphilitic enlargement. Thus I have observed it in my two cases, as in Bulkley's two cases," and it also occurred in Smith's case, making a total of fire against one in which the distal phalanges were swollen. The deformity is very noticeable. The swelling may be slight, but usually is quite well marked, enlarging the bone to twice or thrice its normal diameter, its length being sometimes slightly increased. The general shape of the bone in its breadth is round, while it appears to have in its longitudinal direction an oval shape. It is somewhat broader at its base than at its distal end, the swelling beginning quite perceptibly at the metacarpophalangeal joint, which it enlarges, and ending somewhat abruptly at the next joint. The shape of the bone may be compared with that of an acorn. The rounded appearance of the body or middle part of the bone can be distinctly felt on its dorsal surface; but it. is perhaps more perceptible to the eye on its palmar surface, where this portion of the finger bulges out in the various directions. The integument is generally very much stretched, and it is probable that, when this condition is excessive, ulceration may be induced in it, as we know that the integument of infants inflames under very slight irritating

${ }^{1}$ Op. cit., page 13.

${ }^{2}$ I have also very recently seen, as I have said before, two other cases in which the proximal phalanges were enlarged : in one, two fingers of one hand and one of the other were affected; in the other, one finger of each hand was enlarged. The little finger was not swollen in either case. 
canses. We shall see further on that this ulceration of the integument may also result from localized degeneration of the bony tumor itself. The integument may or may not retain its normal color; I have seen it of the natural hue, when the phalanx under it was enlarged to fully twice its normal size. When, however, the bone-swelling is so great as to cause much interference with the circulation, a redness will, of course, appear, which may be simply of a rosy blush, or even of a well-marked venons color. This redness of the skin covering the phalanx might sometimes lead the surgeon to fear that ulceration was imminent, when really such a conplication was rery remote. Thus, in the ease of simple phalangeal enlargement just mentioned, as well as in one of the fingers of the case of Dr. IIanks, the reduess might have been, upon casual observation, regarded as indicative of phlegmonous inflammation; but an examination of the suppleness of the integument, of its mobility-thongh slight over the parts beneath it-of the absence of heat and pain, and of the fact that slight pressure emptied the vessels for a comparatively long period, convinced me that the process was a passive rather than an active one. The condition of the integument in these cases may be said to be generally that of passive hyperæmia, and that when the pressure from within is excessive, acute inflanmation may be induced. The integument being thus stretched, loses its slight furrows and surfacemarkings, but at either end of the swollen phalanx, just over each joint, a quite deep furrow or wrinkle is usually seen. This hyperæmic condition of the integument may or may not present a characteristic syphilitic hue. Thus it may be simply of a rosy red or even slightly purplish color, and it may remain in this condition thronghout its duration. Or, again, when it has been fully developed, it may assume the somewhat coppery tint peculiar to syphilitic subjects, in which event the feature would perhaps have some little diagnostic import. I saw this condition quite well marked in a case of this complication in which ulceration supervened. However, I think it may be asserted as a quite constant clinical fact, that very often, in cases of tegumentary inflammation, either ulcerative or nonulcerative, this peculiar coppery tint is either slightly marked or absent, and that it is not by any means as constant early in hereditary syphilis as in adult acquired syphilis. 
I am inclined to think that the greater or less degree of distnrbance to the circulation and nutrition of the skin, and consequently its more or less hyperæmic appearance, is dependent on the fact as to whether the bony swelling has ocenrred rapidly or slowly; in the former condition the disturbance is great, as the parts lave not time to adapt themselves to the bony expansion within; when, however, the swelling is slowly produced the parts do adapt themselves to the increasing size, the connective and fatty tissues undergo atrophy, and even the skin itself may likewise be changed, and then there may be no hyperæmia at all. I saw this condition well exemplified, last year, in a case of acquired dactylitis syphilitica, in which two phalanges were increased to fully four times their natural size, and in which the skin showed no hyperæmic or ulcerated condition. It had undergone great atrophy, its connective tissue was perhaps nearly all gone, and it appeared as a very thin tegumentary covering, readily movable over the bones.

I have sereral times noticed a very peculiar and deceptive appearance of the second phalanx, which might lead the observer to suppose that it also was the seat of enlargement. As the expanded distal extremity of the first phalanx ends at the joint, the bone of the next phalanx rests, of course, by articulation upon it, and the ligaments pass from the expanded part of the joint to the other non-expanded end; consequently the whole structure appears enlarged, and as the skin over the enlarged part is stretched out, and does not fit with perfect coaptation to the bone until about opposite the other end of the second phalanx, an appearance is presented as if the proximal half or third of the second phalanx was also enlarged. $A$ careful examination and manipulation of the parts will show conclusively that the lesion is confined to the first phalanx, and this view will be verified as the case is examined from time to time when resolution is taking place. This same expanded eondition of two phalanges, the first and the third, was observed in the case of simple cartilaginous hyperplasia of the second phalanx, just eited. I have, in one instance, seen this tapering condition of the finger so well marked that my impression that the second phalanx was swollen in a diminishing manner, from its base to its end, was so strong that it was only remored by numerous and careful examinations, extending orer some months. 
In a case of dactylitis from acquired syphilis, reported by Nélaton, and quoted by me, ${ }^{1}$ the statement is made that the three phalanges of the fingers were swollen, the first markedly, the second slightly, and the third in a scarcely appreciable manner. I am inclined to think that the first phalanx was the only one involved in the lesion, and that the tapering shape of the finger lesulting therefrom led to the opinion that the morbid process involved the other phalanges in a gradually diminishing degree. This riew has the support of two well-anthenticated facts or observations; the first being that a phalanx has never, as yet, been observed to be swollen in a local manner by syphilis, it always having been found totally and uniformly enlarged $;^{2}$ the second being that in every recorded case where two phalanges of the same finger have been swollen, the enlargement in each has been so great that no doubt of its existence conld be entertained. This point is of very great interest, in a diagnostic point of view, as regards rheumatoid arthritis.

It is interesting to know also that this tapering condition of the fingers is rendered more noticeable and characteristic, when there is an infiltrated endition of the integuments, whether due to inflammatory engorgement or to gummy deposit. In these conditions the examination of the bones is

1 Op. cit., p. 7, Gazette des Hôpitaux, 1860, pp. 105 and 106.

2 The details of all the cases thus far recorded tend to establish this as a fact, and certainly prove that a tapering condition of the bones has never been found. Yet, when we remember that the phalanges are essentially miniature long bones in construction, consisting of a diaphysis and an epiphysis, and also that at the junction of these segments syphilitic changes are prone to develop, it seems reasonable to suppose that these local swellings might occur here. Indeed, it is somewhat surprising that they have not been found already. Should sach a development be noticed, the diagnosis would rest be. tween syphilis and rhenmatoid arthritis. In syphilis the swelling would begin further down on the shaft, and should be more extensive than in the other affection, the swelling of which should be localized at the joint structure, involving it in its entirety; whereas in syphilis the enlargement would stop short at the end of the phalanx. Of course, in arriving at a conclusion, the various other concomitant circumstances should be taken into account. These considerations apply more properly to the syphilis of more adranced age; still, as we meet with rheamatoid arthritis even in very young children, the suggestions are important. This localized form of syphilitic swelling will be spoken of in the section treating of enlargements of the metacarpal bones. Apropos of this subject, it is well to mention that the epiphyses of all the phalanges are situated at the proximal ends of the bones. 
difficult, and the conclusions as to their size are perhaps rendered less accurate. But, as in infants we do not often find coexisting gummy infiltration into the integument of the fingers and toes, this as a complication will perhaps never be met, though of course it may be observed later on in the course of the disease. Volkmanu's case,' which was quoted by me, with its illustration, was that of a woman whose fingers of one hand presented this tapering condition in a marked degree; the lesion being both of the osseons and tegmmentary structures.

There is no.mention in any of the recorded cases of hereditary dactylitis syphilitica of any concomitant lesion of the nails, and it is very probable that if such an affection should be synchronously dereloped, that it would be an accidental rather than a direct result of the bone enlargement. A furrowed condition of the nail, similar to that observed after adynamic diseases, was observed by $\mathrm{me}^{2}$ in my case of dactylitis of acquired syphilis ; bnt this condition resulted mudoubtedly from the interference with the circulation and nutrition of the parts, caused by a very copious gummons infiltration into the integument of the toe. In the early form of hereditary dactylitis, as there is never, as a rule, such a co-existing infiltration ${ }^{3}$ into the integnment, it is very probable that there will not be any complicating lesion of the nail, at least arising from that cause. As the nails are composed of a modified dermal tissne, and are nourished directly from the derma, any lesion of this tissue acts, of comrse, upon the nails and impairs their nutrition.

Lancerean $x^{4}$ makes the suggestion that in acquired syphilis the nails may be affected by osteitis or periostitis of the last phalanges. I think that, for the reason above given, they are much more likely to be involved when the derma is the seat of morbid change, though they may be secondarily involved if the

${ }^{1}$ Op. cit., pp. 11-12.

2 Op. eit., pp. 7 and 8.

'It will be shown further on that a very copious infiltration of the skin has been met with in some of these cases, but it has always been of an inflammatory character, not consisting of gummy granulation tissue, and has resulted as a complication produced by the pressure of the bony tumor, or by being involved in its degeneration. Being then a simple inflammation, it does not seem to impair the nutrition of the nail, as a chronic infiltration has been known to do.

- Traité historique et pratique de la Syphilis. Deuxième edition, Paris, 1873 , page 178. 
osteitis or periostitis undergo degenerative changes. We have no recorded instance of such a complication, though all of the last phalanges were enlarged in Archambault's case, and one of thein was involved in Volkmann's case," there being no coexisting lesion of the nail. I think that the possibility of the eoexistence of these lesions was suggested to Lancereaux's mind in examining cases of stphilitic onychia, in which, as nsually occurs, there was a general enlargement of the phalanx, due to secondary hyperplasia of the dense fibrous tissnes under the nail and around the bone. If such a case is critically examined during its entire course, it will become clearly evident that the lesion is limited to the nail, and that all other infiltrations are simply the result of congestion. As onychia is rery often observed in hereditary syphilis, it is well to clearly under. stand that it is essentially a lesion of the nail structures, and that it does not in a direct way involve the bone, except, perhaps, as a rare occurrence.

In this swollen condition of the fingers there is, of course, some degree of distortion of their position. This is particularly noticeable if the first phalanx is the seat of swelling, and is more pronouneed in proportion as the bone swelling is great, and when it inrolres, as it generally does, the palmar surface of the bone, the dorsal surface, of course, being proportionately enlarged. In this event there will be obserred a decided flexion of the member, and it will be found that even firm and eontinuous pressure will fail to straighten it. This condition results from the pressure of the bony tumor upon the flexor tendon, and raries with the course of the swelling; so that if a case be followed carefully it will be seen that extension returns very gradually with the subsidence of the enlargement of the phalanx. It is most marked in the case of the fingers, and not as much so when the thumb is the seat of swelling.

Besides this temporary deformity, the swelling of a phalanx affects the position of other fingers, particularly if the swollen one is either the middle or ring finger; in which case the others are pushed to each side, when, being thrown out of their direction, their usefulness is somewhat lost. This fact ean be well brought out by giving the child a small thin article to clasp, in

Op. cit., page 12, and Berliner klinische Wochenschrift, No. 7, 1870. 
which ease the movement will be seen to be rery awkward, and the grasp to be unsteady. The everted condition of the fingers is not as great when the index or little finger is swollen, and does not exist when the thumb is involved. Whicherer member is affected, however, the usefulness of the hand becomes impaired.

Our study has thus far been, while treating of lesions of the short and irregular bones, confined to the syphilitic swellings of the phalanges of the fingers, it being fair to assume that the bones of the toes are affected in a similar manner ; in which erent they would present somewhat analogous phenomena. We have not on record a case of hereditary dactylitis in infants affecting the toes; so it will remain for fnture observation to determine the relative frequency of the lesion. To the extent of my reading, the first direct record of syplilitic swellings of the fingers and toes is in the treatise of Baumès,' who speaks of a case of hereditary syphilis in a young child, the phalanges of whose hands and feet were enlarged; but the author alludes solely to the swrellings. But Mahom, in his work on the Syphilitic Diseases of the New-Born, says that children afflicted with hereditary syphilis are subject, among other diseases, to softening and currature of the bones, particularly of those of the hands and feet. Though we have not the recorded fact of an infant the victim of hereditary syphilis presenting a swelling of the phalanges of the toes, such a lesion was found by Volkmann ${ }^{3}$ in his case of hereditary syphilis, the patient being sixteen years of age. In this case all of the phalanges of one toe were swollen; but as the lesion was of the same nature as that produced by acquired syphilis, the case is not applicable to our present study, nor do the statements of Baumès or Mahon in any degree instrutuet us.

The various complications which may arise during the existence of these phalangeal swellings will be treated of at length a little further on; but it may not be inappropriate to state here that degenerative changes of the bones are very fre-

'Précis thćorique et pratique des maladies vénériennes. Partie première, page 178. Paris, 1840.

${ }^{2}$ Recherches importantes sur l'existence, la nature, et la communication des maladies syphilitiques dans les femmes enceintes, dans les enfants nouveannés, et dans les nourrices. Page 456. Paris, 1804.

Op. cit.. page 11 . 
quently met with in the dactylitis syphilitica of infants and young children, and that, resulting from these changes, there is a greater or less implication of the integument. This fact will be bronght out as showing one point of difference between the course of early and late dactylitis. There is no mention in the records of any of the cases of any synchronons development of joint-lesion in these phalangeal swellings, while such a complication is not at all exceptional in the later form of the tronble. This point, which is also a distinguishing one, will be fully bronght ont hereafter. Should, however, a joint complication exist it would in all probahility be a synovitis, with perhaps an liydrarthrosis, both being secondary to the bone lesion; inflammatory in its course, and attended with pronounced symptoms. As this is the condition, and as there is usnally no gummy deposit at this age, the ultimate result would be that scarcely any impairment of the part would be induced; whereas if the lesion was due to gummy infiltration, the course would be very slow, and the result a greater or less destruction, with impairment of the joint.

Taking, now, the varions cases into consideration, it is interesting to determine how frequently the phalanges are involved in the syphilis of infants, as compared with the affections of other bones. Thus, within this limit, I include eleven of my cases, the two cases of Dr. Bulkley, and that case seen by me but once, making a total of fourteen. Out of this number of cases of bone syphilis the phalanges were found to be inrolved four times, making a frequency not quite as great as that of enlargements at the distal diaphyso-epiphysal junction, and slightly greater than the swellings at the proximal junction, and also of bone lesions elsewhere upon the body. Of these four cases, the bones of the hands were involved synmetrically ${ }^{1}$ in but one case, in which two fingers of one hand and two of the other were enlarged; in a second case, two fingers of but one hand were swollen; and in two, one finger of one hand only was enlarged. In Curtis Smith's case, three fingers of one hand

${ }^{1}$ Of the two cases which I have seen since this work was written, in one the lesion involved both hands, enlarging two fingers of one hand and one of the other; in the other case one finger only of each hand was involved. In each the bones of the toes escaped, the phalanges being the only bones of the body enlarged. 
were affected, while in Archambanlt's case every finger was said to be implicated. In the larger proportion of cases, then, an unsymmetrical development was observed, as is the rule in the dactylitis of later life. The swelling of two or more fingers seems to have occurred rather oftener than that of one; yet in so limited a number of cases this slight difference cannot be greatly insisted upon. It is very probable that in a large number of cases the urique and multiple developments would be in equal proportions. The case of Archambanlt, in which every finger was involved, is very exceptional. A perusal of the varions cases shows clearly that in every instance only one phalanx of each finger was enlarged; never were two thus affected. Besides this feature, which is peculiar, there is no instance in which a local swelling of the bone was observed, there being always an uniform enlargement. Perhaps in these particular cases the localization of the lesion to one phalanx of a finger was a matter of chance development; yet, as compared with this fact, we know that in four given cases of late dactylitis syphilitica, two phalanges of the same finger would have been found to be synchronously enlarged once, and perhaps more than once; so that, as a comparative fact, it is important. This synchronous affection of two phalanges will be found hereafter to have considerable bearing upon the derelopment of joint-lesions, and its absence, perhaps, affords one reason why in the early form of the affection we have not observed an implication of these structures. Although we cannot lay down the fact as a rule, that only one phalanx is involved in this early form of dactylitis, the absence of a case showing multiple enlargement of the phalanges of one finger gives considerable weight to the fact, and we may thus accept this as a tolerably constant peculiarity of this affection. It is proper to state, however, that in Volkinann's case of hereditary syphilis there was in several fingers enlargement of more than one phalanx; but this occurred in a person sixteen years of age, and the lesion was of the character generally found in a late acquired dactylitis, which we shall find differs materially from the lesion of the infant life. Parrot found at the autopsy an enlargement of the first phalanx of the right middle finger in his second case. It secms that certain fingers are more liable to this affection than others. Thus in the cases seen by me the 
thunb was affected twice, the index finger twice, the middle finger once, and the ring finger once. In Smith's case, the index, middle, and ring fingers were affected. From this it would seem that the little finger is nut frequently affected, as there is no mention of the fact except in Archambanlt's case, in which every finger was involved. As has been said before, the first phalanx is the only one usnally invaded, while the swellings of the others are quite exceptional. These phalangeal enlargements may coexist with other bone-swellings, as well as, of conrse, with other varieties of syphilitic lesion. In the cases thus far recorded the dactylitis was either coexistent with swellings of the metacarpal, metatarsal and tarsal bones, or existed as the only bone lesion. As we have already noticed a decided predilection for syphilitic hyperplasize to develop just at the junction of a shaft with an epiphysis, it seems singnlar that this form of swelling has not been found upon the phalanges of the fingers and toes, as they also are composed of a body and a distal epiphysis, which remains separate until about the twentieth year. Not only has this form of swelling not been observed in infants, but it has also never been met with in the syphilitic swellings of adults; for, as has been said before, the swelling has in each instance been found to inrolve the whole bone. It is interesting to bear this fact in mind, as the occurrence of such a case is quite probable.

We find that, like the phalanges, the metacarpal and metatarsal bones are also swollen in cases of hereditary syphilis. As shown by three cases, which illustrate enlargements of the first and second metacarpal bones, these swellings are of greater or less extent, and are not locally developed, but involve the whole length of the bones. In the hand the swellings of the bones are greatest at their middle portion, and less at each end, the bone, in its long diameter, having, consequently, a somewhat oval outline. Though the bone is greatly increased in diameter its length is not at all altered. In Morgan's case, which was that of a child three years old, the metacarpal bone was enlarged so much that it measured two inches across, and in my case the same variety of bone, in a child four years and four months old, measured one inch and a half in diameter, while the same measurement of its fellow was hardly half an inch. According to present observation, the surface of these swell- 
ings is smooth. The deformity produced by such prominent swellings is, of comrse, very striking both on the palmar and on the dorsal surface of the hand, where they present welldefined and clearly limited elerations of the skin orer the particular bones involved. This clearly defined and limited condition of the swelling becomes an important point in the matter of diagnosis. The integument is, of course, more or less stretched, and varies in hue according to this condition, as we have found in the phalanges. The function of the finger springing from a bone thus swollen is somewhat impaired, as it is not as steady in its movements as the others are, owing to the fact of the interference with the working of the two tendons, and the power of grasping various articles is somewhat lost. Thus if the thumb of my patient was flexed towards the ulnar side of the hand, it was found that it could not, nor could it be made to tonch the bone of the little finger by a distance of half an inch, an action easily accomplished on the other hand. There can be no doubt but that in Morgan's case, also, the usefulness of the hand was diminished, and that the child could not hold anything with the combined action of finger's and thumb. Though we have no instances of the last three metacarpal bones being the seat of this enlargement, we have no reason for supposing that such a condition might not occur, when undoubtedly they would present the same general features that have been observed in enlargement of the other bones. As there is not a great deal of space, however, between these last-mentioned bones, the swelling would not, of course, develop itself as much laterally as it has been seen to do in the cases already cited. The enlargement of the bone would go on until those on each side no longer allowed it; then probably, if the lesion continued, the swelling would be in the direction of the palm and of the dorsurn of the hand. When fully enlarged, under these circumstances, the bone, if examined upon transverse section, would appear as if rounded and laterally flattened. In the case of the first and second bones there is no hindrance to expansion, as the ample triangular space which exists between them allows of great swelling before it is filled up. In the event of the fifth metacarpal bone being enlarged, it is very probable that the swelling would be mostly developed towards the ulual side of the hand, and there it 
might attain large proportions. These bones, aceording to present observation, have only been fonnd to be involved in two cases.

Turning our attention now to the foot, we study the swellings of the metatarsal bones. In this instance we have very few clinical data to guide us, as there is only one recorded instance in which these bones have been found enlarged. In this ease the lesion was developed in the fourth and fifth only. The swellings consisted of an uniform enlargement of the bones, there being no noticeable difference in their diameter at any part. There was, of conrse, considerable deformity observed on the back of the foot, but the elevation of the integnment was strictly limited to the region of the two bones. To the touch, the enlargement was more evident on the dorsal aspect of the foot, and the contonr of the fifth bone more clearly made out than that of the fourth; of this, the portion which rested against the side of the third bone conld not be elearly defined, and the line of separation between it and the fifth not very accurately traced. But the examination on thị surfaee was not wholly unprofitable, as the bone swellings could be satisfactorily localized; whereas, when they were traced, with every care, by the tip of the finger upon the plantar surface, they could scarcely be distinguished as being swollen. This $I$ attributed to the density and resistance of the plantar fascia, and also to the mass of the soft tissues under and over it. I think that this observation establishes the fact very clearly that swellings of the metatarsal bones cannot be examined well on their plantar surface. Upon the palm, when the first, second, and fifth metacarpal bones are swollen, I think it will be found that their examination is both easy and satisfactory, as at these situations the palmar fascia is not dense; but when any of the intermediate bones are enlarged, I imagine that their exploration upon this surfaee is as profitless as similar explorations on the plantar surface.

As the metacarpal and metatarsal bones are composed of a shaft and an epiphysis, it is not improbable that in the hereditary syphilis of infants, and even in acquired syphilis, np to the age of twenty, swellings may be developed at their junction. In this event the enlargements would be, for all except the first, at the head of the bones, just near the metacarpo or metatarsophalangeal articulation, while at the first bone it would be at the 
base, near its carpal joint. There is no record of such a case in the syphilis of infants, but I have full notes of a case of hereditary syphilis in a girl twenty years of agre, who, among other most extensive and varied osseous lesions, had prominent swellings at the heads of the third and fourth metacarpal bones of the left hand, and a swelling at the base of the first metacarpal bone of the right. This suggestion may explain cases in future which might appear exceptional. As the epiphyses fuse with their shafts at about the twentieth year, it is very probable that such swellings will not be met with after that period, unless indeed the morbid process had begun previous to the twentieth year; though, as I have said before, this peculiar localization of the swelling of the metacarpal and metatarsal bones has not been observed in a living case of a syphilitic infant, such a swelling was found, on post-mortem examination, by Parrot in his fourth case, in which the distal end of the fourth metacarpal bone was found to be enlarged: a fact, I need not say, of very great importance. This observer also found enlargements of the metacarpal and metatarsal bones in his third and seventh cases; as did Wegner and Waldeyer and Köbner at the autopsy in some of their cases.

In clinical practice the carpal and tarsal are eren less frequently swollen in syphilitic infants than any of the other bones composing the liands and feet. From their size, structure, and mode of growth, being composed of ossifying cartilage, it is probable that when affected by syphilis they will be enlarged in their whole extent. As lateral expansion is limited by their close coaptation, the swelling will, of course, point in the direction of the palm or sole, or of the dorsum. As the outlines of these bones cannot be clearly defined in the normal condition, so their examination when swollen will not result in perfectly definite conclusions. At the wrist the exploration can be made either on the internal or external aspect, but at the instep it must be conducted at the dorsum. In cases of enlargement of the astragalus, os calcis, or the other bones of either feet or hands, more externally, or rather, laterally situated, probably their outline could be followed with more precision. In the one case observed by me, in which one of the tarsal bones-it being probably the middle cuneiform-was swollen, the instep appoared enlarged laterally and in height, and 
measurement showed that its circumference was greater by half an inch than that of the unaffected foot. The contour of the bone could not be defined, but the appearance was one of localized swelling. The condition of the parts in this case was rendered more difficult of examination as there was some synovitis of the small joints, and hyperemia of the integument. Thus in this, the only case recorded, there were inflammatory complications. As we know that these syphilitic swellings of bone are mostly indolent in character, it is fair to presume that we shall find this condition to obtain in these situations, and that this was perhaps but an exceptional case. IIowerer, when we consider that these bones enter largely into the formation of joints whose nse is constant, and that in a considerable part of their surface they are covered with synovial membranes, and are consequently more than ordinarily vascular, the suggestion forces itself upon us that here the conditions are farorable to the development of synovitis and tegumentary inflammation; for which reason they may often coexist, and form a complicating feature in these cases. In this event, if the complications are well marked, it can be understood that the original lesion may not be recognized, and even perhaps lost sight of. This would almost undonbtedly occur if the case was seen late in its course. This condition may perhaps explain many of the cases of so-called strumous inflammations of these bones and joints, and should be borne in mind, I think, in diagnosticating swellings and synovitis of these parts. The inflammation of these bones, then, in syphilitic children, presents points of very great clinical interest. They have been found by Parrot and Wegner to he enlarged at post-mortem examination.

\section{X.-TIIE SWELliNgS UPON TIIE CRANTAL BONES AND UPON THE BONES OF THE FACE.}

Before treating of the lesions of the various other irregular bones, we will consider those of the skull. The swellings or nodes on the cranial bones are more or less circumscribed, and are variously scattered over their surfaces. Though a large number of cases have been reported, from time to time, within the past ninety years, these swellings nay yet be considered as quite unfrequent. Thus, occurring only once in my experience, they have a proportion of one in fifteen, being one of 
the most infrequent of the lesions of the bones of young children. This is, in my experience, in marked contrast with their frequency in the hereditary syphilis of later life, anong which I have seen three instances of these swellings, and, of course, widely differing from their comparative frequence in the acquired syphilis of adults. From the number of cases on record, and from my own case, I think it may be assumed that certain of the cranial bones are more liable than others to the development of nodes in infauts. Thus the frontal was the seat of them in four instances: in iny fourth ease; in that of Roger; in Parrot's third; and in Wegner's third case. The parietal was involved in three instances, namely, in Bärensprung's, Desmarres, ${ }^{1}$ and in Wegner's fifth ease. The occipital was affected in one instance, namely, Desmarres' case, in which also the parietal was involved. The description of the nodes in syphilitic infants, judging from my own case, and that of Roger, is similar to that of the same lesions of adults. They consist in well-defined, round, or oval tumors of varying size, from quarter or half an inch to even an inch or more in area, having a height averaging within three-quarters of an inch, and a smooth, ronnded surface. Wegner speaks of slight elevations of the cranial periosteum of the size of flaxseed, as being quite commonly fonnd at the antopsy, so that we may meet cases in which these minnte nodes are developed. They are dne to cellular hyperplasia. In my case the nodes disappeared gradually under treatment, without any inflammatory complications; but I have been struck with the fact that in the cases of Bärensprung, ${ }^{2}$ Desmarres, and Parrot, they nnderwent quite rapid degeneration, and gave rise to extensive nlcers. Doublet, in his treatise, also speaks of the suppuration of tumors of the eranial bones. These facts would certainly point to a peculiar tendency to degenerative changes in this region, and should, of course, be borne in mind in the diagnosis of suppurative inflammations of the head. It is well to mention, however, that in these cases the syphilis was very serere. When the tumors assume an inflammatory condition, and they have then been known to involve very extensive

' Traité théorique et pratique des maladies des yeux. Deuxième édition, tome i., page 626. Paris, 1854 .

${ }^{2}$ Op. cit.

Op. cit.

- Op. cit.

- Mémoire sur les symptomes et le traitement de la maladie vénérienne dans les enfants nouveau-nćs. Paris, 1781. 
surfaces, I can readily see how they might be mistaken for alscesses, particularly if late in their course, or if for any reason the surgeon is unable to elicit a clear history of the commencement of the process. The diagnosis can, of course, be established by the listory and concomitant lesions, and by the fact of the deep-seated sub-integumentary position of the swellings when first discovered. Then, again, when an incision is made, the depth of the ulcer and its appearance, and perhaps the extrusion of portions of dead bone, will settle the question as to the focms of the morbid process. A point which is important, as showing that in their course these nodes in children may resemble those in adults, is brought out by my case, in which, after the resolution of the nodes, a distinct depression in the surface of the frontal bone on the site of each swelling was found. This is not mcommon in adults, particularly when the cases have been neglected, and the nodes have remained for very long periods. It shows distinctly that in the resolutive process fatty degeneration had involved portions of the bone structure, as well as of the cell proliferation and heterologons tissue incident to the inflammation.

Though hardly material to our present consideration, I think it is well to mention the fact, that the internal surface of the eranial bones has also been found to be altered in syphilitic infants. Thus a case of abscess of the internal table of the frontal bone is mentioned by Howitz, in the Hospitals Tidende, and quoted by Behrend. ${ }^{1}$ Cruveilhier ${ }^{2}$ found in a case of a syphilitic child an abscess between the dura mater and the orbital plates of the frontal bones near its vertical portion. Charrier ${ }^{s}$ found an abscess of the internal table of the frontal bone, as did Bargioni, in the ease already detailed. Wegner found internal cranial periostitis in two instances, and Waldeyer and Köbner in one. These facts show that in very severe forms of syphilis in infants these bones are very liable to be affeeted, either on their external or internal aspect, which nodes may be the only osseous lesions observed, as they were in the cases of Desmarres, Charrier, Bär-

1 Ueber syphilitische Knochenleiden und ein eigenthümliches noch wenig bekanntes syphilitisches Lungenleiden bei kleinen Kindern. Syphilidologie, Nene Reihe Dritter Band, pages 602 and 3. Leipsig, 1862.

2 Atlas d'Anatomie Pathologique. Obs. 10, livraison 15, page 6. Paris.

3 Cas de Syphilis infantile. Gazette des Hôpitaux, No. 43. 1854.

4 Op. cit. 
ensprung, Behrend, and Mowitz, or they may be coexistent with lesions upon other bones, as in my case, in Poger's, and in Parrot's.

Tery little can be said of syphilitic lesions of the bones of the face, as they seem to enjoy the same general immunity in syphilitic infants which they do in the acquired syphilis of adults. The only direct mention of any of these bones being affested occurs in the history of Parrot's third case, in which a thickening of the right coronoid process of the inferior maxillary bone was found, as well as the same condition at the symphysis menti. As it is a matter of some considerable doubt whether the coronoid process of this bone is developed from a separate centre, we are unable to say positively whether in this instance the lesion was of the same character as that observed at the junction of the diaphysis with the epiphysis of long bones, or whether it was a periostitis, but it is rery probable that at the symphysis the lesion was of the first order. In his treatise upon diseases of children, Rosen de Rosenstein ${ }^{1}$ says, that in order to determine whether a child has syphilitic osseous lesions, it is necessary to examine the condition of the inferior maxillary, the cranimm, and the bones of the arms and legs, for tumors and exostoses. This statement renders it probable that this Swedish observer had also seen this bone affected in the syphilis of infants.

The necroses of the nasal and palate bones, which occurs during long-continued severe syphilitic ulceration of the mucous membranes covering them, need but a passing mention, as they are quite fully described in the varions general and special works on the diseases of children. Rosen speaks of a case of necrosis of the hard palate following syphilitic ulcers of its mucons membrane; a complication of lesions which $I$ have seen twice in hereditarily syphilitic children aged six and eight years.

\section{XI. - THE SWELLINGS ON THE VARIOUS IRREGULAR BONES.}

In clinical practice tnmors upon the ossa innominata, sacrum, coccyx, vertebræ, and scapula have not been found. At the antopsy of several children they have been observed by Valleix, Parrot, Wegner, Waldeyer, and Köbner to be the seat of syphilitic change. Most of these bones are so deeply situated that their exploration is difficult, if not impossible; therefore it is

1 Traité des maladies des enfants. Trad. fraņ̧. Paris, 1793. 
very probable that very little will erer be learned of these swellings in clinical practice. The cardinal point to remember in the examination of these cases, when swellings are discovered upon them, is, that syphilitic changes are peculiarly liable to develop wherever the body of a bone is continuous with an epiphrsis; but of course we may find periosteal swellings on the surfaces of the bones. The diagnosis then may be arrived at by eliciting the history of the case, and by remembering the varions anatomical points regarding the mode of ossification of the bone in question. Should the patella become the seat of syphilitic inflammation it would be enlarged after the manner of the tarsal bones.

\section{XII.-THE DEVELOPJENT, COURSE, AND DISTRIBUTION OF THE OSSEOUS SWELLINGS.}

Such, then, being the situation, distribution, and general character of these swellings, it remains for us, in our study of their clinical history, to trace their development, course, and deeline, and also to consider the various concomitant symptoms and lesions incident to their existence. From a careful study of all of the cases, we observe that there are two prineipal forms or modes of derelopment of these osseous enlargements ; the first, in which the swelling is dereloped with comparative slowness, and the second, in which it is rather rapidly formed. Although no division ean be so sharply drawn as to apply perfectly to every case, the present one will answer quite well the purpose of simplicity of description, by laying down general faets, and by forming a standard with whieh exceptional features and eases may be compared. In determining the rapidity with which these swellings form, it will be seen that there are certain drawbaeks to be encountered. Thus, the child is always a passive agent, and eannot contribute any information, and as the swellings are not usually markedly salient, it is difficult to trace their progress in an accurate manner, particularly as the amount of increase is very slight. Then again, owing to rarious causes, they may escape observation until late in their course, so that under these circumstances we are frequently foreed to resort to inductive reasoning; as, for instance, having ascertained the child's age, and, if possible, the date of commencement of the 
swelling, we take into consideration its size, and from these points form an approximative idea of the rapidity with which it has been formed. In the main, howerel, our inquiries are attended with conclusions sufficiently satisfactory.

The swellings on the rarions bones are developed within a period averaging between two and six weeks, generally in th? neighborhood of a month. This average was found quite con. stantly in the eases of swellings of the long bones near the epiphyses, and in others generally of considerable extent. It is very probable that they are never formed in less time than two weeks, except in very severe cases, and that they always attain their maximum size within two months. In some instances of circumscribed swellings of local distribution, as at either of the condyles of the humerns, and at the base of the olecranon, or in limited portions of a diaphysal ossifying surface, in which the enlargements are not usually great, it is probable that about two weeks are occupied in their production.

Little need be said, more than has been already, as to the size of the rarions swellings. Those of the diaphyso-epiphysal junctions are never, as a rule, extremely large. The histories of the varions cases show that on the radius and ulna the swellings, on an average, reach an eleration of from one-half to three-quarters of an inch above the normal plane of the bone, and that upon the tibia and fibula they attain a somewhat greater height; it being very probable that these measurements are abont the maximum which will be observed, for the reason that in eases in which a greater enlargement has occurred, degenerative changes have been engrafted npon the swellings when they have surpassed this limit. According to my observations the difference between the normal and abnormal circumference of the wrists averages between three-quarters and one inch, while at the ankles the difference is from one and a half to two inches.

Having reached the various limits of enlargement, these swellings evince a tendency to run an indolent course without any apparent change, in which condition structural changes of the bones may be indnced, such as sclerosis and hypertrophy. But if: appropriate and efficient treatment is institnted early, and followed sedulonsly, the swellings subside, and the bones are left nearly in a normal condition. This fact points strongly and significantly to the absolute necessity of treatment, and also 
shows the necessity of accurate diagnosis in determining the natnre of the tumors. The study of the various groups of cases warrants ns in speaking with considerable precision as to the duration of these swellings, and of asserting that it depends on the following points: the extent and density of the swelling ; the earlier or later period at which treatment is instituted; and the care with which it is ordered, modified, and followed up. Thus, if the swelling is not very large, and has been two months in forming, it is rery probable that two months, at the most, of active and regular treatment will cause its subsidence. If, on the contrary, it has occupied a longer time in forming, and is of considerable size, a proportionately longer tine, say about four months, will be wanted. The rule is simply this, and it applies with equal force to rery many other syphilitic lesions of neoplastic character, that if the cell-proliferation which constitutes the swelling is young and receitt, and has not remained in the tissue framework of the part long enough to become, if we may say so, assimilated, or thoroughly incorporated, it may be quite rapidly removed withont having produced structural change. If, howerer, the cell-proliferation has become old and thoroughly mingled with the tissue framework of the parts, its removal is slow, and certain structural changes are almost inevitably induced; the final result is better, however, if treatment is instituted, even late. In illustration of the first proposition I cannot offer a better example than that of my eighth case, in which the swelling of a metacarpal bone was quite large, and in which treatment was instituted immediately upon its derelopment, when, being followed up regularly, full resolution was brought about in two months, leaving the bone, to all appearance, in a normal condition. Whereas the chronicity of these swellings, and their production of structural change when treatment is commenced at a late period, is well illustrated by my sixth case, in which it was instituted at the fourth and a half month of the existence of a bone-swelling of considerable size, and in which seren months elapsed before its subsidence was indnced. Then, again, Bulkley's second ease is an instance showing that a very long continuance of the bony enlargement, without the intervention of treatment, may result in a permanent alteration and hypertrophy of the bone, over which treatment has scarcely if any influence whaterer. In this case one 
bone had been affected eighteen months, and the other one year. So we may conclude that if treatment is not adopted within six months of the development of these tumors, the ultimate results are not farorable, but that more or less profound structural change will remain. It will also be seen that early treatment exercises a most powerful and salutary influence over these swellings. The natural tendency to resolution without therapeutical intervention is very slight, but still it has been observed, in a rery limited degree, in some of the cases. The arerage duration of these swellings, then, when uncomplicated by degenerative changes or by lesions of neighboring tissues, may be stated to be about three months. .

In these uncomplicated cases, as well as in those in which proper treatment is followed, the bones, as far as can be ascertained by examination, are found to be, after the subsidence of the swellings, in a normal condition; or, if they are at all altered, the changes are so slight that they would have escaped recognition unless the previous history of the case was known, so that, in general, we may take it as a rule that no serious results will follow.

In regard to the distribution of these osseous swellings, it seems that the rule is, as shown by the greater proportion of cases, that a number of bones should be affected at the same time, and that the swellings should be quite generally and symmetrically distributed. These facts are well shown by the cases in which both ankles and wrists, as well as other portions of the skeleton, are involved. Then again there are instances of more than one bone being affected, but not in a symmetrical manner ; and it will even be found that in some cases a single portion of a bone is attacked. As these latter cases are not as numerous as the former, we may conclude that in the point of distribution of osseons lesions in young children, a symmetrical and quite general development is the rule; to which, however, there are certain exceptions. It would seem that in clinical practice the exceptions consisted mostly in those cases in which such bones as the phalanges, metacarpal, metatarsal, and tarsal bones were those affected. When we contrast the development and distribution of the osseous lesions in these cases, we observe that, in these particulars, they resemble very closely those of the various cutaneous lesions. 
There is still another point of considerable interest relating to the development of these swellings; it is, that they usually all appear synchrononsly, and then run the same course. In certain very unnsual instances this character is wantingr, and we meet two, and even three series of osseous swellings. In these cases the first is nsually a general and symmetrical development, and the second and third consist of one or more enlargements, nsually, however, unsymmetrically placed. In these cases, however, the first series eren may have consisted of a local and unsymmetrical distribution. Aceording to the facts to be gathered from the records of our cases, these relapsing series have all appeared within a year after the invasion of syphilitic lesions, and at the longest time four and a half mouths after the derelopment of the preceding series; generally an interval of three months elapses between each crop. A very significant fact, however, is to be noted, in this connection, namely, that in every instance in which more than one erop of osseous swellings has been observed, no treatment had been instituted. This fact points strongly to the suspieion that in many of the cases more bones than those which are detected as being involved in the morbid process are thus affected, but that treatment had removed the naseent pathological changes. In this connection it is interesting to mention again the fact that in the post-mortem observations of Wegner, Waldeyer, Köbner, and Parrot, they very frequently found gradations of pathological change, and that in the same subject the most pronounced lesions of one bone coexisted with incipient lesions in another. This fact also proves the truth of Bertin's ${ }^{1}$ surmise, made so many years ago, that it was probable that syphilitie lesions would be more common than they were if treatment was not regularly followed. I have noticed, in those cases in which the osseons lesions appeared in crops, that when under treatment they disappeared, their resolution was very nearly synchrononsly accomplished, and that a proportionate length of time did not intervene in this process as did between their periods of development.

XIII.-THE EFFECT OF THE OSSEOUS ENLARGEMENTS UPON THE INTEGUMENT AND UPON THE JOINTS

THE integument is usually not at all involved coincidently 
with the bone-lesions, but in some exceptional cases has been found to be secondarily inflamed. The inflammatory process in it varies in intensity from slight hyperemia to deep ulceration. The canses of this hyperemia and ulceration are of two linds, the one resulting from simple pressure of the bony swelling underneath, the other from the activity of the lesion of the bone. The results vary with the cause; for whereas, in the former instance, in which pressure is the excitant, a greater or less-hyperæmia results, and in certain somewhat rare instances even ulceration, in the case of the severity of the inflammatory processes in the bones a lesion of continuity of yreater or less intensity and of varied form is induced. The hyperxmia from pressure has been well shown in one case of extensive enlargement of a phalanx, and it is in the region of the fingers the tendency is most marked. This, of course, is due to the tightness of the investing integument, and perhaps to the excessive mobility of the parts. As the records of the various cases clearly show, swellings eren of quite considerable size at the epiphyses are not complicated with dermal change, for the reason, undoubtedly, of the looseness of the corering integnments. It will be seen hereafter that, in cases of synovitis, the integument may become red and inflamed. As has been remarked already, the swelling of the bone may take place so slowly that no change is indnced, as the integnment accommodates itself to the gradually increasing pressure.

It might seem at first sight somewhat singular that eren in cases of well-marked hony enlargement near joints, the latter structures should escape, even though the lesions are of so chronic a character; yet such is the clinical fact. A study of the anatomical peculiarities in the instances where articular complications have been observed, will, I think, afford good and convincing reasons for this. Ont of all of the various clinical cases, only three joints have been inflamed, yet in certain of the cases of Parrot, in Valleix's, and Bargioni's, a total destruction of joints was found; but this will be shown, further on, to be essentially a different and more exaggerated process. The three instances are as follows: first, the elloow-joint, in which the lesion involved the whole distal ossifying surface of the humerns; second, the same joint, the lesion being an enlargement of the ossifying base of the olecranon; the third, 
an enlarged tarsal bone with synovitis of the joint. When we examine the structure of the hmmerns at its lower end, we find that the shaft joins its epiphyses quite low down, eren within the joint proper, and that the synorial membrane is reflected upon the point of junction of the shaft with the epiphyses. In the case of the olecranon process, the ossifying portions are also inclosed within the joint, at the junction of the base of the process with the shaft; the tarsal bones also are surromded nearly to their full extent with joint structures; so that we see distinctly that the hyperwmia and cell proliferation in these instances goes on in positions where quite extensive synovial membranes exist; on which accomnt it is fair to suppose that a sympathetic or symchronous hyperæmia is set up in this so vaseular memtrane, resulting from which and from movement of the parts we have effusion and its eonconitant symptoms of swelling, redness, pain, and impairment of function. As these anatomical reasons are so clear, and as articular complications have not been observed when the swellings have been developed, owing to the normal relation of the parts at considerable distance from joints, as at the junction of the shafts of the radins and ulna, and tibia and fibula, we are certainly warranted in accepting them as the true explanation, and of drawing the evident conclusion that in the mild form of these osseous swellings articular complications are only liable to arise when the shaft and epiphysis mnite at or within a joint. ${ }^{1}$ As was remarked in a previons part of tliis essay, the joints of the metacarpal bones and phalanges have not been found to be implicated, yet the conclusion now deduced renders it very probable that these structures might undergo change in this position. The lesion, as judged of from clinical data, is a simple hyperæmia of the synovial membrane, and consequent effusion, which, as thus far observed, has not been very copious. There is no reason for supposing that there is any infiltration into the joint structures, such as we find in late aequired syphilis, as well as in the late form of

1 This fact is also all the more clearly brought out in the history of personal cases Nos. 10 and 11; for in them the morbid processes at the junction of the epiphyses and diaphyses of the lower end of the tibia and fibula went on to such an extent that separation of these segments resulted, yet left the joints wholly intact. It must be remembered, however, that the junction of these segments is usually rather more than an inch from the joint, and that thero are no synovial prolongations from it. 
bone syphilis in children of various ages. The tendency of the condition is to ameliorate with the subsidence of the osseous lesion, and may be regarded as of a simple and ephemeral character.

\section{XIV.-THE DEgENERATIVE CHANGES WHICH MAY OCCUR IN THE} OSSEOUS SWELLINGS. THE SUPERFICIAL FORM.

Thodgin, as we have seen, these bony swellings usually run an indolent course, and, as a rule, subside withont mudergoing degeneration, there are certain somewhat rare cases in which destructive changes become engrafted upon them. As has been hinted before, these degenerative changes may be divided into two varieties, each of which has cleally defined features. In the first variety the destruction is limited to the more superficial parts of the swelling, whereas, in the second, the degeneration involves its whole breadth, usually corresponding to the whole extent of the ossifying surface, in which case a separation of the epiphysis from the diaphysis occurs.

The superficial form of degeneration was observed in two of my cases and in one of Bulkley's, while the second form was observed in my tenth and eleventh cases. The bones thus affected were the tibia and fibula, radins and ulna, phalanges, metacarpal, metatarsal, and tarsal bones. As thus far observed the swellings have first reached their maxinum of enlargement, and then the degeneratire changes have become engrafted upon them ; but, of course, cases may occur in which this complication will follow closely, or be coincident with the full formation of the swelling. The earlier features of this process are very liable, for obvious reasons, to escape observation; still, attention may be drawn to them quite early. A localized increase of the swelling is first found on the most prominent part, when very soon the integument participates in the inflammation, and fluctuation is soon felt. An opening then forms, or an incision is made which ulcerates, the ulceration usually going on until it occupies a space corresponding to the size of the necrotic spot on the bony tumor. There is no tendency, or such has not been observed, of this nlceration to increase beyond these limits. When fully developed, the parts present the following appearances: an eleration of the integument, of 
greater or less height, upon which is an ulceration of varying size, from half an inch or less to even an inch and a half, and of a round or oval figure. The edges of this ulcer are mudermined, slighltly everted, red, and thick, while the base is of a brownish green color, formed of necrotic tissues, from which a fetid, sanious pus in small quantity escapes. The tegumentary tissues for a slight distance around are red and inflamed. The ulcer resenbles very much an ulcerating gumma, and certainly might be mistaken for such. Critically examined, this ulcer presents the following points: it is of considerable depth, seemingly, at its middle, about half an inch in some cases; if its edges are moved or slid towards the bone with the tip of the finger, it will be quite distinctly seen that the latter is immovable, and this point can be observed if any portion of the edge be thus manipulated. Then if the base be carefully examined with the end of a probe, it will be found to be somewhat hard and resisting after the instrument has got throngh the thin film of necrotic tissue. These points distinctly prove that the ulcer has bouly tissne as its base, and if we linow the history of the case we may be certain that the tegumentary changes are secondary to the necrosis of the osseous tumor. It is very probable that a simple sinus may form instead of an ulcer, owing to a greater limitation of the necrosis in the bone and derma; a point which it is well to bear in mind, that we may not expect in every instance to find such ulcers as those just described. The reasons for this suggestion will appear further on.

The length of time required for the cure of the cases with these complications was about four montlis. Though, as I have said before, the general appearances of this ulceration, which is secondary to the osseons necrobiosis, resemble that of an ulcerating gumma, it may assume, during its course, features which might perhaps render it liable to be mistaken for a scrofulous ulcer; thus the base nay become corered with more or less profuse, tough granulations, and the edges may assume the callous purple appearance of scrofulons nlcers, and become markedly everted. In this event I can readily suppose that it would be classed as scrofulous. Yet if the history be carefully looked into, these adrentitious appearances will be explained. This further complication is only liable in case of neglect and delay of treatment. The resulting cicatrix may be of variable 
appearance, either thin and depressed, rendered uneren by fibrous bands, or adherent to the bone.

XV.-TIE SEPARATION OF THE EPIPHYSES FROM THE DIAPHYSES.

The most extensive form of degeneration of these osseous swellings, in which there is a separation of the epiplysis from the diaphysis, appears also to be the rarest in clinical practice. This feature has only been observed in two of my cases, and they are, at present, unique in literature, there being no other recorded cases. But in many of the cases of Wegner, Parrot, Waldejer, and Köbier, as in those of Valleix and Bargioni, a distinct separatiun of the epiphyses from the diaphyses was found. In each of these cases, howerer, the child died at or soon after birth; consequently, with the above exceptions, we hare not a case which has been followed up until a cure was effected; and, of comrse, these are the only ones from which the peculiar and very interesting clinical features can be studied. Many interesting points in clinical practice have been simplified, or have been thoroughly explained, by the details derived from the post-mortem examination of the various cases just alluded to, of which the inportance can scarcely be over-estimated. There is no peculiar or distinguishing feature to be observed in the early part of the course of this variety of swelling, except, perhaps, that it attains its maximum size in less time than is required by the first variety. A phlegmonous inflammation of the integument rapidly follows, and if the parts are examined at this time, or shortly after, the following features will be obserred: the swelling is not as distinctly limited to, nor does it begin as abruptly just above the commencement of, the epiphysis as it does in the simple or resolutire variety. On the contrary, it commences on the shaft, just at or above-its middle portion, in an almost imperceptible eleration, which gradually expands until it reaches the epiphysal region, where it becomes a distinct, large swelling. It is very probable that the swelling is at first localized in a similar manner to that in the first rariety, and that the enlargement of the shaft further np occnrs later. The reason of this will be clearly brought out by post-mortem facts. I give the appearances as they were observed in my cases, and they are those which I think will be most generally found at the early and 
late periods of the derelopinent of these swellings. Very soon it is found, as I have said, that the integunent has become involved; that it is less supple, and camnot be moved over the bony tumor beneath; if carefully manipulated it will be discovered that the focus of the tegunentary inflammation is at or abont the point of junction of the shaft with the epiphysis; softening may perhaps be traced nearly round it, if a part such as the arm or leg be involved. In my ease the fluctuating spot was found just over the malleolus, but it was evident that a nearly similar condition existed all around the limb; consequently the spot where the abscess points may be seated anywhere around the limb. As the changes in the overlying tissues are the direct result of a deep-seated destrnctive process, an appropriate examination will at this time reveal the character of the latter. Deep pressure shows that the bone swelling has become more prominent at the junction of the shaft with the epiphysis ; and a softening, or perhaps a feeling of fluctnation, is at this time or soon after felt. The examination being earried further, supposing that the morbid processes have reached their height, abnormal movements may be produced in the parts. Thus holding the foot and the epiphyses (we will suppose the lesion to be developed, as it was in my ease, at the lower end of the shafts of the tibia and fibula) firmly in one hand, and with the other grasping the shafts of the bones, it becomes rery erident that a slight bending morement is permitted between the two segments of the bones just mentioned. If a lateral motion is made by attempting to slide the surfaces over one another, the lower segment moves slightly in either of the direetions, and when the same is attempted in an antero-posterior direction, it is found to be very slightly accomplished. The sliding movements are generally attended with a crepitation of a soft kind, and not at all dry or harsh. This sound, however, may not be elicited, or it may be very faint indeed. In one instance the sensation appeared to me as if two soft bodies were gently rubbed, the one over the other. Its absence or masked condition may be aceounted for by the interrention of the products of degeneration between the two ends of the bony segments. This was well shown by my first case ; for before the contents of the abscess, if we may so term it, were eracuated, crepitation was rery slight, but immediately after the operation it was very distinctly heard: so I 
think that the explanation given is the true one. As the parts are naturally soft and succulent, it is very probable that this sound will always be of the soft variety just mentioned. The morements will, of course, be of greater or less extent, but it is very probable that they will always be more free in a lateral than in an antero-posterior direction. They will, of course, depend upon varions causes; thus the greater the amount of tissue degeneration which exists between the two segments, in that proportion will the movements be greater; then again, the greater or less thickening of the periosteum which we shall find to be thus affected in this lesion, will act in varying degrees as an impediment to motion. Finally, the infiltration of the surrounding integument will also tend in a measure to prevent it. In the case which serves me as the text of this description, the integument over the swelling did not fall into extensive ulceration, but only enough of it was destroyed to allow the exit of the products of degeneration, and a sinus was formed. This sinus presented no very peculiar features; its orifice became thickened by fibrous tissue somewhat after the form of similar openings leading to inflamed ganglia in strumous subjects, but there was less tendency to the invasion of the surrounding tissues, and there was not any puckering of the integument. One case, however, -will not constitute a rule, particularly as the tendency to neoplastic fibrous growths of the skin varies so largely in different persons, even in thrse free from any blood disease. So we may find in these cases. the typical sinus observed after serofulous abscesses. In my first ease the little patient was a mulatto, and I should not have been surprised at such a derelopment in her, as her race is so liable to such growths. We find both in hereditary and acquired syphilis this tendency to the development of fibrous tissue in sinuses or scars. The fact that severe ulceration was not induced, and that a sinus was formed, is of considerable clinical interest, as it shows that we need not of necessity have ulceration of the integument of such extent as has been deseribed as accompanying the first form of degeneration of these bony tumors. So we must accept these clinical facts as being liable to be observed in these instances: first, a circumscribed ulceration; second, a sinus of the skin. In my second case of this lesion a sinus was formed, but owing to treatment it rapidly closed before sufficient, time had elapsed for 
fibroid proliferation to occur. It is interesting to note that a sinus rather than an ulcer was produced. Passing now to the conrse followed by these severe bony swellings, we find that, under appropriate treatment, the enlargement gradually subsides, that, after a time, the viscid secretion, which, however, towards the end beeomes of a purulent character, ceases to escape, that the sinus closes, and, finally, that searcely any evidence is left of pre-existing bone lesion.

The secretion which escapes is, as said before, quite thick in consistence, of a light brown color, of nentral reaction, and found, by microscopic examination, to eontain lencocytes in considerable quantity, a few myeloplaxes, and granular matter. Like all productions of degenerated bone from syphilis, in an uncomplicated case, it is free from pus when first evacuated, though this may appear later on. We have seen, that, in this form of extensive bony degeneration, lesions of continuity hare been produced in the periostenm and in the integument; but the details of my tenth case prove distinctly that the bone (hanges may be almost of the same severity, and yet that these superficial tissues will not undergo any ulcerative action whatever beyoud those absolutely necessary to give rent to pent-up secretions. In my tenth case, upon one leg the epiphyses of the tibia and fibula were found to be completely separated from the shafts, yet there was no extrusion of the products of degeneration, nor did an opening upon the surface oceur. This fact is of great clinical interest, and its knowledge is very important in the matter of prognosis. It proves distinctly that the degenerated débris of bony and eartilaginous tissues may be absorbed, probably by undergoing at first fatty transformation, and that, coincidently, or in a short time afterward, the normal nutrition and growth of the bone are restored. I examined my case in especial reference to this point, and I convinced myself thoroughly that this absorption had taken place without any lesion of the periosteum. One of the most interesting features of this form of lesion is the part which is played during its conrse by the periostenm-a part which, besides being interesting, is of vital importance, as influeneing the final result. As I observed in my case, and as the facts observed at the antopsy of Valleix's and Bargioni's cases further support, this menbrane' undergoes very considerable 
thickening coincidently with the active and serere degenerative changes which are developed between epiphyses and diaphyses. This thickening is, as we have seen, not localized exactly to the seat of bone inflammation, but it extends quite a considerable distance up the shaft. The result is that a very thick tube of bone is formed nnder the periostemn, and that it serres to give stability to parts which have been so materially weakened; when, acting as a splint, it tends to prevent motion, and in a measure keeps the parts from further disorganization. Of conrse, if this sub-periosteal tube was only formed just over the morbid focus; it could not give the power of support which it does, as it extends quite far up. In fact, during the height of activity of the destructive processes this wise provision of nature is the chief; if not the only, means of arerting total disorganization of the limb, and it exerts an equally important influence npon the final result. Then, coincidently with the absorption or extrusion of the softened tissue, bony formations jut inwards between the two detached ends of the segments of the bones, upon which an healthy nutrition soon becomes engrafted; till, in the conrse of time, the two become gradually welded together, and, on the morbid processes ceasing, scarcely anything abnormal can be detected in the parts. In my ease a mere ridge of about the breadth of one line was noticed, and the thickening of the periosteum gradually subsided as the parts assumed a normal condition. The length of time required for the cure of this severe form was, in my first case, six months, being about one-third longer in course than that of the simple uncomplicated swellings. In the second case which I observed of this lesion, the reparative process was established within two weeks, or rather disorganization was arerted in that time, and from the appearances presented by the case at my last examination, I think that a perfect cure would have been bronght about in three months : so that I think we may conclude that, in such cases, from three to six months of treatment are required to restore the parts to as near a normal condition as we by our art can hope to attain. Now, though these cases show us that disorganization of these bones and joints may not - occur, a perusal of the cases of Valleix and Bargioni also show that certain rapidly destructive changes may supervene, and that these tissues and organs may undergo disorganization. 
In these cases the epipliyses are extruded, the joints are wholly destroyed, and the limb, left in a state of permanent defurmity, is more or less useless in its function. $\Lambda$ s thus far observed, these complications have only occurred in cases attended with a fatal result, and we have no record of a recovery under the eircumstances. In these instances it is probable that death was induced principally by the visceral lesions with which the child was afflicted, and was perhaps accelerated by the systemic reaction incident to such profound reflex disturbance as must exist in such a case, and by the exhanstion conseq:aent upon so great a drain npon the system as snch extensive tissue destruction would entail. But as we know that in children not suffering from syphilis this condition may exist in its severest form, and yet not eompromise life, we may assume that in cases of syphilis in which risceral lesions do not exist, or are mild in character, that even this severe form of destruction may oecur, and yet the child live.

The separation ${ }^{2}$ of the epiphyses from the diaphyses may ocenr in any of the long bones of syphilitic children, but the facts observed by the German observers, and by Parrot at post-mortem examinations, seem to show that those of the arms and legs are most liable to be thus affected, and that the proximal and distal ends are thus liable in about the same proportions.

This accident or complication is accompanied by certain well-marked subjective symptoms, which may be summed up concisely in the words, inability to move the affected members. These symptoms were very much dwelt upon by Parrot, and also by Guéniot; ${ }^{2}$ but I think that the former attaches more importance to them than they really deserve. Thus he entitles

1 I find it stated by Parrot (op. cit.) that Underwood says "that a looseness of one or other of the articulations may be accepted as very probable indication of syphilis," und he makes the suggestion that perhaps the English observer had met with cases of separation of the epiphyses from the diaphyses in syphilitic children. Parrot quotes from the translation of Underwood's work, " Traité des Maladies des Enfauts, traduction Française. Paris, 1786, page 361." I have been unable to find this edition of the work; but-in the ninth edition of it, edited by Marshall Hall, and published in London in 1835, I cannot find this sentence.

"Gazette des Hôpitaux, Fev. 9, 1869. This observer reports a case which Parrot uses, and I transcribe it as No. 1. Guéniot did not report it at the time as being syphilitic, but afterwards, at the suggestion of Parrot, arrived at the conclusion that it arose from that disease. 
his three articles after them, calling them a psendo-paralysis, caused by an alteration of the osseous system in newly-born children affected with hereditary syphilis. This false paralysis is simply an indisposition ol want of porrer to move the limbs, owing to a false point of motion existing in their continnity. The same features are observed, and the same conditions obtained in cases of fracture of bones, and as they are explained in so simple a manner I hardly think it necessary to so magnify their importance as to burden literature with another name for them. The appearances presented by children whose bones are thus affected, vary, of comrse, with the particular one involved, as with the end which is involred, and are in the main those which would be observed if any of them were fractured, except, perhaps, that there is much less sensitiveness and swelling of the surrounding parts generally. In one of Parrot's cases, and I must acknowledge that he has observed and recorded his cases faithfully, and that his contribution is one of considerable value, the arms hung heavily down as if paralyzed, the hands being turned towards the trunk. In my tenth ease the legs hung down in a powerless manner, and the feet turned in to such a degree that they rested fully on their immer sides. Owing to the existence of a false joint, or rather false point of motion, there is a total relaxation of the muscles, and no morements are made in the linb; certainly, there are none in that part in which the bony levers are divided into two, whereas in the upper division of the limb, as the thigh or arm, slight movements will be observed. When the parts are handled (to speak from a clear recollection of my cases), they, if moved to their normal position, quickly return to the position they abnormally assume; thus, when I everted the foot, it remained so while held, but, immediately that I loosened it, it tumbled over heavily upon its inner side. I think that this same motion would be observed in the hand. When the hands or feet are tickled or pricked, a slight convulsive motion is induced in the muscles, but mostly so in those of the upper and unaffected region. Parrot says, very happily, that in one of his cases a jerking motion was produced similar to that seen when a jointed toy is pulled by a string. This fact goes to show that the muscular power is temporarily in abeyance, and that if stimulus be applied to the members a disordered and jerking movement 
results. When improvement begins in the osseous lesions, particularly if the parts are subjected to judicions nse, this condition gradually disappears, and when the continuity of the bones is eomplete again, the muscles move these levers in perfect harmony of action and co-ordination. This general suggestive deseription will answer for almost any case which may arise, the features of conse differing according to the conformation and function of the bone affected.

It is well, however, to describe the features observed in my eleventh case, the second one in which I found separation of the epiphysis from the diaphysis. In this an munsual bending of the lower part of the leg inwards was found, the part which allowed and induced this abnormal position being at the junction of the lower third of the tibia and fibula with their epiphyses, the convexity of the resulting bow looking outwardly. This condition was due to the preponderance of action of the flexor muscles over the extensors, which, drawing npon the lower segments of the bones of the leg in which a false point of motion existed, produced the deformity noticed. In the present instance this deformity was slight, but of eourse it may be very extensive. As a slight bending is noticed as the normal condition of the legs of children, so it is well to look into the condition carefully if it exists, and to make comparisons with the healthy leg, or with that of another infant, as by this means fa!se conclusions will be avoided.

\section{XVI.-THE SYMPTOMS INDUCED BY THE OSSEOUS SWELLINGS.}

When we eonsider the severity of the pain which so frequently accompanies the development of osseons and periosteal lesions in the adult, we naturally eonclude by analogy that the varions osseous swellings in infants have been attended with pain in their development and course. The comparison, however, is not a perfect one between the two cases, for in the first instance the lesion is an inflammation in a fully formed, dense, unyielding structure, whereas in the latter the lesion is mainly an abnormal nutrition attended with inflammation, but in a naseent structure, as yet soft, unfinished and yielding; so that in infants there is a probability that as the conditions are altered the amonnt of pain may be less. This opinion or supposition is based on the fact which I was careful to elicit from 
the mothers of the various children, that they did not notice any very unusual suffering of the children. Some were quite restless at night, and appeared as if in pain; but it is well known what direrse and erroneons conclnsions may be and are formed under these circumstances, which often leave us at a loss to say whether or not in these rery young children these lesions are attended with pain. I endeavored to ascertain the fact, from several of the mothers, whether manipulation of the swollen parts gave uneasiness at night when the child seemed restless, but I conld not obtain satisfactory information. When examined in an uncomplicated state I have not found these swellings to be the seat of pain, particularly those of the diaphrso-epiphysal junction of the long bones; indeed, I have been surprised at the unconcerned manner of the infants when I have been very carefully manipnlating them. Still I saw a marked exception to this in the case of a child under the care of Dr. Dessan, the history of which I shall give further oll. In this instance the restlessness and evident pain of the child cansed its mother to bring it to the Dispensary. Here the trpical lesions of syphilis were found. Manipulation of the swollen fingers and of the expanded distal ends of the forearms was evidently attended with acute pain, as the child shrank from the examination. The mother thought that the pains were more severe at night. In the instance of the child with nodes on the frontal bone, I thought that there was considerable sensitireness, as it shrank from my grasp. This fact I hare also observed in cases of enlarged phalanges; so that I have derived the impression that when the swellings are found upon the bones of the head and upon the phalanges and their neighboring bones, considerable pain and tenderness exist, but that on the long bones very little, if any, is, as a rule observed. So that, thongh it is rery probable that pain is a concomitant symptom of these swellings, the demeanor of the children does not manifest it in the majority of cases. Moreorer, in this conuection, we have an important witness in my eighth case; in which there were lesions of the metacarpal bones and of the long bones at their diaphyso-epiphysal junction, for in it we have unmistakable evidences of very severe pain. This case is one of acquired syphilis in a child four and a balf years old, in whom osseons lesions precisely similar to those of infants were ob- 
served. Now this child complained bitterly of her pains, and was old enough to describe them, and to distinctly localize them at the points where osseons enlargenents were found. Moreover, they observed a nocturnal recurrence, not being felt dnring the day; and so much did they resemble those of the child's father, that he himself suspected their syphilitic origin. This being indubitable evidence, the question arises, how does this affect the negative evidence which I have already bronght out? Bearing it in mind, from the fact that many of the infants seemed fretful at night, I am inclined to think that these osseous and periosteal swellings in them are attended with pain. When the varions osseons swellings nndergo the superticial form of degeneration, it is probable, as the destruction of the superimposed epidermis is rery slow, and is not of a phlegmonous nature, that the pain is very insignificant; but if, owing to the rapidity of the osseons degeneration, it does assume a phleginonons nature, it is probable pain will be present.

I have already shown that the subacnte mode of development is the one usually obserred when the epiphyses become separated from the diaphyses, so that I think it may be assumed that this whole process might be accomplished with very little pain and a surprisingly slight-amount of systemic reaction. Yet I can readily see that if the process shonld assume the rapid form which has been observed, that it wonld be attended with pain ; indeed the details of the varions cases of other observers render this supposition very probable. In this form the inflammation of the integument is of a rather more phlegmonous character than the more superficial variety, and of course attended with more or less pain. When a separation of the segments has occurred the pain will be dne to the abnormal condition of the parts, and although, perhaps, it is not spontaneonsly present, any movements, voluntary or involuntary, will, as a matter of course, gire rise to it.

When the bony tumors have reached such a size that injurious pressure is exerted upon the integument, then pain becomes a complicating feature, and exists in proportion as the pressure induces disorganization of the integument. In several instances in which the phalanges have been very much swollen, and in which much cutaneous hyperæmia existed, I 
found by examination very considerable pain and tenderness. In the erent of synovial complications, it is very probable that pain of an acute character will be present, and in three instances I have seen this condition very well marked. These latter conditious which induce pain are, however, merely secondary in their nature, yet, in order to make our study complete, it has been necessary to consider them at some length.

XVII.-TIIE PERIOSTITIS OF THE HEREDITARY SYPIILIS OF INFANTS.

In our previous study we have found that periostitis, as a complicating lesion in hereditary syphilitic children, occurs quite frequently. Thus, in the complex lesion of the fingers, it plays an active part; it is also the essential lesion in the nodes of the cranium; it is developed, as a concomitant lesion, to $\dot{\mathbf{a}}$ greater or less extent, in the diaphyso-epiphysal swelling, and in the separation of the segments attains considerable extent. Yet we have not met with any case of its derelopment in the form of distinct circumscribed swellings along the shafts of the long bones, after the manner observed in acquired syphilis, and also as observed in late hereditary syphilis. This form of swelling is admitted by many authors; but, as I have shown by giving all the cases, not one of which contained an instance of such, it is fair to presume that it is rare. Mayr ${ }^{1}$ distinctly says that he has seen such swellings, and many other anthors speak to the same effect. Yet, as cases are not brought forward, I am disposed to think that allusion has been made to swellings of the diaphyso-epiphysal junction, or perhaps to nodes. As I have already stated, Bertin ${ }^{2}$ says he has seen cases of periostitis and of exostosis, and, as an example, details a case of osseons swelling at the great trochanter of the femur. Indeed, I am in accord in my views with those of Mr. Jonathan Hutchinson," who has studied infantile syphilis with an unusual care and zeal. He thinks that periostitis, rare in infancy, is quite common in childhood. The very severe and extensive osseous lesions formd after death by Wegner and others were chiefly those of

1 Ueber Syphilis hereditaria, Separat-abdruck ans dem Jahrbuche für Kinderheilkunde. Wien, 1862, page 7.

2 Op. cit. p. 360.

sew Facts and Opinions as to Hereditary Syphilis. London Hospital Reports, vol. ii., pages 175 and 176. London, 1865 . 
the points just alluded to; but the former says that he found localized periostitis, and, as we have already seen, he observed this lesion in a very peculiar and diffuse form upon the cranial bones. Althongh in some of his cases this inflammation is described as involving the greater parts of some of the shafts, it was in reality only a complication and perhaps an extension from continuity of surface of the epiphysal lesion, and did not exist unconnected with it. In a recent work on infantile syphilis, M. Violet ${ }^{1}$ gives the statistics of the service of M. Gailleton in the Antiquaille IIospital of Lyons for a period of one year, in which he made autopsies upon thirteen syphilitic children, besides which he gives five made by his friend.M. Poncet, making a total of eighteen cases. Out of this number he fonnd the diaphyso-epiphysal lesion six times; but makes no mention of having observed any periosteal swellings. Clinically, the lesion in the form spoken of is rare, though of course it may occur. I hope to be able to show, in a future work, that periostitis of hereditarily syphilitic children, as of adults, is not at all uncommon, and that it may then reach an excessive development. We shall see further on, as indeed we have already known in a negative way, that in infants the lesion is of a proliferating variety, or rather that it is a simple hyperplasia of periosteal tissue, but that the lesion of older subjects may be accompanied by gummy infiltration, thongh it is very often wholly of the hyperplasic form. It is evident that Lancereaux ${ }^{2}$ has not observed periostitis in hereditary syphilis, as he makes no mention of it, but he speaks in the first edition of his work of having once observed the peculiar separation of the epiplyssis, such as we have studied. Considering the attention which this observer pays to the study of morbid anatomy, his silence on this particular point is significant. Very recently Poncet ${ }^{3}$ has pnblished the result of his in restigations into the bone-lesions of hereditary syphilis. Out of twelve cases he found the diaphyso-epiphysal lesion nine times, and he confirms the observations previously made. He does not speak of periostitis in an uncomplicated form.

1 Étude pratique de la syphilis infantile, page 44. Paris, 1874.

Traité historique et pratique de la syphilis, page 550. Paris, 1866.

'Progrès Médicale, page 237. Paris, 1874. 
XVIII.-TIE EFFHC'S OF THE OSSEOL'S LESIONS LPON THE ULTHMATE STRUCTURE AND SHAPE OF THE BONES.

As can be readily seen there are certain difficulties, and I might almost say impossibilities, in tracing the results in later years of the lesions of the bones with which the infant was afflicted. Yet a determination of their condition after the subsidence of the lesions is a study at once interesting and important, as from it we may deduce facts or indications both as to treatment and prognosis.

The recent very able and exhanstive clinical and experimental researches of Ollier,' and the clinical studies of Poncet, ${ }^{2}$ have done very much to increase our knowledge of the effects of inflammation, in its rarious stages, upon the growth and derelopment of bones. These studies may be practically applied to the eases under our consideration. One of the main points which these anthors have proved is, that inflammation withont destructive change taking place at the junction of a shaft with its epiphysis, results in angmented growth and length of the bone. Several of the foregoing cases are peculiarly appropriate examples for the determination, clinically, of the truth of this view or hypothesis. My observations of the cases, with a few exceptions, have been confined to the period of existence and decline of the osseous lesions, a period at which conclusions canuot be drawn.

I am inclined to think, however, that it will be difficult to settle this point satisfactorily in the long bones, as the lesion is so often developed symmetrically; whence it results that we have no proper standard of comparison, and also because the amount of increased growth must, under any cireunstances, be scarcely appreciable. I examined my second case a year after the cessation of the morbid processes, but could not discover any increase of length. It is very probable that if the lesion is treated early and efficiently, no appreciable change will be induced, but that, if allowed to run its course, it will exert an influence over the future size of the bone.

Inflammation with destructive change at the diaphyso-epiphy-

1 Traité experimental et clinique de la régénération des os. Paris, 1867.

${ }^{2}$ De l'ostéite envisagée au point de vue de l'accroissement des os. Gazette Hébdomadaire, Nos. 42, 46, and 49. Paris, 1872. 
sal junction is known (having been proved by these observers) to produce arrest of development longitudinally. Therefore, in the case of separation of these seginents, we shonld expect that, as the inflammatory processes are serere and destructive, the influence upon future growth would be proportionately manifest. This point is of especial interest in the question of prognosis. It prompted me to follow up the little patient in whom this lesion was so well nlarked, and two years and a half after her cure I examined the bones of the legs carefully; but could not perceive that an arrest of development, however trifling, had been induced. As eompared with the length of the wther long bones, these scened normal, the child being fully as tall as it should have been at the age of three. I am inclined to think that the prompt and efficient treatment instituted averted such structural ehanges as would have interfered with the future growth of the bones. As we know that bone is constantly formed, during its periods of development, by the ossification of a layer of cartilage of greater or less breadth which exists between the shaft and the epiphysis, and which is probalbly replaced as fast as used up by cell-growth from the proximal end of the epiphysis, it perhaps happened that; in this instance this layer was not wholly destroyed, or that it was replaced in the natural condition, and that the process of ossification began again in a normal manner from the shaft. IIad it happened, however, that a bony cicatrix had been formed at this point, it can be readily seen that all future ossification and longitudinal growth would either have ended, or that it would have been very slight. This explanation is, I think, the most rational of any which can be given, and is in perfect accord with our physiological and pathological knowledge. It is now a definitely settled fact, that chronic inflammation alone of the shaft of a bone may eause its elongation. As we have found such inflamination affecting the metacarpal and metatarsal bones and phalanges, we should natmally look for such a sequela. As these bones also have an epiphysis, and as their whole length is usually involved in the inflammatory process, it is probable that the increase of their length is due to two canses; first, the inflammation of the diaphysis; second, that of the epiphysis. In my case, number six, the lengthening of a phalunx was fully one-eighth of an incli more than normal, the result of 
an inflammation of six mouths' standing. For so short a bone this increase is certainly very considerable. I have seen an instance of a phalaux being enlarged longitudinally fully half an inch in a patient fourteen years old, the victim of hereditary syplilis. The case was shown at the February meeting, 157t, of the New York Dermatological Society, by my friend Dr. E. L. Keyes. It also presented other very interesting osseous lesions. The inflammation of the shaft, however, may be attended with considerable destructive change, and still increased length may result. I have learued from observation of my cases that, in every instance in which chronic inflammation has inrolred a shaft, increased length of the bone does not necessarily result. Thus, I have seen two instances in which, after the cessation of the cluronic inflammation of a short bone, its length was materially shortened, and this withont any destructive change. Perhaps this feature is to be explained by the fact that the cartilage at the end of the shaft was very early and rapidly ossified, and thus that thereafter the ossific matrix was not in the condition for copious bone-proliferation.

Increase of diameter will also be observed in some cases, the amount of which will vary with the duration, and perhaps intensity, of the inflammation. In the cases of the phalanges, metacarpal, and metatarsal bones this feature can be rery well obserred. When the irregular bones have been enlarged, their ultimate condition may be that of greater or less enlargement, seldom that of very marked diminution.

These, then, are the main sequelæ of these bone-lesions of children. But what has thus far been said, refers in the main to instances of inflammation uncomplicated witl destructive change. When necrosis or caries complicates the inflammation, the ultimate result varies with the extent and situation of the process, of which it may be said succinctly that deformity and diminution of size are the result. Thus I have seen a metacarpal bone very much attenuated at its centre, a phalanx flattened laterally, and a tarsal bone rendered smaller and irregular in shape. In the one instance of nodes upon the cranium, there was a decided loss of tissue. Now it is necessary to state here, in anticipation, that these sequelæ result from an inflammation which is more closely allied to the simple form than to syphilitic inflammation. In the early stages of hereditary syphilis, the 
osseous lesions are nsually unattended with the proliferation of gunmy or granulation-tissue, and, as has been said, partake in their nature of the character of simple osteitis, consequently having their sequele similar to those of this latter affection. Later on in hereditary syphilis, however, the proliferation of gramulation-tissue becomes a complicating part of the process, when, of course, the sequelæ are different. Thus, whenever this tissue is proliferated, there is a liability to its degeneration, as also to its final absorption; in which events destruction of the hones, of greater or less extent, result, when the sequela may be summed up as a loss of tissue. In these cases the inflammation is generally of a mild character, and the sequela of the more simple form of the process, such as lengthening of the bone, are not generally induced, though of course, in exceptional cases, they may be. In some instances, somewhat rare however, of infantile bone-syphilis, gummy tissue is proliferated, in which cases the final condition of the bones would be such as has just been stated. This fact, as to the difference in the nature of the lesion in early and late hereditary syphilis, is only introduced here incidentally to render intelligible this portion of our study ; a fuller consideration of it being reserved for the section treating of pathology.

In the consideration of these sequelæ, it is interesting to bear in mind that they are, in many instances, to a great extent, if not indeed wholly, preventable by the early adoption of an appropriate and active treatment: a fact upon which attention should be especially invited, as pointing to the prevention of degeneration and deformity of the bones.

Bonchut ${ }^{1}$ speaks of an extraordinary hardness of some of the long bones which he has found in syphilitic ehildren either prematurely born or at term, a condition which he attributes to an abnormal aetivity of development, and which process, he thiilks, is of the same category as the plastic infiltrations into the other organs. I have been astonished at the harmony of statement of a number of observers who deny the syphilitic nature or origin of this condition. Waldeyer and Köbner say positively that they have observed the same state of the bones of children

1 Traité pratique des maladies des nouveaux nés, des enfants à la mamelle, et de la seconde enfance. Sixième edition. Page 1061. Paris, 1873. 
who were not syphilitic. It is probable, then, that this condi. tion is not at all due to syphilis, though it suggests the point, that, in consequence of inflammation of the bones of hereditarily syphilitic children, we may have a sclerosis of the tissue resulting as a sequela; but in that event, it must be subjoined that there wonld be nothing specific in its nature, as this condensation of tissue is one of the recognized results of erery variety of inflammation. I hare no doubt that it existed in several of the bones which I have seen after the cessation of the inflammatory process, bnt owing to their sniall size I was mable to determine the fact. We may, therefore, add to the other sequelæ of these osseous lesions, a sclerosis of the bones.

\section{XIX.-THE PERIOD OF INVASION OF TIIE OSSEOUS LESIONS.}

The facts which have been olserved by Wegner and Waldeyer and Köbner prove beynnd a possibility of doubt that the bones are affected by syphilis in intra-nterine life, it being very probable that the syphilitic impress is stamped upon their derelopment just at the time when it is most active. Since, in clinical practice, we find, as a rule which can be laid down with considerable precision, that the swellings of the bones appear shortly after birth, so it may be that the cell changes which constitute them begin before birth, thongh but recognizable, or recognized, some time after. Ont of ten of my cases the existence of osseons swellings was noticed in six at about the sixth week of life; and this was about the period at which similar lesions were observed in the cases of Ranvier, Archambault, Bärensprung, Bertin, Fournier, Valleix, Bargioni, and in Bulkley's first case. In one of these the period was three weeks, and in another thirty-six days. In two of my cases the swellings were not observed until the child was three months old, while in Bulkley's second case the child was fifteen months. These figures indicate clearly the rery early development of this morbid process, and suggest what we shall find is borne ont by pathological histology, that it is essentially connected with the development of the osseous system, and is consequently most prone to appear early in life, when this svstem is undergoing the most active morphological changes.

In the cases of Wegner, Parrot, Waldeyer and Kōbner, Valleix and Bargioni, as has been said before, the swellings were 
found either in still-born children, at birth or shortly after. They were very extensive, and were complicated in nany instances with profound degenerative changes. The children were afflicted with the sererest form of syphilis, the visceral lesions being very extensive. Wherefore, we must take these as exceptional cases; as examples of the severest form of this syphilitic lesion; and must attribute the somewhat precocions evolution of the enlargenents to the great activity of the disease. The cases, such as we are likely to meet in elinieal practice, and which nay be considered as typical in their nature and course, are my own and those of Ranvier, Archambanlt, Bertin, and Fournier. It is a fact of some importance, that in the greater number of cases in which the lesions appeared at about the sixth week, the swellings were more numerous and more symmetrical than those which appeared later. A comparative perusal of the cases will bring this point ont clearly. We, therefore, may lay down, as a rule, that these osseous lesions are developed at about the third to the sixth week of life, or that period in the history of hereditary syphilis when, in conseqnence of some mexplained eause, we notice an explosion or rather general manifestation of syphilitic lesions and symptoms, in a child who previously, perhaps, had shown no evidences of the disease; that, in a smaller number of cases, these osseous affections may develop late in the first year, and even during the second or third; and that, in these later periods, there inay be, and usually is, an absence of symmetrical distribution, with a number of swellings much less. There may, howerer, be exceptions to these last qualifications. We are nnable to offer an explanation of the fact of the limited extent of developinent of the lesions at this age of the ehild, except it be in the waning power of the virus.

Passing beyond these years we may find these inflammatory or irritative lesions, but the rule is then that they appear of another order, and, in fact, essentially the same as those of late acquired syphilis.

XX.-CAN SMMLAR OSSEOUS LESIONS BE DEVELOPED IN ACQUIRED INFANTILE SYPHLIS?

We come now to a point in the etiology of these bony tu mors which is of the utinost doctrinal importance, as well as of 
practical interest. Thus far, I have always alluded to hereditary syphilis as their cause; now the question arises, can they be developed in the acquired syphilis of infants? Let us look at this question in a comparative light. An infant who has been born in a healthy condition, and who afterwards becomes infected with syphilis, is certainly not as profonndly syphilitic as one who inherits the disease, and who may be said to have never possessed an healthy organism and nutrition. In the first instance, it is probable that the manifestations of the disease would be mild and superficial, and would only involve a limited number of tissues, while, in the second, the extreme of the manifestation might be looked for. So that we should expect, by analogy, that tissues which usually escape in mild forms of syphilis, might escape in this instance. Other than this, I know of no reason for assumning an immunity to bone-lesion in acquired infantile syphilis; on the contrary, our knowledge of the malignant type which this disease sometimes assames in its acquired form in the adult, points ont to us clearly that it may likewise invade the more delicate and immature organism of the infant; so that I think there is no lesion of syphilis which may not be developed in the infant who has by any chance acquired the disease. As these lesions are intimately connected with the natural morphological conditions of the bones, it is necessary for their derelopment that the child should not have reached the age when these changes have ceased, at which time, of course, it would be no longer susceptible of morbid impress. I take the pains to consider this subject at some length for the reason of its intrinsic interest, and also from the fact that such eminent observers as Waldeyer and Köbner assert that this form of lesion is the exclusive appanage of hereditary syphilis. I think that these observers have arrived at this conclusion from the facts, first, that they are disposed to regard such swellingo, when they occur later than the early months of life, as due to rickets ; and, secondly, becanse at the autopsy of a case of syphilis acquired by vaccination, Köbner ${ }^{1}$ fonnd that the osseous system was normal. I think I can show that they are partly mistaken as to their first reason, and I shall certainly show, by

1 Die Übertragung der Syphilis durch die Vaccination. Archiv für Dermatologie und Syphilis. Zweites Heft, p. 147. 1871. 
the details of two cases, that similar lesions of the bones have been found in acquired infantile syphilis. In the entire range of medical literatmre I am able to find but one recorded case; though, of course, others must have occurred that escaped observation; my eighth case being the second example. These two cases will show beyond a doubt, I think, that these irritative or inflammatory bone-lesions may be caused by acquired syphilis. The first case is that of Roger, the details of which have been given already. The sitnation and course of the osseous lesions in this case are such as show clearly that they belong to the same category as those of all the other eases. It will be noticed, however, that althongh symmetry of development is shown, there is not that tendency to a general distribution which some of the cases show so clearly. In my eighth ease the lesions were of the inflammatory order peculiar to those of infants, and though identical bones were not symmetrically involved, there is an evident invasion of the bones of both sides of the body, showing a tendency to symmetry. Summing up these two cases, thell, and comparing them with the typical ones which we have studied, we observe that the lesion is of the same inflammatory nature, and shows the same tendency to involve the diaphyso-epiphysal junction of long bones, and the whole length of short ones, in the same manner that we observe in infants. We may assume, then, that the processes are identical; whence these cases prove conclusively that these peculiar osseous lesions may result from both the hereditary and acquired syphilis of infants. It is almost needless to call attention to the fact that the lesions in these cases did not resemble, either in their erolution, course, or decline, the bone swellings due to gnmmy infiltration. It may happen that hereafter cases will be found of acquired infantile syphilis, in which the distribution of the lesions is as general and symmetrical as those of the hereditary form. This condition would undonbtedly be dependent in a great measure upon the time of development of the lesions. Thus, if the infection occurred soon after birth, the lesions would, perhaps, be similar in their distribntion to those of hereditary syphilitic infants, for at this time of life the osseous growth is most active; should, however, infection occur later, a more sparse and unsymmetrical development wonld, perhaps, result. This view is drawn by analogy from onr knowledge of 
the course of the lesions in hereditary syphilis, and of the mode of development of the osseous system. We inust also take into consideration, as regards the less pronounced character of the lesions, and their comparative infrequency in acquired infantile syphilis, that the infection is very probably much less intense than in the hereditary form. Again, there is another point of much importance in this connection, namely, that of the greater or less tendency, or even immunity, to the action of syphilis possessed by the infant.

XXI.-TIIE INTENSITY OF STPIILIS IN THOSE CASES IN WHICH OSSEOUS LESIONS ARE OBSERVED.

The histories of all of the cases, withont any notable exceptions, show that the concomitant manifestations of syphilis upon the organism generally, and upon other tissues than that of the bones, were well marked; proving that the disease was in a quite active stage. As the concurent testimony of all the cases points so clearly to this fact, it is unnecessary to dwell any farther upon it; and I think we are warranted in drawing the conclusion from it, that, in infantile syphilis, osseous lesions are generally met with in those cases in which the disease, if not severe, is yet active. It is almost unnecessary, however, to state, that even in this severe or active condition of syphilis, osseous lesions may not develop, as it is quite probable that they will not be observed in very mild cases; yet can we not insist very strongly on this point, as some of the preceding cases were certainly not very serere. The cases of Wegner, Waldeyer and Köbner, and Parrot were of the most malignant form, the superficial and visceral lesions extensive, and the osseons lesions of the most marked type; insomuch that it would seem very probable that the extent of distribution and severity of the latter lesions are materially influenced by the more or less malignant character of the disease which they manifest. The same remarks apply, of course, to every other variety of lesion. Diday, ${ }^{1}$ when he wrote his book, seemed evidently surprised at the immunity of the osseous system in infantile syphilis, and allndes to the vital hyper-activity of this system at the earlier periods of life. We are now in possession of facts which show that this im- 
munity does not exist, and have engent reasoms for believing that the morphological activity of the osseous system tends serionsly to predispose it to syphilitic modification. Behind all these conditions, namely, of intensity of the virus and active morphological change, there is a point of very great interest to be remembered; it is, that in some individuals there are local tissue tendencies to abnormal cell-proliferation, and such may enter as a very serions modifying influence in the production of the bone-lesions. Such tendencies to hyperplasia are commonly seen in children, affecting all tissues and organs, a point of no little importance in forning onr conclusions, prospective or retrospective, in cases of the sort. The condition just alluded to is generaily spoken of as scrofula, but under whatever name it is considered, certainly must be conceded to exercise a powerful influence on the course of inflammations in children. I an inclined to think that this tendency. existed in my elerenth case, in which separation of the epiphysis occurred; for the cutaneous lesions were of a very mild eharacter, and the general condition of the infant did not indieate a profound cachexia. The scope and purpose of this treatise does not permit me to consider this subject more fully; so that I have to confine myself to a simple mention of it.

\section{XXII.-THE CONDITION OF THE SYPHILIS OF THE MOTHERS IN}

WHOSE INFANTS OSSEOUS LESIONS ARE OBSERVED.

The question of the intensity of the syphilis in the child brings ns to the consideration of one of the final points in the clinical history of these osseous lesions; what is the condition, as regards syphilis, of the progenitors. of these children? Knowing, as we do, that the recent development and the severity of the syphilis of the mother tend to prodnce severe syphilis in the child, we might summarily pass over the etiology of these lesions by briefly saying that they were undoubtedly an expression of a severe form of syphilis in the parents. But I think that, as we have facts from which to draw conclusions, it is well to bring them out, and endeavor to establish their bearing in this matter. I shall not introduce the rexed question of the influence of the syphilitic father upon disease of the child, as it is still an unsettled point; one, besides, which has recently been very ably handled by my friend Dr. F. R. 
Sturgis,' and also been treated of at some lengtl in France by Miremr, and, quite exhaustively, in Christiania, by Oewre." My remarks and conclusions will be based upon the history, as far as obtainable, of the syphilis of the mothers of the children whose cases I have detailed.

Of my twelve cases, the mothers of three of the children had been syphilitic fully two years; one of them was at the end of her first year of syphilis; three were infected at the fifth month, and two became syphilitic at conception. The case not included in this category is the one of acquired syphilis, and will be treated of separately.

Comparative analysis of these cases shows us rery clearly that a recent infection and serere form of syphilis in the mother were attended by extensire and profound osseous lesions in the child; but we cannot also deduce the antithesis of this proposition that a quite distant infection and a mild form of the disease were attended with osseons lesions limited in extent and severity. The ninth and tenth cases show clearly the weight of the first assertion. The mothers became syphilitic at conception, and, although the disease was active, were not treated, while the children had extensive osseous lesions, complicated with severe degenerative changes. The three cases in which infection of the mothers occurred in the fifth month of preguancy, show osseous lesions of a somewhat milder form. In one of these cases degenerative changes occurred, but they were not as severe as they were in those cases, nor were the lesions nearly as extensive. The mothers did not undergo treatment. In another of this second series the mother was negligently treated for about three months, and the lesions, though numerous, were of the resolutive variety. The third of this group is the one most marked. The mother of this child gare evidences, during her pregnancy, of severe syphilitic lesions and profound cachexia, and I felt apprehensive that her child would be still-born. She followed quite regularly, under my instruction, an active treatment, and, thongh her child showed

\footnotetext{
'On the Etiology of Hereditary Syphilis. New York Medical Journal, July, 1871, and July, 1873.

${ }^{2}$ Essai sur l'hérédite de la syphilis. Paris, 1867.

- In a series of three articles published in the Nordskt Medicinskt Arkiv, for the years 1871-72 and 73 .
} 
severe syphilitic manifestations, they were not as bad as I should have expected, and the osseous lesions were not as numerous as in the other cases, exhibiting no degenerative tendeney. When all the symptoms of the mother of this child are compared with those of the mothers of the first group, it can be readily seen that we have every reason to think that, unless treatment had been followed, the osseous lesions would have been equally as profound as in the children of the first series.

The lesions of the children whose mothers had been syphilitic from. one to two years, show no well-marked characteristies, except that perhaps they were rather more extensive than might have been expeeted to ocenr at the rather late period of the infection. They did not show degenerative tendency, but in some instances were quite as numerous as those resulting from recent infection. An important point here presents itself, and one which we must not lose sight of, namely, that the mothers were scarcely, if at all, treated, and we have every reason to believe that, if they had been, the children might have escaped with perhaps an almost uncontaminated organisn. The eleventh case also belongs to this category, and is interesting in the fact that the child's syphilis was not manifestly very active, thongh born of a mother within the second year of her disease, which had not been properly treated. In this instance, I thonght that there was an inherent tendency in the child to tissue degeneration. These cases show clearly that a remote period of infection of the mother does not give to her offspring a total inmunity to the development of syphilitic lesions, including those of the bones. However, some of these cases are what inas be called examples of remote contagion. We, to-day, recognize clearly the fact that, within a period of one year and a half or two years and a half after syphilitic contagion, there is engrafted upon the organism a tendency to the development of its peeuliar hyperæmia and hyperplasia, which we speak of as syphilitic lesions. After this time, this tendeney, we know, may gradually cease and even become extinet; yet are we unable to lay it down as a law, at what period this extinction ocenrs; consequently, as the tendency to the development of these lesions is transmissible, we cannot say when this transmissibility also ceases. We know that this peeuliar proliferative action 
is greater and more lasting in. some persons than in others, but are unable to assign any reasons more exact of this variation than those herein already giren. Some mothers, whose nutrition may not be affected by syphilis, may, and we see such cases very often, transmit children, who have a like immmnity. As we have no other reliable records of cases, we must assume, judging from our present knowledge, that the tendency to the transmission of serere forms of syphilis with osseons lesions is confined to the early years of the disease in the mother, and that, as her tendency to hyperplasia and hyperæmia wanes, so will it gradually become less apparent in her offspring. As I have said before, we cannot lay down any rule, except, perhaps, that, after the fifth or sixth year of contagion, hereditary transmission of syphilis in the form of grave lesions ceases, or manifests itself but very feebly. The dates, as far as given by other observers, show that the contagion was quite recent in most of the cases, and in none of them very remote. This point is one of great importance, and one which will well repay acenrate clinical observation and stndy in the future.

There is, in this matter of the transmission, one point which has been well brought ont by one of my cases, and, in a negative manner, by nearly all the rest; I mean, the value of treatment. This caunot be too much insisted on in the cases of pregnant women as tending to insure a healthy organism in the foetus. The development of the osseous lesions in the child four years and four months old, who was the subject of acquired syphilis, is an instance of the disturbance of normal nutrition by the syphilitic virus; but this lesion was simply a proliferative one, such as we see very frequently in the early stages of acquired syphilis; a mere thickening of the fibrous tissues of the joints and bones, and not proceeding from gummy infiltration, as manifested by external and other symptoms. This case and that of Roger, as has been said before, prove clearly that syphilis may induce the same developmental changes in the bones in its acquired as well as in its hereditary form. This peculiar condition of the system, in which predisposition to active abnormal cell-proliferation may exist in the mothers, and may then render their disease grarer in character. The transmissibility of this condition with syphilis to the child, and the effect of the two mpon-its organism, are points in pathology of 
rery great import, worthy of attentive observation and reflection. It might also be desirable in such an investigation to consider the age of the mother, as we know that a very young organism is usually more sererely affected by syphilis than a mature one. The fact of the youth of the mother rendering her syphilis more severe, makes it probable that the disease in her offspring would be equally so. This was suggested to me by my eleventh case, in which the mother received the contagion in her serenteenth year, in whose child was found a tendeney to active cell-proliferation.

In order that a clearer view may be given of the comparative condition of the syphilis in the mothers and children of my cases, I will here, in parallel columns, oppose the main facts of each instance.

MOTHERS.

CASE 1. Mother two years syphilitic; rather mild form of disease. No treatment.

Case 2. Mother two years syphilitic; apparent waning or and symmetrical. running out of the disease. Treated for short time.

CASE 3. Mother infected at fifth month of pregnancy; treatment for three montlis; syphilis severe and not sufficiently modified by the mercury.

CASE 4. Mother within second year of syphilis ; 10 regular treatment; form of disease in crops. not especially severe.

CASE 5. Mother nearly a year syphilitic; disease not of grave form; treatment for three months.

Lesions in child were not extensire, but underwent degenerative changes. Infant's health not bad.

CASE 6. Infection of mother Lesions in child not extenat sixth month of pregnancy; sive, but underwent degenerarather severe form of disease; tive change.

no treatment. 
CASE 7 . Infection of mother at fifth month; severe form of sive, nor symmetrically dis disease; active and regular tributed; mild in type. treatment.

Case 8. Acquired syphilis.

Case 9. Mother infected at the beginning of pregnancy; disease rather severe; no effi- eration. cient treatment.

CASE 10. Mother infected at the beginning of pregnancy; treatment (not active) for two months.

Case 11. Mother syphilitic fifteen months; no treatment; disease rather mild of form; probable strumous tendency.

CASE 12. Syphilis of mother not active; no treatment.
Lesions may be classed as being moderately severe.

Lesions extensive and symmetrical, followed by degenLesions in child very extensive; underwent profound degeneration.

Syphilis of the child not very severe; a limited number of bones affected; degeneration of osseous lesions probably induced by struma.

Lesions of child mild ; limited number of bones affected.

\section{XXIII.-PATHOLOGICAL ANATOMYY.}

WE now come to the consideration of the nature and character of these osseons lesions, and, in order to clearly and correctly understand them, it is necessary to recall to mind the minute changes which take place in the development of bone, as these affections are, in the main, deviations of greater or less extent in the course of the normal growth of that tissne. These changes we have fonnd to be seated in two distinct portions of the bones; at their ossifying ends, and on their surfaces: consequently, as the conditions of derelopment are somewhat different, we shall have to study them separately, beginning with the lesions of the diaphyso-epiphysal junction.

Normally, there exists at the end of the spongy portion of the shaft, and between it and the cartilage, which may be permanent, as in the ribs, or temporary, as in the other long bones, a narrow line of cartilage, somewhat lighter in color than the rest, which can only be detected by careful examination. This line 
is very narrow, being the laver called by Guérin the couche chondrö̈le, and in it take place the processes which precede the formation of bone. It extends transversely across the end of the bone, either in a straight line or in a curre. The ossifying process may le briefly described as follows: At the distal end or edge of this layer the cartilage cells are found to be enlarged, flattened, and placed the one on top of the other, in such a manner that they appear as if arranged in so many vertical lines. The tissue on each side of these lines is the cartilage matrix, forming a framework or trabecula, from which thin processes of this tissne pass between each flattened cell. This prolongation inwards, howerer, is exceelingly thin, and, as we approach the bone, becomes gradually thinner, until finally, from the very close approximation of the cells, it disappears altogether. Passingr down towards the bone, we find, of course, that the cells are packed more and more closely together, so that at last they touch, and leare no interrening tissue. But between the rows of cells in the longitudinal direction the cartilaginons trabeculae continue to exist; but near the bone, that is, near the proximal edge of the layer of Guérin, it is noticed that these becorne slightly granular, being here cartilage which has become calcitied, from the deposit of lime salts. Following the cells up torards the bone, we observe that near it they lose abruptly their peculiar character, becoming large, granular, and terminating in processes, varying in length, and somewhat caudate. Then, examining the condition of the parts, just as the cartilage and bone meet, we find that the trabeculæe have become firm, and here consist of a tissue ready to be converted into bone. They are more susceptible of color from carmine here than further on, and this shows that it is a nascent tissue. On examination, these trabeculæ are found to form canals which run chiefly in the longitudinal direction, thongh some transversely. Within these channels, or medullary cavities, we find the peculiar granular cells which are called osteoblasts, arranged in concentric circles; and into these also project the vessels, which are developed from the spongy substance of the diaphysis. So that, to sum up, we have in this region, as factors of the future bone, a calcified matrix perforated by canals or medullary cavities which are filled with osteoblasts or cells, which then undergo change, and, it is probable, form the 
lacunæ and also vessels in abundance. Some text-books on histology give very clear illustrations of this process. Thungh we cannot state precisely the exact changes, yet we know that it is upon the calcified matrix, the cells, and vessels, that the formation of the bone depends. In the healthy state the line of demarcation between the eartilage and the spongy bone is sharply and accurately marked. In syphilitic infants, as we shall find, this condition is very much altered.

In giving the description of the pathological changes, I have thought it best to follow Wegner in his division of the subject; but the appearances I give as observed by inyself, as in some minor points we are at issue. He describes three stages of this affection of the ossifying process. In the first stage, if the bone be examined with the naked eye, it is seen that the line of Gnérin is not as even and regular as normal, but somewhat wary and irregular; it is perhaps twice thicker than usual, being, we assume, from a half to a line in width. It has a white shining or whitish-red color, and is compact of structure. Under the microscope, the abnormal width is clearly seen. The cartilage cells are found to be proliferated in an musually abundant manner. The lesion is then in this stage simply an exuberant cell proliferation, without corresponding ossification. In the second stage, we observe that the line of Guérin is rather more uneven in its relation to the epiphysal cartilage; that it is nodulated; and that there are warty or papillæ-like processes of calcified cartilage projecting into the distal hyaline matrix. Wegner compares them, from their broad bases and tapering ends, with the papillæ of the cutis. Between these papillæ, if we may so call them, in the hyaline cartilage, we find spots of lime appearing like isolated clusters of calcified cartilage. On the periphery the infiltration encroaches further into the cartilage than at its centre. Then, when we examine the relations of this calcified line to the spongy bone, we find corresponding depressions into which the spongy tissme passes. When a section in this stage is examined under a lens of three hundred diameters, we observe that the longitudinal rows of the cartilage cells are more abundant than in the first stage, and that there is rery little intercellular substance. The vessels are abundant, and their canals at the ossifying line are surrounded by a considerable quantity of 
connective tissne. The walls of the eavities are broader at their bases, and are sclerotic. In many places an osteoid substance is developed from the cartilage, and from the medulla which enters with the ressels. This substance is found to be in some places true bone, which passes into the spongoid layer. Beyond the layer of Guérin, we find irregnlarly distributed spots of calcified cartilage, forming a zone of considerable breadth.

The principal points in the second stage, then, are greater pro-

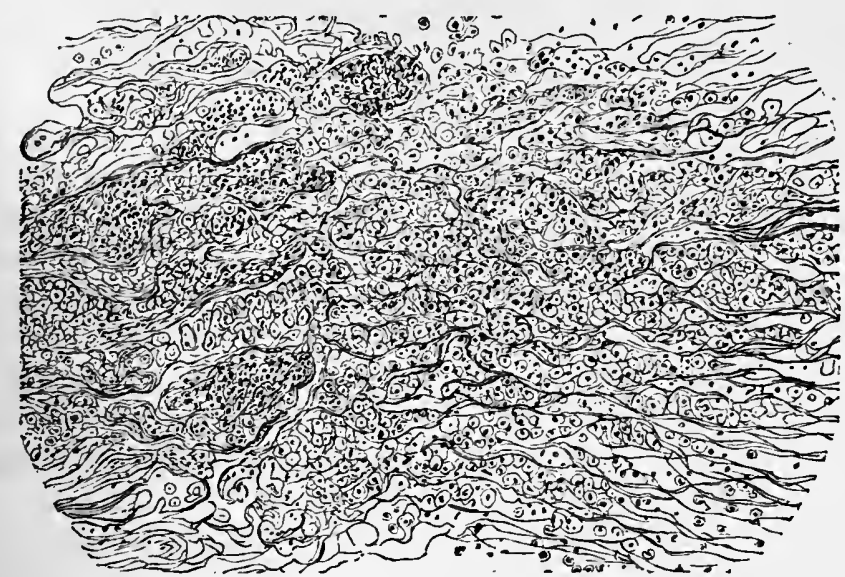

liferation of cartilage cells, premature sclerosis of the intercellular substance, formation of bone in the form of processes beyond the normal layer, and delay in bone formation elsewhere; in other words, irregular osteogenesis, abnormally premature in some spots, in others retarded. In the third stage, there is a general enlargement of the epiphysis, with a thickening of the perichondrium and periosteum. Under the microscope the following appearanees are discoveralle: The lowermost layer of hyaline cartilage is bluish, transparent, moist, and swelling when cut. Then comes a layer irregular and wary, with serrated processes, exhibiting a grayish-white and homogeneons mass. This layer, though greatly altered, is brittle, and can readily be removed. Next to this comes a layer of grayish-red or yellow substance, soft, and sometimes viscid, which is gradually lost in the spongy substance of the diaphysis. The medullary tissue of the latter continues for a considerable distance further, and, instead of being of a normal 
red, is of a gray or grayish-red color. This layer seems to destroy the firm colnesion of the ephiphysis to the shaft. Uuder the microscope, we find, in this stage, that the proliferation of cartilage cells is greater, as is also the lime infiltration. In the layer nearest the bone we see nuclcated cells, a grannlar detritus, and spindle-shaped cells. In this, the third stage, the layer which is just described after Wegner, in reality consists largely of granulation-tissue. This tissue is formed at the end of the shaft in great abundance, and follows the ressels into the medullary spaces. Wegner does not consider it a granulation tissue, or at least does not say so. My sections show clearly that it is such, and Waldeyer and Köbner say that they observed this tissue. The changes may then be summed up as follows: In the first stage we have a simple liyperplasia of eells, with irregular deposition of lime salts; in the second, an intensification of this condition; and in the third, a new element, namely the abnormal proliferation of all the elements of the tissues, with an infiltration of granulation-tissue into the medullary spaces following the vessels. In the first stage we find nothing of this kind. This is the condition simply and succinctly stated. Wegner calls the process osteo-chondritis, and eonsiders it due to irritation which arises from the eondition of the blood. As such, it would not be a specific process ; but when we consider that there is proliferation of granulation-tissue, we must certainly regard this opinion as faulty. Waldeyer and Köbner do not, as I have said, partake of this view, but are disposed to look upon it as a specific process. Parrot rejects Weguer's view of the origin of the disease, not seeming to be aware of the views of Waldeyer and Köbner, and applies to it the name dystrophie syphilitique des os. As this simply means an abnormal condition of nutrition, it does not in any degree place the matter in a elearer light. He thinks that the process is not at all of an inflamnatory nature. When we examine this morbid process, we eertainly see an inflammatory condition in it; wherefore, on this subject there can be no doubt; so that I am disposed to look upon it as an exaggerated and perverted nutrition of these tissnes, in some instances complicated by the proliferation of a grannlation-tissue. Wegner thinks that he did not find many ressels in the region of cartilage thus affected, but Waldeyer and Köbner distinctly say they found them in abundance, and 
my own preparations lead me to coincide with them. Applying these details to clinical observation, I think we may assume that in the majority of cases of swellings at the diaphysoepiphysal junction, the morbid alterations do not pass beyond the second stage; consequently, that they are scarcely ever composed of grannlation-tissue. In the cases in which we found superficial destruction of the swelling, it is very probable that the necrosis was due to localized degeneration of the cartilage cell elements, and that the granulation-tissue was not formed. But in the cases in which there was separation of the epiphyses from the diaphyses, granulation-tissue was undoubtedly formed, which softened down, and then destroyed the continnity of the bone. Thus we have a envincing reason why the swellings rum the course which they are seen to take. The presence of granulation-tissue in this inflammation shows us its specific character, as we know that this is one of the constant prodncts of ssphilis. It brings to our mind the fact already elieited, namely, that its developinent in the bone lesions of infants is not as constant as it is in those of older children. Thus, in infancy, the lesion is of the inflammatory nature above described, superadded to which we have, in very marked and severe cases, granulation-tissue infiltration; whereas in bone lesions of older children we shall find that granulation-tissue is a very constant morbid product of hereditary syphilis. It is almost needless to say that mature granulation-tissue constitutes the so-called gammy masses. In the light of this knowledge, we must look on the eases in which granulation-tissue is formed as representatives of the most advanced of the morbid changes in children ; the simple form of inflammation is, however, the more common. It seems somewhat anomalous that the bones should not be invariably the seat of granulation-tissue infiltration, seeing that in the viscera of infants we so constantly find this tissue in great abundance.

Such, then, are the clinical facts as explained by pathology. The situation of these swellings being similar to those of rickets, it is easily seen how they might be, and have been, mistaken for that disease. We shall speak further on of the diagnostic points as observed at the clinie; here it is only necessary to allude to the fact, that in syphilis there is a superabundance of a calcareons deposit, besides the other morbid 
changes, while in rickets everything is normal, except that the cartilage cells are exuberant in quantity, and that tise cartilaginons trabeculæ are not calcified. Then, in syphilis the essential changes are strictly limited to the epiphysis, certain other changes being adrentitions and secondary, while in rickets the whole bone is involved, though the changes are most perceptible in this part. There is a pathological fact of some interest which explains a feature observed in the clinic, which is, that in many of the cases the changes in the bones are found in rarions stages of derclopment, some just beginning, and others fully formed; this accounts fur the variety of size in which we find the bone swellings.

The lesion upon the flat bones is periostitis, and this may be of the same rarieties as are found in the acquired syphilis of adults. In cases such as we shall nsually meet in practice, it is probable that the inflammation is of the proliferative or fibrous form, being then a simple periostitis. Though we should expect, from the general character of the osseous lesions in infants, to find the periostitis, as a rule, to be of this variety, though really of an inflammatory nature, there is every reason to beliere that we may also find the gummons form of periostitis. This difference is, howerer, simply one of degree; the first is a hyperplasia of the normal tissue of the periosteum, while the second is the same process complicated by the additional proliferation of a granulation-tissne. We have found instances of this gummous form of periostitis as detailed in the various cases of Bargioni, Parrot, Bärensprung and Desmares; but these cases are examiples of the most serere and fully dereloped type of osseous lesion, similar in character to those in which we find separation of the epiphyses from the diaphyses. In one of my cases large nodes were found, upon the resolntion of which a loss of tissue was observed. This condition points to the existence of an infiltration of grannlation-tissue, and its snbsequent fatty change, with absorption of it and the normal cells of the texture. Wegner found very frequently proliferating periostitis of the skull, and in one instance general hyperostosis. Thus, then, we may conclude in the majority of cases, such certainly as are usnally met with in clinical practice, that the lesion will be fonnd to be a simple proliferating periostitis, but that in exceptional ones we may find the 
gummous form. In the latter there may be great destruction of bone and of the investing integmment.

The morbid anatomy of periostitis has so often been described that I think it superfluous to go minutely into its consideration here; on which account I confine myself to a general sketch of the sulject.

We have found in the clinical part of our study that periosteal swellings of the shafts of long bones are not very common. Still, they may be met witl, and will be of either of the two varieties abore mentioned. In cases of osteochondritis of the bones we find well-marked thickening of the periostenm and of the perichondrium. This is usually limited to the focus of the lesion, and only exists as a complication; which we have observed to act in a very beneficial manner in those cases in which the epiphyses became separated. Here the proliferating process becomes very active, assumes an ossifying state, and, by the formation of a bony tube, prevents the total destruction of a member, acting as a splint.

The lesion is of a complex character when the phalanges and metacarpal bones become inflamed. We have no microscopic data upon which to speak positicely,so that we are forced to reason by analogy, as well as by the clinical history of the swellings. It is probable that the affection begins in the periosteum, and that the cell-genesis is very copious, since the size of the swelling is sometimes considerable. At the same time the cancellons structure of the bones becomes involved, and we hare. general enlargement of it. These two morbid changes involve also the nutrition of the cartilage of the epiphysis, and here also we have hyperplasia. Thus the condition is periostitis, osteitis, and perhaps osteochondritis. In such profound bone lesions, it is common to expect a considerable degree of subsequent deformity; and we have already called attention to instances of permanent enlargement, and also to hypertrophy in the longitudinal direction. In the small irregular bones the lesion is a cellular hyperplasia beginning probably at the centre of ossification, and consisting in a very active and exuberant proliferation of the cartilage cells. There is also a concomitant periostitis. In this form of inflammation, also, the periosteum plays an important part, as from it new bone is formed, which takes the place of that lost by softening, when such occurs, of the pro- 
liferated cell elements of the cartilage. The bone may remain smaller and perhaps distorted.

The periostitis, besides being of the simple or proliferatire and gummous form, may also be of the ossifying rariety. In fact, in some of the bones, the history of which we have studied, there has been this complication; and it is well to remark that we may expect to find it, secing that ossifying periostitis is a frequent sequela, or, in point of fact, the ad vanced form of the proliferative variety, when it runs a chronic conrse, and is not complicated by degenerative changes. Thus, it will be seen that in infants the whole structure of the bone is liable to inflammation. It may be limited to a region or a tissne, may involve more than one tissue, and, in point of fact, each and erery component tissue of the bones. The lesion is usually of an inflammatory type, consisting in a hyperplasia of normal tissues, and in cases somewhat exceptional, a new tissne formation is superadded, namely, the gramulation-tissue, and this complicates the other form of trouble. All of which lesions are intimately associated with, if not perhaps excited by, the activity of the nutrition of these structures, necessitated by the advancing requirements of the new being.

XXIV.-THE QUESTION OF THE RELATION BETWEEN RACHITIS AND SYPHILIS.

It is necessary, in order to render complete our study of syphilitic osseons lesions, to consider the relation between rickuts and syphilis. This question, thongh, in strict truth, a side issue, rather than a leading point, is rendered all the more worthy ofstudy by the fact that the riews generally held regarding it are not clearly drawn, and are wanting in scientific precision. By most authors the point is summarily passed over with the assertion that syphilis may cause rickets, learing the pathological relation of the two diseases wholly untouched. This is one of the many instances in medical science in which conclusions are drawn from coincidences, rather than from stndy, and a rigid induction of a number of cases. Now, it certainly does happen that children the subjects of hereditary syphilis become rachitic, but it does not necessarily follow that the latter condition was caused by the syphilis. It is somewhat surprising that so eareful an observer as Parrot should have fallen into this error. He 
reported recently a case of a child born syphilitic, who, when ten montlis old, became rachitic. The history of the infant in the interval is not given. In his deductions from the case, ${ }^{2}$ he, appears to think himself warranted in stating that syphilis may be eonsidered as one of the canses of rickets. The effect of snch assertions is to perpetuate error; indeed, the case of Parrot has already been quoted in an unqualified manner. Waldeyer and Köbner report a case of rickets in a syphilitic child; while Poncet, ${ }^{3}$ in an analytical talle of cases of infantile osseons syphilitic lesions, reports one in which rickets supervened.

Submitted to a rigid scientific examination, this question shonld be put as follows: Is rachitis one of the usual eonditions or lesions produced by syphilis? This brings the question to a scientific standpoint, while if it is put as follows: Can syphilis canse rickets? it is unprecise and not in accordance with onr advanced views. In the light of recènt knowledge of the pathological histology of syphilis, we know that there are certain well-marked lesions developed in the various organs and tissues by that disease; also, that besides producing these lesions, which may be considered specific in character, it may induce a general condition of cachexia. This latter condition may impair the funetion of organs, and induce disturbances of nutrition, which, though they owe their origin to syphilis, cannot be properly and scientifically called syphilitic. In the previons chapter we have found certain well-marked lesions, and both clinical and pathological facts warrant the assertion, that they are specific in character, peculiar to syphilis, and produced only by an active condition of that disease in the organism. When compared histologically, the lesions of rachitis and syphilis are found to be very dissimilar; now, as there are undoubted lesions indueed by syphilis, it certainly is fair to infer that lesions entirely different in character are not indnced by it. Then, again, looking at the origin of rickets, it is found to be a disease of development due to the absence of some of the component parts of the blood. This condition does not obtain in syphilis. Therefore I think that as syphilis has its own clearly-marked osseous lesions, which differ so strongly from those of raehitis, and as the

' Observation de Rachitis d'origine Syphilitique. Gazette Médicale de Paris, No. 14, 1874.

$$
{ }^{2} \text { Op. cit. } \quad \text { Op. cit. }
$$


latter disease is induced by a state of the blood not observed in syphilis, that, in point of fact, there is no connection between the two diseases. We are, then, in the position to state definitely that there is no specific relation whatever between rickets and syphilis. But it is not well to dismiss the case by simply considering syphilis in its specific manifestations. We liave already alluded to its power of inducing cachexia, of impairing the nutrition of tissues, and the function of organs. Now, it is in this influence in my opinion, that the connection between rickets and syphilis exists, if it exists at all. The condition of cachexia is freqnently induced by syphilis in the child, and results very often in lowering its nutrition, and renders it liable to intercurrent diseases. In this condition we observe glandular engorgements, eatarrhs of mucous membranes, tendencies to local congestions, and other affections, which, without being specific in character, renotely owe their origin to syphilis, and as such eannot, with accuracy, be elassed as syphilitic. In this condition it is very probable that rachitis may derelop itself, as we know that debilitating and adynamic influences are potent in the eausation of that disease. Yet under the circuinstances the specific action of syphilis does not take place, but it acts remotely as otlerer lowering influences do. So that while we are prepared to admit that syphilis may be one of the causes of rickets, it must be nuderstood to arise in the qualified manner we have specified. A point of importance as corroborating the view that rickets is not identical with syphilis (to state the question clearly) is that, in any given case of a syphilitic ehild, who becomes rachitic, the latter disease is not at all under the eontrol of anti-syphilitic remedies; and we know full well the great inflnence they exert over tissue changes dne to the specific action of syphilis. Finally, there is a clinical point of some weight, which is in support of the view either that rachitis in syphilis is a result of the cachexia, or that it is a mere coincidence; which is, that the rachitis, as observed in mally of the cases, appears late, after the syphilis is exhausted, so to speak, or has been thought to be eured; in other words, not in the regular period of evolution of syphilitic lesions, but many months after, at a period when we expect the eachexia as a result of the influence of the syphilis; indeed, at a period when a child not affected with syphilis wonld be liable to it. 
XXV.-TIE DIFFERENTIAL DLAGNosis.

In drawing the distinguishing features of these swellings from those produced by other affections which nay simnlate them, we shall follow the same general division which we have established in the study of their clinical history. Diagnosis is always one of the most essential parts of chinical investigation, and at the present time, in the study of the syphilitic bone-affections, it becomes urgently necessary that it shonld be clearly and accurately elaborated. The swellings at the diaphysoepiphysal junction are liable to be mistaken for three different affections. In their first, or resolutive form, they may be confounded with rickets; in the form in which the swellings are locally developed on either sile of the bone, they may be mistaken for hereditary epiphysal exostoses; in the third, or degenerative form, in which separation of epipliyses occurs, they may be falsely diagnosticated as cases of abscess, or synovitis, or of that form of bone inflanmation which has been variously called osteite, ostéoperiostite juxta epiphysaire, abscé sous periostique aigu (Chassaignac), decollement des epiphyses, epiphysentrennung (Klose), medullite aigü̈ des os, ostéides epiphysaires des adolescents (Gosselin), necrosis, and separation of the epiphysis. The idea of fracture might possibly occur, but it could be readily dissipated by a stndy of the case. There are also points of diagnosis in the syphilitic osseous lesions of the clavicle, of the bones of the hands and feet, and of the cranial bones, which require study. That form, also, in which the swellings undergo superficial necrosis is liable to be confounded with certain other conditions, which we shall take care to consider.

\section{Diagnosis of the Osseous Swellings of Syphilis from those of Rickets.}

There are certain points in the concomitant symptoms and lesions which, if clearly brought ont, will generally establish the difference between rachitic swellings and the osteo-chondritis syphilitica. Thus in rickets we generally have a prodromal stage in which the general healtl of the child shows signs of impairment by well-marked symptoms; a condition not observed in syphilis. A point of the greatest importance to remember 
is, that usually these swellings in syphilis show themselves rery soon after birth, having been developed, in all probability, in utero; while, in rickets, they usually comc on after the sixth month, but though in some rare instances at an earlier date they are hardly ever formed during the fœtal period. Then, again, in syphilis there is nsually a history of other symptoms or manifestations, such as snuffles, coryza, cutaneous and mncous lesions; in addition to which, thongh the condition of the child may give evidence of cachexia, it is not, in the great majority of cases, as well marked as in rickets. In the latter disease the syphilitic symptoms are wanting, and the following is more probably: what may be expected. The child is pallid, is noticed to sweat around the neck and head, is restless at night, and troubled with gastro-intestinal disorder, soon followed by a general hyperresthesia. A little later we find bone lesions, and perhaps laryngismus stridulus, with convulsions. All of which prodromal symptoms are wanting in syphilis, and do not make their appearance at similar periods. Thus, in syphilis, thongh we find the radins, ulna, tibia, and fibula, enlarged at either end, we very rarely find the skull-bones and ribs to be involved coincidently. In rickets the lesion is generally upon the occipnt, and consists of a thiming of the bone in spots, constituting the condition known as soft occiput or cranio-tabes; while at the same time a thickening is observable at the sutures. These, moreover, are, in almost every instance, present. In syphilis the lesion consists of a circumscribed tumor, or tumors of greater or less extent, seated upon the frontal and parietal bones, and rarely upon the occipital bone. These lesions, moreover, are not very common in syphilis. In rickets the ribs are almost always implicated; so that Dr. Parry, who has written two of the best and most comprehensire ${ }^{\prime}$ articles, in any language, upon this subject, and those experience is very great, says that he has met with but one case in which the forearms were affected and the ribs not.

In rickets the extremities of all, or of nearly all, of the ribs are enlarged symuetrically; while in syphilis the number so

1 Observations on the Frequency and Symptoms of Rachitis. American Journal of Medical Sciences, Jan., 1872.

Remarks on the Pathological Anatomy, Causes and Treatment of Rickets. Same Journa!, April, $18 \% 2$. 
affected is small, and the swellings unsymmetrical. In syphilis the fontanelles are noticed to close at the usual period, in rickets there is delay. The subsequent course of the bone trouble is conspicuously different in the two diseases, being generally followed in syphilis by resolution, withont change; in rickets, on the contrary, we may find both bending of the shaft, and distortion of joint. In syphilis also there is a tendency to necrotic degenerative change, which never oceurs in riekets. The main points, therefore, to guide us in this differential diagnosis are found in a comparison of the prodromal and concomitant symptoms, in the difference noticed in the periods of evolution of the bone lesions, and in the changes in the cranial bones, which in rickets are clearly distinet, as well as of invariable occurrence; bearing in mind, also, that the ribs are so frequently, universally, and in a symmetrical manner, involved in rickets, in direct opposition to what may be observed in syphilis. In cases of syphilitic bone lesion in which, in addition to the changes which resemble those of rickets, we find nodes, enlarged phalanges, and metatarsal bones; but especially when degenerative changes and other oncomitant symptoms, such as sinuses, eutaneous ulcers, or synovitis exist; there can be no doubt entertained as to the syphilitic origin, to the total exclusion of rickets. $\Lambda$ s there is a probability of the coincidenee of rickets with syphilis, some uneertainty might perhaps exist in any individnal case as to the real canse of the bone lesion. In this event attention to the points already brought out will lead to correct conclusions, and will enable the surgeon to institute a proper treatment. If, in such a case, the prodromal symptoms of rickets are deteeted (and they should be carefully inquired after), and if then the lesions had been developed after the manner just stated as being peculiar to rickets, it is fair to assume that the case is one of the latter disease. In snch an instance the age of the child would be an important consideration; for as rickets usually appears after the sixth month, and very rarely before, and as the number of bones involved is usually large in syphilis at this early age, there would in all probability be a smaller number of bones affected, and the symmetry of evolution would not be as well marked as in rickets. Besides this point, the others already brought out would, if carefully considered, lead to a correct diagnosis. 
Diagnosis of Swellings at the Sternal end of the Clavicle.

In the event of the swelling involving the sternal end of the clavicle, it is well to bear in mind that near this situation we may have enlarged lymphatic ganglia, or gumnny tumors of the sterno-cleido-mastoid muscle, the latter being developed usually near the tendon. Both of these might perhaps be incorrectly regarded as bone swellings; but if the child's head be allowed to fall backwards, and the parts then examined, all doubts will be quickly remored. Gummatous nlcers occur at this site, and are to be diagnosticated by their implicating only the skin.

Diagnosis of Swellings complicated with Superficial Necrosis.

In the cases of superficial nlceration of the integument, and of destruction of the upper part of the bony tumor, the peculiar features of which have already been bronght ont, mistakes might be occasioned by regarding them as gummatous nlcers, or eren as inflamed bursa in the sitnation of the malleoli, but an inquiry into the history and features of the case will enable us to remove the error. The position of the ulcer or ulcers will be a point of some significance, and an examination with a probe would very probably discover that their base is seated upon the boue; upon which, besides, it may, in many cases, be found that the edges are movable. In adults it is a wellknown clinical fact that gummatous ulcers develop in greater frequency at the upper and lower thirds of a limb than at its middle; but in children having hereditary srphilis, this feature, according to my observations, is not so well-marked, and, consequently, does not so frequently arise as a sonrce of error in diagnosis. In infantile life, since bnrsæ are as yet so slightly dereloped, and not at all liable to suppurative inflammation, these ulcers should not be attributed to this canse.

\section{Diagnosis of Swellings seated on the lateral borders of the Shaft.}

In case we find the localized tumors at the diaphyso-epiphysal junction of either side of the bone such as we have already described, we perhaps might mistake them for hereditary epiphysal exostoses; but the latter swellings are scarcely if erer congenital, rarely appearing before the end of the first year; attain to variable sizes, many of them being mueh larger 
than we ever discorer in syplilitic swellings, some even being as large as an orange; they may coexist with smaller osseous growtlis on the shafts; and, besides, not being attended with any other syphilitic lesions and symptoms, are, of course, uninfluenced by anti-syphilitic treatment, which canses those of a syphilitic nature to subside rapidly. In this connection, it is well to direct attention to a remarkalle case ${ }^{1}$ reported by Dr. Poore, of the Charing Cross IIospital, London, and also to Virchow's admirable lecture upon osseous ${ }^{2}$ tumors.

\section{Diagnosis of those Swellings in which there is Separation of the Epiphyses from the Diaphyses.}

The clinical facts bronght out by the varions cases show that this complication may supervene, and proceed either rapidly or with comparative slowness. If sufficient attention is bestowed upon the case, the diagnosis of simple abseess will certainly not be arrived at. Leaving out of consideration the history of the case, and perhaps the existence of syphilitic lesions, or, again, traces of such as have passed away, there are peculiarities in these cases which will assist in making the distinction. Thus the fact that the bone is enlarged in its whole diameter, with softening localized at one spot, or perhaps extending more or less around the limb, is distinctive of bone lesion rather than of phlegmonous inflammation. The position of the inflammation would also seem peculiar, and the amount of functional impairment or disturbance would be ont of all proportion for an abscess of whatever severity. If seen before necrotic changes supervene, the case will not be liable to be thus regarded; and if, as so often happens, a similar condition, though in a less advanced stage, exist in other portions of the extremities, a false conclnsion will searcely be arrived at. There is a bare probability that this condition of separation of these segments may be mistaken for synovitis. In the legs, as the epiphyses are of considerable length, the focus of inflammation will occur so far up the shaft that this suspicion can hardly be entertained; but in the arm and upper part of the forearm, or even at the approximating ends of the femur and tibia,

${ }^{2}$ Hereditary Exostoses, Lancet, page 771, November 29, 1873.

'Pathologie des Tumenrs, Trad. Franc. Dix-septième leçon, Tome Deuxième. Paris, 1869. 
where the epiphyses are shorter, the inflammation being so closely contiguous to the joint, might be regarded as having its focus in it. The distinguishing feature would be the comparative absence of pain both in moving the joint proper, the segments being held steadily, and also when the articular surfaees are pushed forcibly together. Besides this, the inflammation of the connective tissue would be much greater at a much earlier period than in synovitis. In either event, whether the case be looked upon as abscess or synovitis, an incision being made, the nature of the morbid condition can be clearly understood. In those very severc cases in which there is total destruction and perhaps extrusion of the epiphysis, the gravity of the lesions wonld indicate the state, and then it would be necessary to determine whether or not it was due to syphilis.

As bcfore stated, the fact of the separation of the epiphyses from the diaphyses being due to a syphilitic canse, might be overlooked, and the case be regarded as simple in its character, when one of the nanes already mentioned conld be assigned to it. There are certain facts and featmres connected with the sypliiitic process which materially assist in arriving at just conclusions. Let us consider, first, the features of the simple or non-specific form of inflammation, and then contrast them with those presented by the syphilitic. There occurs during the period of derelopment of the bones a violent form of inflammation, which often results in the separation of the distal segments from the shafts. This aceident occurs usually subsequent to infancy, or during the period of adolescence; hence called by Gosselin 'ostéide epiphysaires des adolescents, while Frank, who has written a good account of it, (and it is singular that such is totally wanting in the English language.) denominates the condition Krankheit der Entwicklungsjahre. For my own part, I am inclined to think that it rarely if ever occurs in infancy, and that the view of Gosselin, that it is a trouble coincident in derelopment with the ossification of the epiphyses, is sustained by clinical observation. I camnot find an instance anywhere mentioned of its occurrence

${ }^{1}$ Mćmoire sur les Ostéides epiphysaires des Adolescents. Archives Génórrales de Médecine, Nov., 1858.

${ }^{2}$ Ueber entzündliche Epiphysenlösung, eine Krankheit der Entwicklnngsjahre, Giessen, $18 \mathrm{j1}$. 
in a child under one year of age, nor have I ever seen such. Frank states that it may oecur between the twenty-third day and the twenty-first year'; but the only example of it which he cites in the infant, is the ease of Valleix, which, as we have seen, is very probably syphilitic in its uature; his other cases, as well as those reported by other observers, are those of adolescents. Here then we have an important fact which materially assists us in arriving at correct conclusions. All of the reeorded cases of this form of lesion, when produced by syphilis, have been those of infants under three months, while the simple form is shown to appear much later in life. In syphilis the inflammation is coincident with the development of the shaft; in the simple form it coexists with the ossification of the epiphyses. Bonchut ${ }^{1}$ has recently shown that a phlegmonous form of perinstitis may ocenr spontaneonsly in young infants; wherefore, it is fair to assume that we may have the same process in the ends of the shafts, and extending into the epiphyses. In the simple form of epiphysal separation there is sometimes a history of tranmatism: it may result from exposure to cold, and has been known to occur in much debilitated subjects; it may be confined to one bone, or, thongh rarely, involve several. In syphilis, as the lesion is in most cases eridence of a severe form, there are nsually other lesions or symptoms which indicate that disease; there is no history of tranmatism, or of cold, but in all probability an implication of other bones, which latter may be affected in various degrees. Thus, perhaps, on another shaft the morbid process has simply reached the stage of enlargement; bnt, in addition, there may exist such osseous lesions as nodes and phalangeal enlargements which would positively indicate syphilis. Besides all these there is the age of the child, which we have already seen to be an evidence of so much importance. The course of the morlid process, when of a non-specific origin, presents certain characteristic particulars. Thus pain of an acute character referrible to the joint is felt at the outset, redness and swelling soon supervene, and symptoms of severe systemic reaction follow. These symptoms are always mnch more pronounced in the simple than in the specific form, going on even to the

1 De la périostite phlegmoneuse aiguë chez les enfants. Gazette des Hôpi$\operatorname{taux}, 20,21,1874$. 
development of a typhoidal condition, which sometimes results in death. Then, again, after the redness and swelling have appeared, which are nsually not so clearly limited to the epiphysal region as in the syphilitic form, evidence of implication of the lymphatics is soon seeri in red elevated and painful lines extending up the limb. In fact, in this trouble we have an inflammation of the greatest severity, attended with the most formidable symptoms. There are, of comrse, cases which are of a milder character. Let ns contrast this condition with that of syphilis, bearing in mind, as nsual, the difference of age. Thus we have seen that even when the process was of the most aggravated typc, the systemic reaction was not in proportion to the activity of the lesion; in fact, this point is not only significant, but also somewhat surprising. Thongh redness and swelling supervene, these featnres are somewhat less pronounced than in the other form. There is a greater tendency to a localization of the morbid processes to the original focns; there is usually no lymphangitis; and, as far as can be learned by observation, the pain is not as great as might be expected. These, then, are the distingnishing guides in serere instances. Now, then, my cases show that there may be a total separation of the parts, and yet the visible sigus and symptoms may be of a mild character. Thus, the swelling occurs slowly; the separation coincidently with it; and, thongh an abscess occurs under the skin, it is not accompanied with very much heat or redness, which, besides, are quite sharply localized; fimally, there is scarcely any evidence of implication of the system, which may not be in any degree affected. If we reflect on the nature of the changes, we may arrive at a reasonable explanation. Thus, in syphilis, the separation is due to a softening down of immature cells, and the subsequent symptoms result from the cutting off of the blood supply; whereas, in the simple form, the process is inflammatory from the commencement. In the milder form also there will be a history of syphilis, in addition to which, other lesions, of an undoubted cliaracter, may coexist, leading to a correct diagnosis. Wherefore, I think that if a given case is carefully studied, both in itself, and in its concomitant lesions and circumstances, unistakes of diagnosis may be aroided. The main points of assistance are: first, the age of the patient; second, the previons history; third, the 
coexistent symptoms and lesions; and, fourth, the dissimilarity in the course of the two affections; the violent phlegmasic character of the simple form, and the comparatively subacute character of the syphilitic. Perhaps the fact of the perceptible thickening of the periostenm of the shaft above the epiphysis may be a point of assistance as settling a syphilitic origin. If a case of this kind was seen after separation had occurred, a diagnosis of fracture might possibly be made; but the absence of injury, and the fact that swelling had existed prior to the separation, the probable existence of other bone lesions, and the history of the case, taken together ought certainly to prevent that error.

\section{Diagnosis of the Enlargement of the Phalanges and of the other Bones of the Hands and Feet.}

In infants and young children, the phalanges are sometimes observed to be very much enlarged, and inquiry into the history of the case fails to elicit that syphilis is the cause. The clinical features of these swellings are similar to those of the syphilitic enlargements described in chapter nine. Indeed in their development, course and decline, these non-specific enlargements are similar to those of syphilis; and, after careful comparative study of these cases, I must confess that there are almost no distinguishing points; so that we are forced to rely upon the previous history and upon coexistent lesions or their sequelæ. Some of these cases may present no dificulties, owing to the presence of other bone lesions undoubtedly syphilitic. However, during the years in which I have been studying these syphilitic osseous lesions, I have met with a number of cases of enlargement of the phalanges in which no history of syphilis was obtained, and which I am convinced were not syphilitic. In several of these cases I have found an extremely debilitated condition of the system, due sometimes to poverty and want of care; in others to the depressing influence of a past attack of the exanthemata or of diphtheria. In these eases that concatenation of lesions and symptoms which is called scrofula was present-a condition which, when suecinctly stated, may be described as a tendency to local congestion and abnormal cell proliferation in rarious organs and tissues. As results of my owu study and observations, I am led to the opinion that 
in this condition hyperplastic processes may occur in bone; for as the natural morphological changes in that structure are usually actire, under the influence of this dyscrasia they become abnormally so, and induce enlargements of the bones. The lesion in such cases is an osteitis and periostitis, and is mnch less amenable to treatment than the syphilitic variety. The enlargements we are speaking of may be the result of tranmatism even in a healthy subject. It is necessary to bring these points prominently forward, as there has been a tendency of late to class all cases of enlargement of the phalanges in children as syphilitic. If, then, in a given case, upon careful inquiry into the history of the mother and of the child, and after a thorongh examination of the latter, no evidence of syphilis is obtained, the suspicion of that disease should at once be rejected. The features which point to syphilis, besides the history and concomitant symptoms, are the somewhat gradual and painless enlarging of the bone, the absence of any joint complication, and the fact that necrotic processes, if they complicate the case, are dereloped after the swelling has attained its maximum size-that is, rather late. In cases of traumatism, pain, and consequent uneasiness of the child, may be noticed, while the necrotic change appears earlier. In the variety of swelling due to the depraved condition of the system abore spoken of, I have sometimes noticed that the enlargements occur rather more rapidly than in syphilis; that they are more liable to undergo a rapidly destructive change; and that they more frequently involve the joints. But, as I have before stated, these distinctions are far from being absolutely reliable, and in any case the diagnosis hinges npon the history and concomitant symptoms and lesions. It will be remembered that in the descriptive part I pointed out that the hyperæmic condition of the integument of the fingers, in cases in which excessive pressure is exerted by the bony swelling, was sometimes accompanied with a coppery appearance of the member, yet as this peculiarity is infrequent, and as it is simulated by simple chronic congestion, we cannot attach much importance to it.

As we sometimes see rheumatoid arthritis even in young children, though not in infants, it is well to state the points of distinction between its lesions and those of syphilis. This 
disease is usually attended with well-marked fever; the joints, particularly the large ones, are affected, and if the fingers are involved, it will be found that the enlargements of the phalanges are greatest at the joints, which are affected much more profoundly than in syphilis. The main points of distinction are: the antecedent symptoms, the great pain, the loealized intensity of the inflammation, with consequent swelling, which, as stated, are first limited principally to the joints. These points, as contracted with dactylitis syphilitica, are so well characterized as to prevent any error in the diagnosis.

Little need be said of the enlargements of the phalanges produced by exostoses and enchondromata, as their size, localization, and history, are usually such as to clearly suggest their nature.

A perrusal of the case, given in a foot-note to chapter xv., will give a sufficient idea of the appearances presented by the phalanges, when the seat of cartilaginous hyperplasia. This condition begins necessarily in utero, is localized to one, or perhaps two bones, and discorerable at birth. Being unattended with inflammatory symptoms, the phalanx will, upon inspection, appear translucent. The condition is very rare, as the case detailed in the note is the only one which I have seen, or indeed, read of.

The diagnosis of the swellings of the carpal and metacarpal bones, and the corresponding bones of the feet, depends largely upon the history of the case. In these swellings joint complications are rather more frequently observed; in which event the general redness and swelling might mislead the surgeon into the belief that those structures were the focus of the inflammation ; but inquiry into the history of the case, and a eareful examination of it, would undoubtedly lead to more enrrect conclusions. It is necessary to bear in nind that these swellings may arise from the same condition which produces the phalangeal enlargements, and also that they may be the result of traumatism ; but here also articular complications are rather more liable to occur; indeed, in many instances the morbid processes begin in the structures which compose the joints. However, to render the matter certain, the history of the case, and its concomitant features, must be thoroughly looked into, by which eourse only a correct conclusion can be arrived at. 


\section{The Diagnosis of Nodes on the Cranial Bones.}

The swellings upon the cranial bones, in like manner, present several points of interest in diagnosis. The small variety of node described by Wegner, consisting as it does of minute oval or round elevations, exists thus far only as a pathological rarity, and is not simulated by any other affection. Therefore, if met with, it can be uneqnirocally ascribed to syphilis. In the larger variety, in which the swellings develop to a considerable extent, they might perhaps be regarded, when in an indolent and uninflamed condition, as sebaceons tumors, which are deeply seated, and have become attached to the pericraninm. But, besides that in the young child this peculiar condition of the wen is very rarely if ever met with, there wonld be the absence of any other symptom or lesion to canse a suspicion of syphilis, and the sebaceons tumor, if carefnlly examined, would be found in many, perhaps the majority, of instances, soft upon pressure, rounder, and more abrupt at the edges, than the node. The situation may likewise assist to guide us, as nodes are seated generally toward the lateral parts of the frontal, and upon the parietal bones. We have scen, in the clinical part, that in several eases inflammatory complications rapidly supervened. In these the general appearances and symptoms were those of phlegmonous inflammation of the snbentaneons tissue of the scalp. So that we have reason for suspecting nodes which have indergone degeneration, in the event of meeting with snch abscesses on the heads of syphilitic children. Bnt these are the faets which help ns. The node is deeply seated, and may be attended in its evolution with pain, and generally enlarges gradually; points which, once ascertained, there is no longer likelihond of mistake. But in those instances already allnded to, in which a rapidly destructive condition of the bones early complieates the case, the diagnosis will remain donbtful until after an incision is made in the part, when the nature and extent of the condition can be ascertained. The depth and perhaps the occurrence of bony sequestra will then be determining points. A history of syphilis or the existence of its lesions may assist. These cases require eare in their diagnosis. When the node runs a chronie course, is fully developed, and then, afterwards, nndergoes necrotic change, with its concomitant 
symptoms, usually no difficulty will be experienced in arriving at a conclusion; but, as I have said before, doubt.will more usually arise in those cases in which the necrotic tendency begins with the development of the tumor. There is a point of considerable importance in diagnosis which deserves mention; it is this, in rare instances wens undergo ulceration of a persistent character, which involves the tissues around in inflammation, is only cured by its enncleation, and might be mistaken for an ulcerating gumma of bone and integument. Should such a condition obtain in the infant, one, however, that we can hardly expect, it is easy to see how it might, from its being deep-seated and chronic in character, be looked upon as an instance of the inflammatory node.

I once saw in a typical case of rickets, in which, unquestionably, there was no syphilitic complication, a state of the skull bones which struck me at the time as being very likely to be regarded as syphilitic. The patient was a child eighteen months old, who at its sixth month had the usnal symptoms of rickets, with swellings at the distal ends of the ribs and of the radii and ulnæ. It had continued in a miserable condition of health, and at its ninth month a swelling was found on the left side of the frontal bone, just outside the eminence; this increased, and was followed by a similar swelling on the right side, at its fourteenth month. When first seen by me, the left or first swelling was elevated above the plane of the bone about three-quarters of a line ; it was oval in sliape, having a flat, smooth surface, and being an inch and a half long, by three-quarters of an inch wide. On the right side was a swelling precisely similar, except as to size, which was but one-half that of the other. These swellings differ strikingly from the typical nodes, but still they are exceptional as occurring in rickets; and indeed I camnot find such an instance mentioned. The lesion ${ }^{1}$ was simply a thickening of the

1 This was undoubtedly an instance of that abnormal periosteal osteogenesis which is caused by rickets. It consists in an excessive development of the young connective tissue, and a corresponding increase in the number of the capillaries. Such swellings may be found upon the surfaces of the bones generally, and are to be remembered in questions of diagnosis. When occurring on the cranial bones, they are, according to Rindfleisch (A Manual of Pathological Histology, Vol. 2, London, 1873), usually sharply circumscribed as in the case in the text, differing from those upon other bones, where they usually are not thus limited. 
periosteum, and was caused by the rachitic blood disorder. We not unfrequently find thickening of the periosteum in rickets near the sutural margins, but, as I have said, not usually in the situation here spoken of. It is well, therefore, to bear in mind, in making our diagnosis, the probable existence of this form of flat, broad rachitic' swelling of the skull, as a precaution against error.

\section{XXVI.-TIIE TREATMENT.}

We now come to treatment. Though perhaps foreign to the present investigation, it may be well to briefly mention the beneficial results of a proper and well-regulated mercurial treatinent of a preginant woman, in preventing the future development of syphilitic lesions in her child. My own cases clearly indicate that the neglect of treatment of the malady in the parent has resulted in her bringing forth a tainted offspring,

2 These rachitic periosteal thickenings of the cranial bones, as well as their resulting enlargement, are particularly to be borne in mind in making a diagnosis between rickets and syphilis. In the case just mentioned the tissue was undonbtedly still unossified, and it is fair to suppose that on the completion of the ossific process, a deformity, misleading in its appearances, would result. I saw this condition in its developed state in a patient, whose lesions were such, that doubt was entertained by several as to their etiology. Its import. ance therefore warrants its insertion in this connection. The patient was a girl fourteen years old, who, in early life. suffered severely from rickets, and whose frame was thereby much distorted. She was under my treatment for several years, for a very extensive lupus vulgaris of the face. She also had upon the right lateral portion of the frontal bone a swelling having an area of an inch and a quarter, and being about half an inch high. It was perfectly smooth, and its margins sloped imperceptibly into the surrounding bones. The case was seen by many physicians; by some of whom it was thought that the association of the cutaneous and osseous lesions was an evidence of hereditary syphilis, though there was no history of that disease ; others argued that, as lnpus was an undoubted evidence of scrofula, therefore the osseous lesion was the result of that disease. Should the last hypothesis be accepted, we shonld come to look apon nodes as lesions of scrofula, an opinion not tenable. Now, inquiry into the chronology of the affections and a knowledge of the lesions of the cranial bones, which rickets produces, clears up the case conclnsively. Thus, in her early infancy, the girl had rickets affecting the osseous system generally, at which time the peculiar hyperplasia of the periosteum, which that disease induces, occurred on the frontal bone. The cell proliferation being active, a large swelling resulted, which, later on, became ossified, and proceeding in growth with the craninm remained permanent. The lnpas, which developed several years iater, was probably the expression of the debilitated state of health. 
one in which, perhaps, are developed serere osseons and other lesions. Wherefore, as a prophylactic consideration, this matter deserves especial attention.

Let us now consider, with brevity, the indications for the treatment of infants hereditarily syphilitic affected with osseous lesions. We have already seen, in studying their pathological anatomy, that they are essentially celnular hyperplasia of the forming bone, and of the periostenm, produced by a recent acute syphilitic action. This state differs, in being more advanced, from that of cases in which such bony lesions are absent; and thris, while we have to treat a recent syphilitic condition, we have superadded the lesions already alluded to. $\Lambda$ superficial knowledge of these eases might lead to the opinion that children thus affected had lesions of a tertiary character, as they are of bone, and hence that they required the treatment nsially employed in that stage; but, as I have, I think, clearly shown, these lesions are of a different character from gummy tumor proliferation, being less adranced, and more closely allied to simple cell proliferation. The condition, as warranted by patholo$\mathrm{gy}$, can be rightly compared with that of the late adult acquired syphilis in which gunmy tumor proliferation has not yet appeared. Now, in this stage, it is well known that the combined or mixed treatment of mercury and iodide of potassinm is much more efficacious than is either of those medicines administered alone. And my experience in the treatment of these osseous lesions is that the infant should be treated by the same remedies, and on the same principle. The prescription which I have used, and which I see no reason to modify, is as follows:

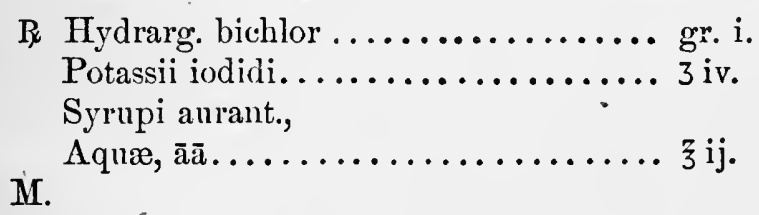

We may also use the bin-iodide instead of the bichloride. The dose of this mixture, for a young child about two months old, is five drops, which shonld be gradually increased, in the manner recorded in the cases. I have pushed this remedy as high as twenty drops in some cases of severe hereditary syphilitic lesions. A matter important to be borne in mind is, that 
as the taking of medicine has of necessity to extend over a long period of time, we must use such a remedy as is not likely to derange the gastro-intestinal functions, or will induce cachexia, but which, yet, will be sufficiently powerful to control the disease. These indications are, I think, fully met by the prescription above given. Fears may perhaps be entertained by the practitioner, that this long-continued treatment might result injuriously to the health of the child; but such are entirely without foundation. It will be found that under the influence of the mixture alone, even withont the simultaneons administration of tonics, the health of the infant will be greatly improved, sometimes in a very striking manner. There need be no apprehensions of salivation, or of any noxions effect of the mercury; for when this combination is used, the iodide of potassium corrects such a tendency, and this constitutes another advantage in its faror. There is good reason for believing that the power of the mercurial, in such a protracted course of treatment, will, after a time, from the system lecoming habituated to its action, fail of the desired specific effect. This also oceurs in adult syphilis, and is to be snccessfully met by discontinuing the treatment for a short period, several times during the course. In this interval of rest, the system becomes again subject to the mercurial influence, and its action is again made manifest. I have omitted to mention, in my remarks npon treatment, the propriety of ordering these intermissions, though regarding thom as essential ; for the reason that very frequently they occur in the cases of these children by the negligence and sometimes the indifference of the parents. The practitioner will sometimes undoubtedly encounter great difficulty in enforcing regularity in the treatment, and periods in which the medicine is not giren, and perhaps forgotten, will certainly occur, even among intelligent people.

Cases may be met with in which the assimilative processes of the child are imperfectly performed, as well also as instances in which the digestion is slow, and attended with an acid condition of the stomach. Under snch circumstances a proper preparatory treatment, the nature of which will be indicated by the peculiarities of the case, is necessary, in order that the medicine shall be well borne, and that benefit shall result from it. 
It is of importance also to advert to the necessity of a wellregnlated and sufficient diet during the period in which specific medication is followed. In order that good should be prodnced, and to avoid cachexia, plenty of nourishing food should be given, otherwise the action of the medicine is lowering to the econony, even to the point of being harmful. This remark applies with equal force to the treatment of all forms of hereditary syphilitic lesions, as it does also to the adult. In the treatment of cases annong the poorer classes, a want of food will often be found to be a serions obstacle to success. It is unnecessary to go fully into a consideration of the forms of diet required; for it is a well-known fact that the mother's milk, if of a good quality, and of sufficient quantity, is the best food obtainable; or, in defanlt of this, that of a wet-nurse $;^{1}$ or, again, a good quality of cows' milk. In addition, much good may be obtained from the administration of cod-liver oil in full doses; preparations of iron and quinine will also be found in many cases beneficial, and in some essential.

I have used the hypodermic injections of corrosive sublimate in hereditary syphilis, and coincidently given the iodide internally, but, from a no inconsiderable experience, would advise that this treatment should not be used. These injections induce great subcutaneous infiltration and inflammation, and are very frequently followed by abscesses. I have seen severe systemic reaction follow them, even when used with cantion, independent of which objection they are almost inadmissible by reason of the pain they indnce, and the repugnance they excite in the minds of the parents. In fact, I think that for infants they are a cruel method of treatment, and that they should scarcely ever be employed. There may be cases in which the

1 It would be improper to pass over this point without careful consideration. There is, as is well known, a very great liability that a syphilitic child may convey syphilis to any healthy woman who nurses it at the breast; conse. quently, under no circumstances would it be right to expose such a person to that serious risk. Though the child might not have, when examined, lesions of the mouth, there is a probability that such might develop; or, again, as its blood possesses contagious properties, this also might be the means of conveying the disease. As to the propriety of suckling it by a syphilitio woman, whose milk may appear to be of good quality and sufficient in quautity, if by such a better nourishment can be given than by its mother, it may have that; but in such cases cows' milk is really the best diet. 
course of the osseous lesions is so rapid, that we wish to induce the effect of the remedy immediately, in which event we may have, of necessity, to use them; but I should strongly advise their discontinuance just as soon as the urgent indications have passed away.

Much has been said of the value of mercurial inunctions as a speedy and certain way of inducing the effects of the mineral. They are, in many instances, of infinite value in adult acquired syphilis; but in that of infants are apt to produce severe cutaneons inflammation, and sometimes grave systemic disturbance, such as great enfeeblement, impoverishment of the blood, with cachexia. For these reasons, and also because in these cases their use is to be extended over such a long period, and that it is almost impossible to get the attendants to use them intelligently and regularly, I an not disposed to advise them, notwithstanding their great poteney as used in the adult.

As to the method of continuing the use of the mixed treatment, I should advise the reader to follow the history of several of the eases, as such a perusal will give a more praetical idea than any didactic statement can possibly convey. In summer, gastrointestiual disorder's may supervene, in which case the hydrargyrum cum creta, with astringents, can be given, and perhaps the iodide continued. During the continuance of warm weather, it is well to anticipate these frequently-occurring troubles, and prudent to send the little patient into the country. Another point is, that if the mother is able, she should continue to give the child the breast, as in that case it is less liable to bowel difficnlties. I say nothing of medication of the child through the mother, as it is totally ineffectual.

Locally, in the case of the ulcerations, I think that nothing is as beneficial as the application of iodoform into their cavities, with a covering to the other parts of balsam of Peru ointment.

When separation of the epiphyses occurs, the indications are the same as in fracture, namely, immobility of the parts by means of an aceurately fitting splint, or a bandage. Adhesive plaster, plaster-of-Paris, and the starch bandage, may severally be made use of. The adhesive plaster, if properly applied, is, perhaps, the best, as it is readily removed, easily reapplied, and adjusted as the swelling diminishes. It is rery necessary not only to keep the parts in juxtaposition, but also to main- 
tain pressnre, which is as beneficial in these cases as it is in synovitis. When the latter complication arises, rest shonld be insisted upon, and cooling lotions applied, in addition to sueh medicinal treatment as the disease requires. Surgical interference may be demanded when the epiphysis is wholly separated, which then acts as a foreign body. In such an instanee, the removal of the fragment, the application of carbolized lint in the cavity, asd the maintenance of a fixed position, are the main indications.

It may happen, in ease of enlargement of the phalanges, that the medicine lias no effect, and that the swelling persists. In such an event the surgeon might, perhaps, think of resorting to exsection, a proceeding which, in my opinion, should be delayed as long as possible. Indeed, I thinik that the mercurial preparation should be persevered with for eight or ten months, while at the same time pressure is made use of. Eren in case of failure, there is no good reason for remoral of the bone if it be simply in a swollen condition. Should, however, necrotic changes supervene, together with sinuses, and the usual chronic inflammatory condition, perhaps an operation would be imperative; but I should strongly connsel delay, and a persererance with treatment.

In cases of enlargement of the phalanges, or of either of the ends of the shaft, when ulceration does not complicate the case, benefit can be obtained by slight continnons pressure, combined with the constant application of a nercurial preparation, either in the shape of the ointment, which should be half of the officinal strength, or of a mereurial plaster, either of the simple rariety, or the Emplastrum de Vigo. When such an application is made, care shonld be exercised that inflammation of the skin is not produced, as uleeration of a chronic character might resnlt. At any rate, the plaster or ointment, kept in close position by a bandage, should be frequently changed, as it becomes lonse in a few days.

The nodes on the scalp require, in the uncomplicated condition, little or no local treatment, beyond daily frictions with mercurial ointment. When they degenerate into abscess, and consequently induce a phlegmonous state of the sealp, a free crucial incision should be made, the detritus carefully removed, and the whole thoroughly mopped with carbolic acid rendered fluid by a few drops of water; the cavity then to be 
stuffed with charpie, and cold-water dressing applied to the scalp. The next day this shonld be removed, and if the parts present a slonghy appearance, the application of the carbolic acid should be repeated, taking care to merely moisten the surface, and not to allow any of the acid to flow from the wound. Or, the cavity can be dinsted with iodoform, and then stuffed with lint, and a cooling lotion applied to the spot, and to the scalp for some distance beyond it, as long as any inflammatory symptoms remain. This latter application is of much importance, as such phlegmonous inflammations of the scalp very often give rise to adenitis of the post-cervical ganglia, which in syphilitic subjects are particularly liable to suppuration. These directions as to treatment of bony abscesses about the scalp apply equally to those developed in other parts.

Such, therefore, are the main outlines of treatment, which will be found to meet the principal indications. Some minor points may arise and demand treatment, for which the practitioner will find a sufficient guide in general principles.

XXVII.-THE SWELLINGS WHICI OCCUR LATER IN THE LIFE OF THOSE HEREDITARILY SYPHILITIO, AT THE JUNCTION OF THK DIAPHYSES WITH TIE EPIPHYSES.

In connection with our study of these diaphyso-epiphysal swellings in hereditarily syphilitic infants, it is appropriate to call attention to some observations made by Furneaux Jordan upon somewhat similar lesions developed in later periods of life in victims of hereditary syphilis. ${ }^{1}$ This snrgeon reports a number of cases in which enlargements occurred at the lower ends of the femur, hnmerus, radins, as also at the great trochanter, on the ilium, and at the upper end of the humerns. These swellings ran an indolent course, attended with but slight pain, and while in some instances they had led to sclerosis of the bones, in others caries occurred, and dermal sinuses were formed; in some instances a secondary synovitis was induced. This author thinks that when the humerus, radius, or ulna are affected, the joint complication comes on sooner than when the

${ }^{3}$ On the Hereditarily Syphilitic Character of an Inflammation of the Bones hitherto regarded as Strumous.-Medical Times and Gazette, March 16th and $23 \mathrm{~d}, 1867$. 
larger bones of the leg are the seat of swelling. Sometimes, thongh rarely, he found synovitis of the knee-joint the first evidence that enlargement had occurred in the femur. In onethird of his cases (he reports fifteen), the npper end of the shaft of the femur was attacked, the lesion being linited to the base of the great trochanter, while the head and neck of the bone remained unaffected. In one instance he found snch a swelling at the internal condyle of the humerus, a situation which we, in our studies, have found to be mnch prone to syphilitic swellings in infants. In the one case, in which the ilium was involved, he satisfied himself that the inflammation was on the dorsum, and that its crest, with its separate centre of ossifieation, was free. M[r. Jordan ventures the suggestion that caries of the vertebræ coming on late in adult life is mostly, if not always, due to hereditary syphilis.

As regards the intensity of the morbid process, there is considerable variation ; in some cases the osteitis is very slight, in others it produces sclerosis, while in the worst form caries is induced. Necrosis is not a result of this lesion, according to this anthor. Its chronicity, however, is worthy of mention; sinee, in one instanee, a sinus remained open for eleven years, in another, as long as twenty. But while in those instances in which degeneration oceurs we may observe this extreme chronicity, there are, Jordan is of opinion, cases so sliglit as sometimes to eseape deteetion, while others are observed, partienlarly in dispensary practice, in which the patient complains of stiffness of the wrist, elbow, or ankle, or of a larger joint, and perhaps impairment of motion, either in extension or flexion, pronation or supination. In these instanees an enlargement of the distal extremities of the bone or bones is found to be the canse. In the majority of these cases Mr. Jordan thinks that in hereditary syphilis is to be found the origin of the trouble. As already said, the greater or less immminity of joint complication depends upon two facts ; first, the chronicity and severity of the inflammation, and secondly, as to the size of the epiplysis; for, if long, the inflammation naturally is more remote from the joint, but if short, it runs its conrse near the joint, which is very liable to be implicated with it. It will be seen that, in my own observations upon joint complications secondary to diaphysoepiphysal swellings, this fact was clearly bronght out by 
sereral of my cases, and was also explained in my eomments thereon.

The focus of this osteitis, which, from inference, I should consider as simply inflammatory, and not attended with gumeny tumor or granulation tissue proliferation, is at the end of the shaft in the cancellons tissue. According to Mr. Jordan, the inflammatory process is greatest in the shaft; and may or may not involve the epiphysis. Being developed at a time when the changes of the cartilage are less active than in the earliest periods of life, it is very probable, as suggested by Jordan, that the epiphyses are scarcely, if at all, affected; hence, that the lesion is an osteitis rather than an osteo-chondritis.

The ages at which he has noticed this tronble are between the fifteenth and thirty-fifth years of life, and eren as late as the fortieth. The illnstrative cases are open to the same objections that many cases of supposed hereditary syphilis are subject to, namely, that the hereditary syphilitic diathesis is assumed from the existence of the remains or sequelæ of lesions which are thought to be of syphilitic origin, and are considered as not being prodnced by any other condition of the system. This fact is to be sincerely regretted; since, in drawing such important conclusions as these cases suggest, it is very essential to establish beyond a shadow of a doubt the inflnence of syphilis as the canse of the lesions. Yet I think that many of Mr. Jordan's cases will warrant the suspicion, I may even say the diagnosis, of syphilis, for which reason his conclusions, which he states in a very modest way, are certainly of great value. They are snggestive rather than conclusive; jet open ont to us a field of study which shonld be earefully examined, for by drawing true conclusions in these cases we are prepared to undertake their trentment in a more definite or intelligent way, and rescne such cases from that great gulf of ignorance which we unfortunately call scrofula. Another point of very great importance is adduced by Mr. Jordan in these eases, which is, that mereury exercises upon them a beneficial effect. This fact may be in faror of the syphilitic origin of the lesions, and shonld, therefore, be bome in mind.

Since we have found that in the early infancy of syphilitic children this peculiar part of the bones is liable to undergo in- 
flammation, when we consider how active the natural changes are at this point, and that they remain thus for such a number of years, it certainly seems very probable that it should be affected later in the life of the syphilitic individual, as well as in its early life, particularly as in the majority of eases it is a lesion consisting in perverted nutrition.

During the past summer I have had under my observation a patient sent to me by my friend, Dr. Gibney, in whom the peculiar osseons lesions described by Jordan are manifested. The case is that of a German girl, eight years of age, who presents a clear history of syphilis, which was acquired at her third year. Shortly after, having a typical rash and condylomata, she was attacked with severe pains in the bones, recurring especially severe at night. When the child was five years old, having been in the meantime sickly, it was noticed that some of her bones swelled near the joints. The swelling increased slowly, mitil enlargements of considerable size wero produced. Thongh treated by varions practitioners for a long time, no diminution was observed. When first seen by me, late in May of 1874, I fond that the index and middle fingers of the left hand were slightly enlarged, that the distal diaphysoepiphysal junction of the radius and ulia in each arm was manifestly swollen, and that a similar condition existed at the lower extremities of the femora. I tried iodide of potassium in inereasing doses, combined with iron and quinine, with the result of relieving the nocturnal pain, which was severe and continuous. This failing to reduce the swelling, I nsed the mixed treatment, according to the formula already given, administering half-teaspnonfiul doses. As thus far observed, in a trial of two months, the effect is very gratifying, as there is a perceptible decrease in the size of the swellings, and much more suppleness and mobility of the limbs, particularly the lower: moreover, the general health has materially improved. It inust be borne in mind that, in eases where the swellings have existed, as here stated, so long, the chances of the nltimate restoration of the parts are not very great, as the bones have then passed into a selerotic condition, difficult if not impossible to be removed. This remark applies with equal force to any form of syphilitic bone lesion. Therefore, we cannot say definitely, in any such chronic case in which anti-syphilitic 
treatment is not absolutely successful, that this fact militates against the correctness of the diagnosis.

It may be well to state in reference to this case that, though the child is younger than any of those spokien of by Jordan, nevertheless I am disposed to think that the lesion was an osteitis of the end of the shaft rather than an osteo-chondritis. The peculiar character of the case supports this view. Thus the swellings occurred at the period when osteitis is to be expected; they grew much more slowly than those of infancy, and did not attain such a relatively large size as when the cartilaginous segments are mainly implicated. There was, besides, an evidence, in the tapering condition of the bones, that the process had extended a short distance up the shaft, thus seeming to show that it had originated in it. This case would favor the view that this condition can be dereloped at an earlier period than is stated by Jordan, and there is no anatomical reason why it should not.

Another important consideration is, the occurrence of this lesion in acquired syphilis. This, together with the fact that the true osteo-chondritis may be the result of this form of disease, as in my eighth case, in which the existence of that lesion is clearly shown, go to prove that the bones are affected similarly in both the hereditary and acquired syphilis of children. Added to this, we know that in both of these varieties of syphilis, gummous proliferation may also be devoloped in a similar mammer. Thus, there is ample evidence adduced to warrant the general statement that the osseous lesions in infants and older children are similar in nature and character, whether resulting from hereditary or acquired syphilis. This knowledge is very important; for while the hereditary osseous lesions have hitherto been slightly and incorrectly understood, there was scarcely anything known of the osseous lesions of acquired syphilis in children; indeed, the fact of their occurrence has hardly ever been mentioned.

XXVIII.-THE COURSE OF THE GUMMOUS OSSEOUS LESIONS OF OLDER CHILDREN, CONTRASTED WITI THE LESIONS OF INFAXCY.

It has been shown in the clinical division of this work, and also in the pathological part, that the osseous lesions produced 
by hereditary syphilis in the infant differ somewhat in nature, course, and features, from those of later life. Space will not permit me to describe the lesions of more advanced years in an exhanstive mamner in this work; but for the sake of completeness I have thought it best to give a general idea of them, as supplementary to the description already given. To this end I have sclected from nyy notes the following case, as it will show somewhat fully the points of contrast:

The patient was a German boy, Ienry Schwartz, who was first seen by me in 1871 , he being then a little orer nine years of age. Being accompanied by his mother, he came to the college in February, having been sent by one of my friends, who was his teacher. IIis mother bore evidences of a serere form of syphilis, in the fall of the nasal arch, in a nasal twang with which she spoke, owing to luss of tissue in the palatal region. She also had deep cicatrices at the side of the nose, running up the left ala. Her husband had suffered from syphilis, and had died of a nervous affection which was ushered in by hemiplegia. Prior to the birth of the present child the mother liad had two miscarriages, late in pregnancy. Shortly after his birth he had severe syphilitic manifestations. He remained sickly, weak, and delicate, until he was fire years of age, during which period he was irregularly and, as I learned, not properly treated with mercurials. When abont five and a half years of age he was afflicted with a series of bony swellings, which troubled him for two years.

When first examined by me I found the following abnormalities of the osseous system: On the right hand, the index finger was a mere stump, just reaching to the first phalangeal joint of the middle finger. When I had carefully manipulated the parts, I found that the whole of the first phalanx, the proximal third of the second, and the distal third of its metarearpal bone, had been absorbed. The latter bone tapered off gradually to its end, at which point a band, undonbtedly of fibrous tissue, was attached, which, at its other end, held the remains of the second phalanx. This fibrous band could be distinctly felt, and it was found to allow of slight extension when traction was exerted upon the end of the finger. It answered, in a measure, the purpose of joint structures, and allowed the finger to be bent to an abnormal degree, in all directions. Very 
slight voluntary motion was present, and the grasp with this finger was not firm. There was not as mnch redundance of integument as might have been expected, there being, however, a large fold at the base of the finger. The remaining bones of this nember were unnaturally small and thin, and the nail was very small and curved. There was no trace of cicatrix about the parts. The little finger of this hand reached to the first phalangeal joint of the ring-finger, but all of the phalanges were perfect, and the shortening was found to be due to the loss of one-half of the corresponding metacarpal bone. A similar fibrous band held the bones together, but there was not such extensive preternatural mobility of this finger as there was of the index.

Similar changes were also found upon the left hand. The first phalanx of the thumb had disappeared, and the second abutted against the end of the metacarpal bone, which seemed enlarged and bulbous. The same condition of mobility existed as was found in the right index finger. In the middle finger the second phalaux was found to be wanting, and the first and third were joined together with fibrous tissue. An attenuated condition of these bones was also found, but they were slightly enlarged at their approximating ends. There was unnatural mobility of the parts, and the power of the grasp was destroyed. Besides these alterations there was a loss of nearly an inch of the distal end of the left radius, and of fully an inch and a half of the right ulua. These bones ended by conical-shaped extremities. There was surprisingly little disturbance of the motions of the forearms induced by this loss of bone. In the region thus affected the integument appeared normal. These latter affections had appeared six months after the swelling of the phalanges. The boy had also had nodes on the ulna and on both tibiæ, while on the latter slight depressions in the bones resulting therefrom might be felt. There were, also, large depressed cicatrices upon the anterior surfaces of the legs.

The swellings on the tibiæ and ulna began when the boy was about five year's of age. They were preceded by pain, which, thongh at some periods worse at night, at others was severe during the whole day. They grew slowly and gradually larger, until they were perceptibly prominent; during the whole 
period being the seat of pain. In a year they reached their maximmm size, and during the two following years, mnder an irregular treatment, they more slowly subsided; until, in the end, those on the tibire were replaced hy depressions.

Six months after the swellings on the extremities had appeared, the bones of the hands were observed to enlarge slowly, there being also severe pain, sinilar in character to that in the nodes. In rather more than a year, the hands were rery much disfigured by the enlargement of the bones, their movements boing mich interfered with. The affected fingers were found to be movalble only with difficulty, and, when the others were flexed on the palm, remained extended. They would yield, however, to artificial motions. The joints were said to be the seat of greater swelling than any other part of the fingers, and the mother stated that at one time the tissnes orer them were red, inflamed, and painful. These members then remained more than a year in this indolent swollen state, and then gradually began to grow smaller. The process of attenuation occupied rather more than a year, and, finally, resulted in the conditions described as found by me. $\Lambda$ fter careful inquiry I elicited the fact that, though pain of severe form existed during the period of the increase of size of the bones, when they reached the greatest extent of enlargement, and during the period of subsidenee, it was of a mild form, and sometimes not at all present. During these years the general health of the child had been quite bad, and he had an affection of the left eye, undonbtedly a keratitis which had left a small opacity over one border of the pupil. He had also suffered severely with frequently recurring pulmonary tronbles.

Let us now merely stndy the bone-lesions. It is an undonbted fact, proved not only by the history of the case, and by its state of evolution, but also by the en-existence of gummatous ulcers in the subeutaneons connective tissue, that the nature of the osseons lesions was of the gummy tumor variety. Hence the case is interesting, as showing, in a typical manner, the evolution and decline of these lesions. Occurring at a more advanced age, and at a corresponding stage in hereditary syphilis, they attack both long and short bones. Under the periostem and in the bone structure, this granulation tissue is slowly proliferated, the process occupying a long time. In the 
neighborhood of joints, the tissues become thoroughly infiltrated with this morbid growth. An ephemeral lydrarthrosis then complicates the case, as reconnised by its peculiar symptoms, this being the only evidence of inflammatory action observed, which we, appreciating the nature of the case, know is merely an epiphenomenon. Going on in this indolent manner, the bone becomes very much swollen, remains in that condition some months, and then this enlargement, in a similar slow manner, grows less, until, finally, portions of some bones, the whole of others, with their articular appendages, are totally absorbed. The disappearance of the joint structures shows undonbtedly that their substance was preriously infiltrated. The integument mas be inflamed by pressure, bnt usually the action is subacnte. This gives, in the main, a clear idea of the course of the gummons osseons lesions. It may happen that degeneration complicates the case, when the same subacute indolent condition may also be noticed. This state, contrasted with that of infants, differs in the age at which the ossents lesions are dereloped, in the slowness of their conrse; thrse in infancy being more rapid, and in presenting greater evidence of inflammatory action, and involving the tissues and organs around and connected with them in a more aente morbid action. Then, in the stage of decline and in the sequelæ there are distinctive points; thins, in infancy if the bone remains permanently enlarged, still its size is less than when it is the seat of gnmmy degeneration; and, when subsidence does occur, it ceases when the normal size of the bone is reached, not usnally going on to absorption in ally marked degree. The joints are in some cases involved in active inflammation, bnt, at the decline of the morbid action, remain in their integrity, not having, as in the later affection, undergone absorption. Thns summed up suecinctly, the syphilitic osseons lesions of infancy are attended with signs of a somewhat aetire inflanmation, which reacts in a similar manner on those tissnes which are near the bones; whereas the lesions of syphilis of more advanced life, run a very chronic course, being, as a rule, attended with symptoms of a subacute character; and while the former may result in B. sne disigurement or distortion of the bone, the latter are frequently followed by a greater or less total destruction of them. 


\section{XXIX.-MISCELLANEOUS CLINICAL NOTES.}

I was asked by iny friend, Dr. S. H. Dessan, physician to the children's department of the New York Dispensary, on the 5th of Jume, 157t, to see a child which had been bronght to his service for treatment, the mother alleging at the time that its affection was restlessness at night. It was first bronght to the dispensary on the 22. d of May, and was then two monthis old, consequently, heing abont ten weeks old when first seen by me. At this time I found the following lesions: There was a very copious, large papular syphilide over the face, erusts on the scalp, mucons patches in the mouth, and fissures at the labial commissures, while the child suffered much from coryza. There were a few papules aronnd the buttocks which had not gone on to ulceration. At the distal extremity of each radius and ulna at the diaphyso-epiphisal junction, was a well-marked enlargement of the bomes. The swelling began abruptly from the shafts, and, attaining a height of abont half an inch, declined by ending in the epiphsses, which it enlarged, except at the carpal joints, where they appeared of the normal proportions. The swelling was of an intermediate condition between the ringed form of enlargement and that which in volves the whole epiphysis, both of which forms hare been already deseribed. The surfaces of these swellings were perfectly sinooth and not at all unequal, nor adherent to integument, which, not being stretched, was freely morable orer the bones. There were also osseous lesions upon the hands; the first phalanx of the right index finger was enlarged to about donble its size ; the enlargement being quite eren, and the bone having the shape of an acorn. The joints at either end of the bone were maffected. The integument was not rery mueh stretehed, and was unaltered. The tapering of the finger was well marked. The index finger of the left hand was not as much swollen, and in every particular resembled that of the right hand. The left ring finger was enlarged in a somewhat greater degree than either of the two tirst described, and in all its characters resembled the other two. It was rery evident that mild spontaneous pain existed in the swollen parts, as the child, which was generally good tempered, flinched from gentle manipulation, and eried piteously if the parts were thoroughly examined. MY impres- 
sion was that the bones were slightly painful, and I am of the opinion, as there are no other known reasons for the child's restlessness at night, that pain was present in the swellings. This, perhaps, was due to the fact that they were as yet in an adrancjing stage, and, consequently, still the seat of inflammation.

The mother stated that she noticed the swellings when the child was a month old, and that they were then as large as when $I$ first saw them. The mixed treatment was administered, and local applications were used. On the 17th of July, the cutaneous and mucous lesions had disappeared, and all the swellings were markedly dininished in size. At this date, owing to the advancing cachexia, which was undonbtedly rendered more severe by the want of care and of proper and sufficient nourishment, cod-liver oil was ordered, in addition to the alterative. On the 19th of July, a severe and persistent diarrhœa set in, and the child was not seen again. It is supposed that it died, as the previons attendance of its mother had been, for a dispensary patient, exceptionally regular.

The chief value of this suggestive case is, I think, in the weight which it carries with it in favor of the view that the course of these lesions is attended with more or less pain. It is unnecessary to dwell any longer on this point, as it has received full attention in the chapter devoted to the consideration of that snbject. In a diagnostic point of view, it is of interest as showing that the coexistence of diaphyso-epiphysal swellings with enlarged phalanges would clearly establish its syphilitic nature. The existence, moreover, of nndoubted syphilitic lesions of the skin and mncous membrane would settle the question. An interesting point in treatment is suggested by the ease, namely, the urgent necessity of sufficient and nourishing food during the period when mercury is being administered. The weight of this fact has already been considered.

Since that portion of this work which contains the eases of other observers was written, three cases of syphilitic osseons lesions in infants have been reported; two by 'Parrot, and one by ${ }^{2}$ Charrin. As they suggest no new points, being only confirmatory of sueh as hare already been fully and carefully described by me, it is unnecessary to give even brief descriptions of them.

1 Gazette Médicale de Paris, No. 44, 1873.

- Gazette Médicale de Paris, Nos, 31 and 34, 1873. 
XXX.-CERTAIN NON-SPECIFIC AFFECTIONS OF THE BONES, SOMLTIMES REGARDLD AS SYPIILITIC.

As supplementary and even essential to the knowledge of the osseous lesions of syphilis in infants, it is necessary to consider, somewhat fully, a non-specific condition, already alluded to in a previons part of this treatise, which frequently predisposes to inflanmation of the bones. By examining the distinguishing characters of which I hope to show the real nature of what is ordinarily and vaguely classed as scrofulous. Althongh it is generally conceded that there is a scrofulons affection of the bones, yet the knowledge of it is so very limited, that in no text book is it described with any degree of clearness; affections of the bones when not presenting the features of rachitis are often vaguely classed as syphilitic or as scrofulous, whence it has occurred that the points of distinction between the lesions of these diseases have not been clearly and forcibly elaborated. To add to this want of precise and accurate knowledge, scrofnla has, by many, been looked upon as in some mudefined manner, remotely dependent upon syphilis; so that there has been no serious painstaking endeavor made to differentiate in a scientific manuer the features of the bone affections of the two diseases. And further, the view has been entertained by many, that because the lesions of the osseous system are of such grave character, they must necessarily be of syphilitic origin; so that in many instances, although there was not the slightest reason for suspecting syphilis, cases of osseous inflammation and swelling have been unequivocally, and of course, wrongly called syphilitic. In illustration I camnot do better than quote from a clinical ${ }^{1}$ lecture by Prof. S. G. Gross of Philadelphia. This gentleman, to whose opinion in matters of general surgery the utmost respect should be accorded, exhibited to his class a colored child, aged two and a half years, as presenting a syphilitic lesion of the osseous system. A year previous its hand had been trodden upon, and, in consequence, the metacarpal bone of the thumb had become inflamed and swollen, in which state it remained. Although there is absolntely no history of syphilis, past or present in the child or in its parents, the lectur-

1 Philadelphia Medical Times, October, 1872. 
er told his class that it was a case of dactylitis ${ }^{1}$ syphilitica, and that the bone would never have swollen if there was not a syphititic taint in the child's system! Under the influence of such teaching, what progress can be made in the study of the bone affections in infants? Such a statement is undoubtedly based on the opinion that syphilis is the necessary cause of most of the osseons affections in the young. Such being the condition of opinion, I have thought that my work would be incomplete in an esscntial particular, if I did not contribute to this subject the result of my obserrations, made while studying with care cases of syphilitic osseous lesions, as well as those which did not arise from that disease.

During the past four years my attention has been called particularly to a series of cases of children affected with osseous lesions. In them there was no history of syphilis, no coneomitant lesions or symptoms to point to that disease; neither were the parents syphilitic. I state these facts, as the cases were examined with more than usual care, and used as a means of contrasting syphilitic with non-syphilitic lesions. How, then, shall we explain the origin of the bone affections in these cascs? What is their etiology? Examined carefully, these children were found to be pallid, weak and thin, their assimilative processes were far from perfect. They sererally suffered with lesions of a hyperplastic character, indicating a lowered state of the vital processes. The hyperplastic or proliferative changes, consisted in glandular engorgements, in tendencies to active hyperæmia of the mucous membranes. In them, inflammations were very readily and quickly set up, very severe in character, and were attended with the production of large quantities of pus. The antecedent history of these children varied; in some there had been exhausting attacks of the exanthemata; in others porerty and want of proper food and care had induced a low state of the system; while in a third class a naturally feeble organism had,

' In Dr. Gross's “'Snrgery," published in 1872, he states that dactylitis syphilitica, which, as is well known, is universally regarded as rare, is common in his practice. At that time, this statement seemed somewhat remarkable, as there were then less than six cases of it reported in all literature; but since the publication of this case and the comments thereon which shows us clearly in what an unprecise and easy manner the diagnosis of syphilis is arrived at, it is readily understood why the Professor enjoys such an exceptional ex. perience. 
by the influence of a suecession of mild affections, or perhaps of a persistent dyspepsia, or of a diarrhoea fallen into a state of great anæmia. Their condition may, perhaps, be called scrofnla, yet whaterer name is applied to it, it consists essentially and pathologically in a state in which the blood-making function is greatly impaired and the general nutrition of all of the tissnes seriously at fault. In the latter there is a tendency to excessive cell-proliferation, while hyperemia of great intensity is very liable to occur. In the osscons system of snch subjects there is no immunity to these alnormal changes, but, on the eontrary, by reason of its very rapid growth, they are liable to develop. In this comnection it is well to remark that owing to this activity of growth, tranmatic canses, even slight, are capable of inducing inflammation, which, moreover, may be exceptionally severe if it occurs in a child whose nutrition is lowered in the mamner just now described. It is also true that in tranmatic osseous iuflammation syphilis may exert a powerful modifying influence. I think that these facts, which are based on careful and extended clinical study, will convince observers that a condition of lowered nutrition of the infant may predispose to the development of osseous lesion, and that such may oceur as a result of tranmatism sinply and withont the existence of a syphilitie taint.

An important question here arises, namely: Are there any distinguishing characteristic in these osseons lesions which will enable the physician to promptly and correctly diagnostieate them from those of syphilis? It inust be confessed that in the main they resemble in many partienlars the lesions of syphilis, still there are certain quite constant features which are important to know. As a rule the osseous lesions, above alluded to, are developed rather rapidly, may be complieated early by degeneration, and, for the most part, do not primarily affect the joints. There are usually a smaller number of bones inrolved than in syphilis, and there is a greater tendency to insymmetrical development. Pain is generally a constant symptom, and, in short, there is usually a much more pronouneed condition of inflammation than we find in syphilis. When degeneration occurs there may follow sinuses which have the typieal scrofulons appearance, which we have observed to be not constant in syphilis. Finally a point of some inportance may be determined by the bone or bones involred; thus, in this condition. it is very probable that the cranial boues 
would be unaffected, and that the lesion would be limited generally to the long bones, or perhaps to the phalanges, whereas in syphilis we have found that a number of different classes of bones were often coincidently involved. Still, as I have said in the ehapter on diagnosis, the distinction very often rests upon the history of the ease, and npon the co-existence of lesions, which are undoubtedly syphilitic. Treatment will not always afford conclusive evidence, but it may sometimes assist in a measure. There is an interesting clinical fact worthy of remembrance, which is, that when these same osseous lesions oceur later in the life of the child, there is a decided tendency to articular complication, indeed, in many children under these eircumstances, the morbid process begins in the joint.

I. S. C. Busey, of Washington, has recently reported a case, which is of decided interest in this connection. It was that of a female child, in whose parents there was no history of. syphilis and in whom there is no mention of syphilitic affections. Apparently healthy at birth it had, when three months old, an ermption affecting the entire scalp and described as scabby. A bronchial affection supervened when six months old, followed by a severe diarrhoea at its tenth month. These two affections continued until the child was reduced to fourteen pounds in weight. When thirteen months old, being still in miserable health, a swelling of the left middle finger was found, limited to the first phalanx and measuring near its metacarpal articnlation two and half inches. Remaining indolent for four months fluctuation was discovered, which, on its being incised, gare vent to pus. During the following two months the swelling decreased slightly.

In the total absence of any evidence of syphilis, $I$ am inclined to think that this osseons inflammation was induced by the profound state of cachexia. The case illustrates very forcibly the general position which $I$ have taken as regards the development of bone-inflammation. There are points in the case which are interesting, and at the same time suggestive of a non-syphilitic origin. The details of the case and its illustration show that the lesion begun and was greatest at the proxinal end of the bone. Now, we know that in this position the

${ }^{1}$ Case of dactylitis syphilitica in a child eighteen months old.-American Journal of Medi.al Scicnce, Oct., 1874. 
epiphysis is situated, consequently it is fair to assume that the lesion was developed at its junction with the shaft. In our study of syphilis of the phalanges, we found that in every recorded case of infants, the whole bone was miformly enlarged, and that the peculiar syphilitic processes which occur at the diaphyso-epiphysal junction had not as yet been met with in these bones. We are warranted then in assuming this to be the rule, nevertheless it may have its exceptions. Thus this point militates somewhat against a syphilitic origin, and in the event that it was syphilitic the instance wonld be exceptional. At a recent meeting of the Dermatological Society, Dr. E. L. Keyes exhibited a cachectic child, with inflammation attended with degeneration at the junction of the distal epiphysis with shaft of the radins. Of the cases seen by me, which illustrate this condition, in some the phalanges, in another the metacarpal and metatarsal bones, and in others the long bones, were involved. Some of these were my cown cases, while others were subnitted to me for study and opinion by friends.

It is to be hoped that, in future, in the study of these cases a hasty diagnosis of syphilis will not be arrived at and that observers will bear in mind in forming their opinion, the condition here described.

\section{A P P E N D IX.}

IN the chapter on pathological anatomy the description of the morbid process is given with the idea of conveying a general view of the subject; it is necessary, however, to present a special description of the features shown by the illustration, which is taken from a micro-photograph of three hundred diameters. On the left of the figure the trabeculæ are much enlarged, and instead of appearing as if composed of lacunze and canaliculi, are seen to be infiltrated with small, round, nucleated cells. The medullary spaces are obscured and compressed by the cell-growth, and in some specimens the contained-blood-vessels are also choked. In the median line these small cells constitute a complete layer running through the specimen. There are here some fusiform nucleated cells and granular matter. To the right the intcrference with the ossifying process is clearly shown. The cartilage cells are there in a condition far from normal, being greatly increased in number, and in size much smaller than they should be. They are also more irregularly placed, not being, as they should be ranged in longitndinal rows. Besides this change, the intercellular substance is seen to be much increased, as shown by the wavy lines in black, and near them are spots of localizcd calcareous deposit, which, owing to their transparency, are not delineated, but are shown in the drawing by blank white spaces. In this region, also, the peculiar round cells are seen following the blood-vessels, which are numerous. This specimen demonstrates clearly not only the presence of granulation tissue, but also that the process is of an inflammatory nature. 


\section{IN DEX.}

ACQUIRED Infantile Syphilis; do osseons lesions occur in ? 122 ; answered affirmative $\mathrm{ly}, 123$.

Archambault; case of syphilitic digital swcllings in child, 43.

Arthritis rheumatoid, distinguished from syphilitic, 150 .

BÏreNsprưa; necrosis from syphilis in child, 43.

B.rrgioni ; case of suspected hereditary syphilis ; autopsy, 47.

Baumès, case of, 84.

Bertin, case of, 43.

Bones, certain non-specific affections of, $1 \% 1$; how diagnosed from syphilitic, 1 iร3.

" intra-uterine syphilis of, 120.

" early periods of attack of after birth, ibid.

" hardness of, probably not due to syphilis, ibid.

" of lnfants, syphilitic lesions in, case $i$, 13.

" " " with syphilis in other tis. sues, case ii., 16.

"6 " with roseola and condyloma, case iii., 17.

"4 " showing nodes on cranium, case iv., 18 .

"4 " with roseola, condylomata and aphthae, case v., 20 .

“ " " with abscess and distortion of fingers, case vi., 21.

46 "6 with coryza and mucous patches, case vii., 25.

4 " " accompanied by roseola mncous patches and condylomata, case viii., 27 .

" " " progress of, in a patient otherwise healthy, case ix., 29.

* " " appearing on clavicle, ribs, humerus, and ankle, case x., 32.

4 " " discovering motion between epiphyses and shafts, case xi., 38.

" " " discoverable in phalanges, case $x$ i.i., 41.
Bulkley : osseous lesions of syphilitic origin in child, 4.

Busey, Dr. S. C., interesting case reported by, 174.

Carpal, Tarsal, Metacarpal, Metatarkal bones, with phalanges, enlargements of, 75 .

" bones, less liablo to swellings in in“ fants, 90.

Cartilage, hyperplusia of, 77 .

Charrin, case of osseous lesions by, 170 .

Clavicle, enlargements on, 65 .

Cranial internal periostitis, 98.

Cranium, minute nodes of, $9 ?$; diagnosis of, 152 rachitic swellings on, diagnosis of, 153.

Degenerative changes in osseous swellings, 102 ; duration of treatment of, 103 ; confounded with scrofula, ibid.

Dessau, Dr. S. H., case, having papular eruption on buttocks, etc., with enlargements on bones, 169.

Diagnosis differential, 141.

" of non-specific affections of bones, 173 .

4 of rachitis on craninm, 153.

" of nodes on "4 152.

" of separation of diaphyses from epiphyses, 145.

" of periostitis in infants, 136 .

"6 of eyphilis in phalanges, 150 .

" of swellings on ribs, 67 .

" " " clavicle, 144.

Diday, errors of, 9,124 .

EPIPHXSES, extrusion of, 109.

" subjective symptoms of, 109.

" errors of Purrot relating to, $t b i d$.

" and diaphyses, separation of, rare,

104; examined post-mortem, ibid; method of exploring, 105 : facts relating to, 106 ; diagnosis of, 145 .

Exostoses epiphysal, hereditary, 144.

Facial bones, little liable to syphilitic lesions, 94.

Femur, swellings upon, 72 .

" lower end of particularly liable to certain syphilitic changes, 73. 
Femur, swe'lings at upper part of, difficult of detection, ibid.

Fingers, distortion of, occasioned by swellings, 8.3.

Fournier; cases of osseous syphiiit:c lesions in infauts. 43.

Frontal and parietal oftener attncked than other cranial bones, 92.

GIBNEY, Dr,, case of peculiar awellings near joints, 163.

Gross, Dr., statements of, note, 172.

Guérin, couche chondrozde, 131.

Gummous os-eons lesions, 164: case of, 165; course of, 168 .

Hoilkuts less frequently affected than radius or uina, 63.

Hutelinson on periostitis, 114.

IIjperplasia, tendency to, 125 .

INTEGCMENT not primarily involved, 100.

" condition of, in bone-swellings, ibia.

Jorsts, immunity of, ibid.

Jordan, Furneaux, on diaplysso-epiphysal syphilitic swellings in adults, 160 .

" doubts as to a syphilitic origin in cases given by, 162 .

KEYES, Dr. E. L., case furnished by, 175.

MAHON, views of, 84 .

Malformation resulting from osseous lesions, 116.

" admitting of arrest by treatment, 119.

Mayr on periost tir, 114.

Metacarpal bones, swellings of, 87 .

Metatarsal bones, swellings of, 89 .

Sill attacks not usma!ly productive of osseous lesions in child, 124.

Mlorgan; swelling of metacarpal bone, 48 .

Mother, valne of tre.ttment of, as a prophylactic to the child, 154 .

" and child, equal severity of symptoma in, 12!).

"recent severe syphilis in, most likely to affect infant, 126.

Mothers and ehildren, comparative table of syphilis in, 129.

NODEs on the cranlal boner, diagnosis of, 152 ; resembiance to in case of rickets, 153.

ONYCHIA of hereditary syphilis does not involve the bone, 83 .

Osseons and cartilaginous tissues, absorytion of, 107.

-. enlargements, average period of development of, 95 ; average size of, 96 ; usual course of, 46 ; termination of, $\boldsymbol{9 7}$; nniform distribution of, 98 ; synchronous, 99 ; pust mortem examination of, ibid.

Osseons lesions in the upper extremities, 58.

" " pathological anatomy of, 130.

Ossifying process, morbid ehanges in, 131.

" " dissent from Wegner conceruing, 132.

Osteochondritis, characters of, 137.

PaIs as a diagnostic symptom, 112.

" comparative absence of in osseons swellings of infants, 111.

Pathological anatomy, 130.

Parrot, views of, 109.

" case of separation of tibia and fbula

from epiphyses in child; autopey, 50 .

" " reported by, of infantile paralysis; autopsy, 50.

" " cranial and other bones af fected, 51 .

" “ periosteum detrched, 52.

" " corneæ, head, and mouth ulcerated ; hunerus, etc., involved ; ibid.

" " femur and tibia affected, $i b i d$.

"antopsy of still-born child, ibid.

" 6 " " child, $i b t d$.

"6 cases of osseons lesions reported by, 170.

"6 observations on syphilis in bones of children, 10.

Felvic bones rarely attacked, 94 .

Periostitis, varieties and diagnosis of in infants, 136 ; parts attacked by, 114 ; infrequency of, 115 ; diagnosis of, 136 ; acnte phlegmonous, 147.

Periosteal osscous tube serving as splint, 108.

Phalangcs, enlargement of, from cartilaginous hyperplasia, 77.

“ especially liable to osseona enlarge. ments, 76.

" the proximal nlost frequently attacked, 78.

" comparative frequency of syphilitic swellings of, 85.

"s enlargement of, 149; syphilltic, diagnosis of, 150; exsection of, rarely to be resorted to, 159 .

Phalanx, second, deceptive :ppearancea of, 80 . " rheumatoid arthritis of, note, 81 .

Plan and scope of the present Work, $12,13$.

Poncet, cases of, 115.

Putegnat: case of hereditary syphilis in thigh of child; case of cranial exostosis in aypliilitic ehild, 44.

RADros and nlna, swellings on the distal ends of, 60 .

" 6 on npper end of, 61.

Ranvier had shown how syphilis may affect the bones, 11 ; case of, 46. 
Ribs, swellings at sternal end of, $6 \pi$; diagnowis, Tibia, ulprer part of, more frequently swollen ibial.

Rickets pathologically distinguinhed from syphiti=, 125.

“ and -yphilis relations between, $13 \mathrm{~S}$.

Roger, infantile syphilitic swellings on humerus and tibia, with noder. care of, 42.

Smith, Dr. T. C., care of spphilitic swellings in fingers of child, reported by, itid.

Skull, syphilitic lesions of, in infauts, infrequent, il.

Syphilitic lesions confounder with kcrofula. 10. . $\quad$ " crroneons opinions on the frequency of. 9.

Swellings at the diaphyso-cpiphysal union liable to be confounded with syplitir, 141.

، at sternal end of clavicle, diagnosis, of, 144 .

6. complieated with necrosir, ibil.

. on the borders of shaft, diagnonis of. 144.

* witlı separation of epiphyses from diaphyses, 145; oceurs only in the early nonths of life, 14i; other distinetions concerning, 148 .

Tarsar bones, little liable to swellings in infantr, 90 . than fibula at same points, i2.

، and fibula, swellings at extremities of, ijs.

". apparent ilsproportion between shafts and epiphyses (of, 6:).

" swellings of, freuncnt. ibial.

Toes, syphilitis swellings of, 81 .

Truatment in the muther prophylactic to the chilu, 154.

" of hereditary syphilis in infante, 15j.

. mixed. no risk in prolonging. 15ti.

" necessity of sustaining the system during, $15 \%$.

". injections hypodermic, hurtful in, ibil.

" mercurial inunctions in, objected to, 158 .

VALE1X, syphilitic tumors on radius and ulna of child: antopsy, 50 .

Vidal, errors of, 9.

Violet, cuses of. 115.

Volkmann's case, $\$ 2$.

WALDEYER, Prof., on occurrence of syphilis in bones of children, 10 ; cases. 54 .

Wegner's eases, particulars of, 53 . 




Date Due

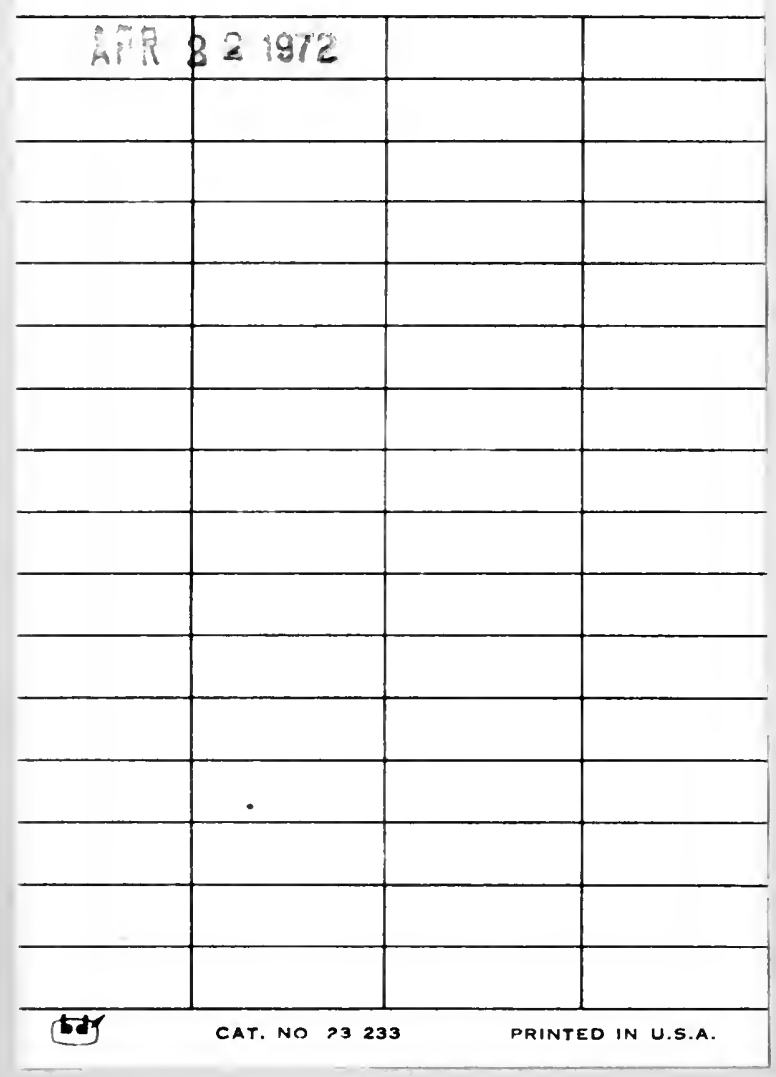




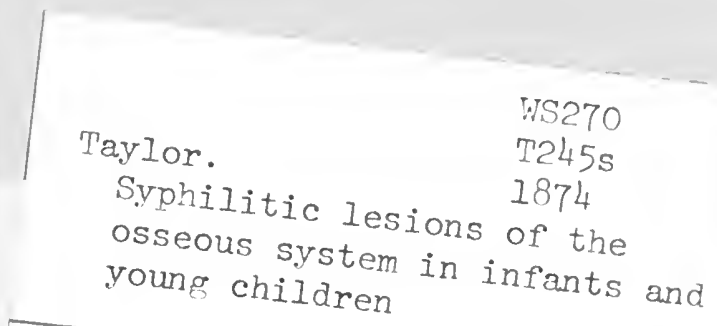

Taylor.

$$
\begin{aligned}
& \text { Tylor. } \\
& \text { Syphilitic lesions of the } \\
& \text { osseous system in infants and } \\
& \text { young children }
\end{aligned}
$$

Syphilitic lesions of the osseous system in infants and young children

CALIFORNIA COLLEGE OF MEDICINE LIBRARY UNIVERSITY OF CALIFORNIA, IRVINE IRVINE, CALIFORNIA 92664 
$\therefore$

$\bullet$ 